
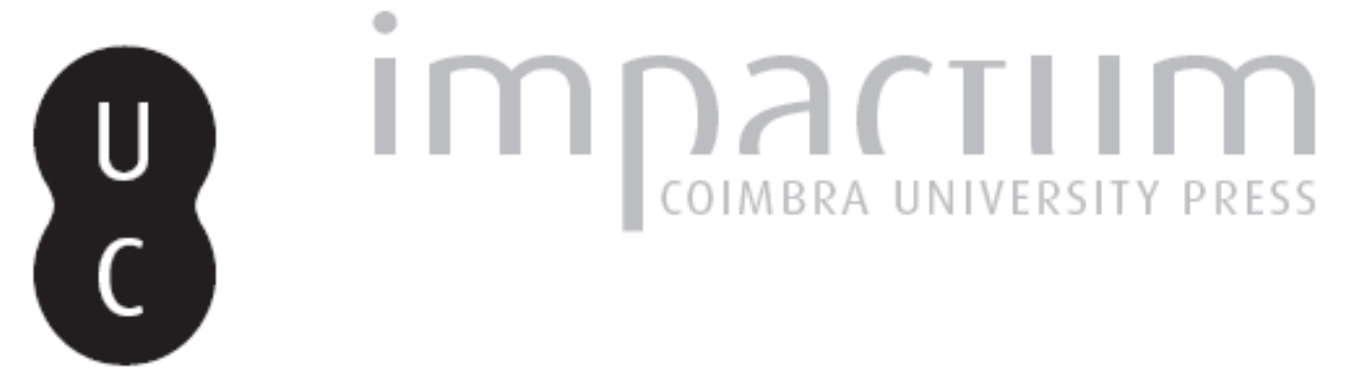

\title{
La mosaïque cosmologique de Mérida: propositions de lecture
}

\section{Autor(es): Quet, Marie-Henriette}

Publicado por: Imprensa da Universidade de Coimbra

URL persistente:

URl:http://hdl.handle.net/10316.2/45721

DOI:

DOI:https://dx.doi.org/10.14195/1647-8657_19_1

Accessed : $\quad$ 26-Apr-2023 13:00:22

A navegação consulta e descarregamento dos títulos inseridos nas Bibliotecas Digitais UC Digitalis, UC Pombalina e UC Impactum, pressupõem a aceitação plena e sem reservas dos Termos e Condições de Uso destas Bibliotecas Digitais, disponíveis em https://digitalis.uc.pt/pt-pt/termos.

Conforme exposto nos referidos Termos e Condições de Uso, o descarregamento de títulos de acesso restrito requer uma licença válida de autorização devendo o utilizador aceder ao(s) documento(s) a partir de um endereço de IP da instituição detentora da supramencionada licença.

Ao utilizador é apenas permitido o descarregamento para uso pessoal, pelo que o emprego do(s) título(s) descarregado(s) para outro fim, designadamente comercial, carece de autorização do respetivo autor ou editor da obra.

Na medida em que todas as obras da UC Digitalis se encontram protegidas pelo Código do Direito de Autor e Direitos Conexos e demais legislação aplicável, toda a cópia, parcial ou total, deste documento, nos casos em que é legalmente admitida, deverá conter ou fazer-se acompanhar por este aviso.

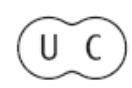


FACULDADE DE LETRAS

INSTITUTO DE ARQUEOLOGIA

CONIMBRIGA

VOLUME XIX

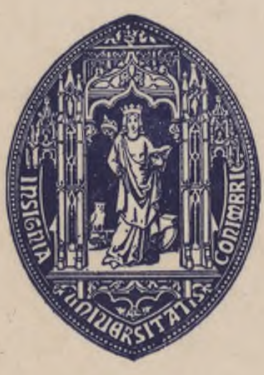

UNIVERSIDADE DE COIMBRA

1980 
MARIE-HENRIETTE QUET

Maître-Assistant à l’Université de Nantes

\section{LA MOSAÏQUE COSMOLOGIQUE DE MÉRIDA. PROPOSITIONS DE LECTURE}

Conimbriga, XIX, 1980, 5-127

RÉSUMÉ: Dans la première partie de son étude («Conimbriga», XVIII, 1979,

5-103), l'auteur avait présenté le pavement et comparé le monde maritime et terrestre qui est figuré sur la mosaïque cosmologique de Mérida à YOikouméné romaine. Elle avait assimilé l'apparition du Temps (Saeculum) et de l'ordre du Ciel (Caelum) succédant au Chaos (Chaos), la stabilisation de l'Univers sur Taxe des pôles (Polum), à la création et à la stabilisation du monde romain dans la paix de l'âge d'or.

L'auteur rapproche ici la mosaïque cosmologique du traité du Péri Cosmou et étudie comment sont figurés, dans le tableau, la régularité des cycles cosmiques et l'écoulement régulier du temps, par la présence des luminaires (Oriens, Occasus), l'alternance des saisons dans Tannée et l'apparition des autres phénomènes (vents, pluies...) qui se produisent dans l'atmosphère.

Le personnage à tête ailée, Aeternitas, qu'elle rapproche des autres représentations figurées, portant ou non la légende $A$ ion, et plus particulièrement du génie à tête ailée de la mosaïque de Sentinum et du génie aux ailes dorsales du piédestal dé la Colonne Antonine est la force vitale du Cosmos, susceptible d'introduire l'éternité et l'identité dans la matière.

L'auteur refuse l'interprétation mithriaqu e proposée par A. Blanco-Freijeiro et G.-Ch. Picard et souligne l'influence du stoïcisme dans la conception du pavement. Elle donne enfin plusieurs lectures de la mosaïque: strictement géographique, cosmologique, philosophique, religieuse, rhétorique et idéologique.

S'interrogeant sur la signification historique de l'existence de ce pavement à Mérida, l'auteur conclut que «la mosaïque cosmologique est un exemple privilégié de la nouvelle culture syncrétique panhelléno-romaine qui s'élabore dans l'Empire, au cours du $2 \mathrm{e}$ siècle de notre ère». 
Resumo : Na primeira parte do seu estudo («Conimbriga», XVIII, 1979, p. 5-103), a autora descreveu o mosaico cosmológico de Mérida e aproximou da oikouméné romana o mundo terrestre e marítimo ${ }_{9}$ Í figurado. Assimilou a aparição do Tempo (Saeculum), a ordenação do Céu (Caelum) e a estabilização do Universo em torno do eixo dos polos (Polum) à criação e estabilização do mundo romano na pax romana.

A autora aproxima o mosaico de Mérida do tratado Peri Cosmou e analisa o modo como naquele se representam a regularidade dos ciclos cósmicos e a sucessão do tempo.

A personagem designada Aeternitas, que relaciona com outras representações designadas ou não por Aiôn, e particularmente com os génios alados do mosaico de Se ntinum e da coluna de Antonino, é a força do Cosmos, pela qual a matéria se torna eterna e igual a si mesma.

A autora recusa a interpretação mitraica de A. Blanco-Freijeiro e G. Ch. Picard e acentua a influência do estoicismo na concepção do mosaico. Apresenta, seguidamente, diversas leituras do mosaico: geográfica, cosmológica, filosófica, religiosa, retórica e ideológica.

Interrogando-se sobre o significado histórico da existência deste mosaico em Mérida, conclui que ele é «um exemplo excepcional da nova cultura sincrética pan-heleno-romana que se desenvolve no Império, no decurso do século n d.C.». 


\section{LA MOSAÏQUE COSMOLOGIQUE DE MÉRIDA: PROPOSITIONS DE LECTURE*}

LIVRE II

LES TROIS LECTURES DE LA MOSAÏQUE

CHAPITRE III

\section{L'ÉTERNITÉ DE L'UNIVERS, L'ÉTERNITÉ DU MONDE ROMAIN}

L'Univers, une fois créé et stabilisé, se trouve dans la mosaïque de Mérida, selon les conceptions cosmologiques du temps, voué à l'éternité $\left({ }^{403}\right)$. Le mosaïste représente, comme l'ensemble des écrivains que nous avons cités, la durée infinie et l'éternel renou-

* La première partie de ce mémoire a paru dans Conimbriga, XVIII, 1979, p. 5-103; tous les renvois jusqu'à la note 402 concernent cette première partie désignée par le sigle I.

(403) Soulignons la différence de conceptions qui se manifeste dans les Astronomica de Manilius où le poète reconnaît, dans une perspective uniquement cosmologique, l'éternité au seul firmament (Mundus) et souligne la mobilité des phénomènes terrestres et des affaires humaines (I, 515-521, éd. GOOLD):

«Omnia mortali mutantur lege creata, nec se cognoscunt terrae vertentibus annis exutas variam faciem per saecula ferre.

At manet incolumis mundus suaque omnia servat, quem neque longa dies auget minuitque senectus nec motus puncto curvat cursusque fatigat; idem semper erit quoniam semper fuit idem».

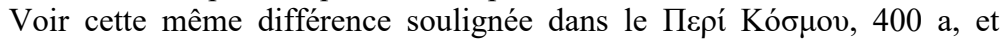
dans les conceptions religieuses et idéologiques du $\mathrm{II}^{\mathrm{e}}$ siècle où l'accent n'est pas mis sur les Saecula varia, mais sur l'unique Saeculum aureum, et où la vie de la nature sur terre et les phénomènes atmosphériques sont eux-mêmes regardés comme des garants d'éternité. 
vehement du monde, en accordant une place essentielle à la puissance créatrice du principe générateur qui anime l'Univers (Natura), en évoquant la régularité des cycles cosmiques par la marche des astres (Oriens-Occasus), l'alternance des saisons, l'existence des phénomènes atmosphériques réguliers, les nuées et les vents. Il réserve par ailleurs, dans sa composition, la place centrale à la figure $d C$ Aetlernitas].

Nous examinerons successivement chacune de ces légendes en respectant la distribution des personnages dans le tableau, et commencerons par les figures situées au sommet du cintre, le plus près $\mathrm{du}$ groupe céleste: les phénomènes atmosphériques. Ils occupent toutes les régions de l'air entre le ciel et la terre et témoignent, comme la plupart des autres figures, de l'importance des spéculations cosmologiques et des conceptions astrologiques dans l'Empire comme champ d'affrontement (404) ou creuset des syncrétismes philosophiques et religieux $\left({ }^{405}\right)$ et comme lieu d'intériorisation de l'idéologie impériale ( ${ }^{406}$ ).

(404) Sur l'importance aux yeux de Flavius JosèPhe de la présence des symboles cosmiques dans la conception du Tabernacle et sur la tunique du grand prêtre dans la religion juive pour protester de la piété des Juifs et de leur innocence en même temps que de leur respect des divinités qu'adorent les autres habitants de l'Empire, voir Les Antiquités juives, III, 179-187, qu'il faudrait pouvoir citer en entier; retenons ceci: "C'est faussement que l'on nous accuse, puisqu'il est aisé de voir par toutes les choses que j'ai rapportées, qu'elles représentent en quelque sorte tout le Cosmos» — il cite

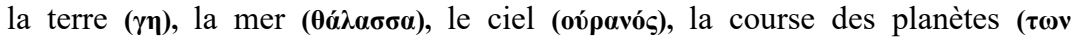

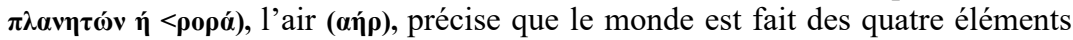
et indique la symbolique des couleurs.

(405) BOuChÉ LeClercQ, VAstrologie grecque, p. 594 et sq..

(406) J.-P. Darmon, Sur deux mosaïques de l'Yonne dans La mosaïque gréco-romaine, II, Paris, 1975, p. 307-317, pose le problème des niveaux de lecture et propose pour la mosaïque aux chevaux de Sens trois lectures possibles; les quatre chevaux pointés vers les points cardinaux et vers les quatre saisons peuvent donner lieu à une lecture cosmologique: Sol invictus, maître de l'espace et du temps; à une lecture idéologique: Sol, qui est aussi l'empereur, est mis en relation avec les factions du cirque par la couleur des colliers des chevaux; reste une lecture anecdotique du thème mythologique: le soleil dompte ses chevaux emportés après la chute de Phaéton. Cette mosaïque a été publiée par J.-P. Darmon et H. Lavagne, dans Le recueil général des mosaïques de la Gaule, II, Lyonnaise, 3, (suppi. X à Gallia), Paris, p. 45-52, pl. XI à XXIII. 


\section{A) Les phénomènes atmosphériques}

De façon générale, au Ir siècle avant J. C., à l'exception des comètes $\left({ }^{407}\right)$, les phénomènes atmosphériques et les vents en particulier n'ont pas de fonction idéologique. Leurs effets, néfastes ou bénéfiques, sont évoqués et les vents sont rarement perçus comme des phénomènes particulièrement favorables $\left({ }^{408}\right)$, même lorsqu'ils sont mentionnés au milieu d'autres manifestations comme des preuves de l'ordre du monde. Sous le règne d'Auguste pourtant, l'étude des phénomènes atmosphériques trouve sa place dans le

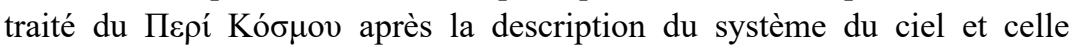
de la terre habitée. Elle occupe un long développement $\left({ }^{409}\right)$ dans un ouvrage qui, comme le souligne A. J. Festugière $\left(41^{\circ}\right)$, fait prédominer la théologie sur la philosophie et subordonne les considérations scientifiques à certaines vues religieuses sur le monde, dont l'unité et l'harmonie révèlent la providence divine $\left({ }^{4 n}\right)$.

${ }^{(407)}$ Sur les relations établies par la cosmologie antique entre les comètes et les difficultés politiques, les guerres, les épidémies, voir Manilius, Astronomica, I, 892-fin, sous le règne d'Auguste (cf. W. Gundel, s. v. Kometen, dans, $R E$, XI, 1921, col. 1143-1193.

$\left(4^{\circ} \mathbf{s}\right) \mathrm{y}_{0} \mathrm{j}_{\mathrm{r}} \mathrm{d}_{\text {ans }} \mathrm{j}_{\mathrm{es}}$ Géorgiques de Virgile, I, 95, 370 et II, 315 pour Boréas; II, 106-108, 330, 339, 370 pour Eurus et Zéphyr; II, 444 pour Notus qui est présenté comme un véritable fléau des arbres et du bétail; ils sont collectivement, presque toujours, présentés comme dangereux: I, 356, $365 ; \mathrm{IV}, 9$.

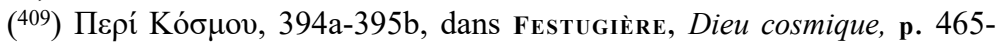
-467. Le traité retient tous les phénomènes, résultant de l'exhalaison humide (394a, brouillard, rosée, gelée, nuage, pluie, neige, grêle), de l'exhalaison sèche (394b-395a, vents et mouvements violents de l'air, classés en météores aériens, ouragan, bourrasque ... et météores ignés, tonnerre, éclair...), phénomènes lumineux (395a-b, arc-en-ciel, halo, étoile filante, comète...).

(410) Festugière, Dieu cosmique, p. 478.

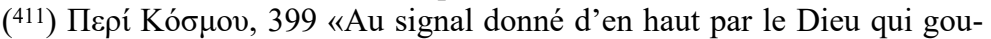
verne l'Univers, les astres et tout le ciel inaugurent leur mouvement éternel, le soleil qui brille sur toutes choses entreprend sa double course, soit que par son lever et son coucher il divise le jour et la nuit, soit que, se glissant à travers les signes zodiacaux en avant vers le Nord, en arrière vers le Sud, il amène les saisons de l'année; pluie, vents, rosée et tous les autres phénomènes qui se produisent dans l'atmosphère viennent en leur temps grâce à la Cause première et originelle. En conséquence, les fleuves s'écoulent, la mer se gonfle en vagues, les arbres croissent, les fruits mûrissent, les animaux se reproduisent, 
$\mathrm{Au}$ second siècle, au contraire, pour tous les habitants de l'Empire, les phénomènes atmosphériques sont perçus comme des manifestations de l'ordre divin $\left({ }^{*} 412\right)$ et les vents en particulier renvoient, selon les cas, et parfois simultanément, à divers registres : cosmique ou cosmologique, religieux, parfois même politique et idéologique $\left.{ }^{413}\right)$.

Dans la mosaïque de Mérida, les phénomènes atmosphériques se limitent au tonnerre que nous avons étudié plus haut $\left({ }^{414}\right)$, aux vents, aux nuées, à la neige. Les vents $\left({ }^{415}\right)$, au nombre de quatre, sont les quatre vents des quatre directions de la rose des

toutes les créatures trouvent à se nourrir, atteignent la force de l'âge puis dépérissent... (399b). En effet les phénomènes, tous ceux qui se produisent dans l'air comme sur la terre et dans l'eau, on peut bien dire qu'en toute réalité, ils sont l'oeuvre du Dieu qui règne sur le monde» (traduction FesTugiÈre, Dieu cosmique, p. 472-473).

(4i2) $\mathrm{y}_{0} \mathrm{j}_{\mathrm{r}} Q$ M. A. Hanfmann, Season Sarcophagus, p. 148.

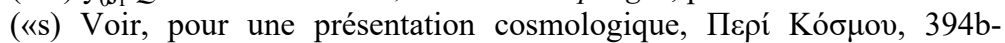
$-395 \mathrm{a}$; les vents sont classés soit d'après leur lieu d'origine, soit d'après les points cardinaux, soit d'après la rose des vents, soit d'après leur direction, soit d'après les saisons. Dans le domaine religieux ils apparaissent dans de nombreux cultes: voir TÜMPEL, s.v. anemoi, dans-fíi?, I, 2,1894, col. 2176-2180; L. RовERT, Hellenica, IX, p. 59-63; Vermarseren, C.1 .M.R.M., I, 339; 955; 966; 985; II, 1083 , A. $10 ; 1127 ; 1160 ; 1161 \mathrm{~B} ; 1216 ; 1225 ; 1247 \mathrm{~B} ; 1281 ; 1283 ; 1292,2$; 1292, 3; 1300; 1331, 6; 1359; 1388; 1685 et Cumont, T.M.R.M.M., p. 93. Pour leur relation avec YAiôn, voir R. Turcan, $R$. A., 1975, p. 305-318 et C. R. Chiarlo, A.C.O., 26, 1977, p. 69-78. Pour leur importance idéologique, voir Hanfmann, Season Sarcophagus, p. 121 et E. J. BIKermann, Le culte des souverains dans l'Empire romain, dans Entretiens de la Fondation Hardt, XIX, 1973, p. 13 et, pour l'utilisation rhétorique du thème, voir MÉNANDrE de Laodicée, dans L. Spengel, Rhetores Graeci, III, p. 377, et le Panégyrique de Maximien (GUF, Galletier), III, III, 5. Pour leur figuration dans les mosaïques, voir H. STERN, La mosaïque de Tourmont (Jura), dans Gallia, XIX, 1961, p. 248-254.

(414) Sur Tonitrum, voir supra, notes 62 et 388.

(415) Voir Garcîa-Sandoval, p. 18-20, les rapprochements établis avec les Géorgiques de Virgile, sans références, p. 24-26 et supra, note 60; Blanco-FreiJeiro, p. 162-165, cite les Fragments Orphiques 81 et 82, insiste sur la présence des vents dans l'iconographie mithriaque (163), souligne que leur disposition est la même que sur la mosaïque de Chahba-Philippopolis (les têtes seules des vents y sont figurées de profil et groupées, deux par deux, aux deux angles supérieurs du tableau: NOTO $\Sigma$ avec EYPO $\Sigma$ et BOPEA $\Sigma$ avec ZEФYPO $\Sigma$ ), et note la présence des drosoi enfants (p. 163-164, et fig. IX). 
vents; ils sont nommés d'après les quatre points cardinaux $\left({ }^{416}\right)$, mais ne sont pas placés aux quatre points cardinaux de la mosaïque. Ils sont disposés, deux par deux, mais chacun à un niveau différent, de chaque côté de l'axe qui partage la mosaïque en deux parties de Yoikouméné. A côté d'Oriens la légende Eurus (f11), le vent d'Est; au-dessus du quadrige d'Oriens, Notus, le vent du Sud, qui, enlaçant de son bras droit Nubs $\left({ }^{418}\right)$, le nuage orageux, figuré sous les traits d'une jeune femme nue, parfaitement gracieuse, semble s'élever dans les airs; devant le bige d'Occasus, Boreas, le vent du Nord, figuré en buste et seul ; au-dessus de la tête d'Occasus, Zephyrus, le vent d'Ouest qui semble soutenir de son bras droit et pousser à la fois Nebula $\left({ }^{419}\right)$, la brume, figurée en jeune femme nue, dont le regard se dirige vers Zephyrus. Les légendes en latin sont la transcription latine des noms grecs des vents et non leurs noms latins $\left({ }^{4}{ }^{\circ}\right)$, à la différence de ce que l'on constate dans les Géorgiques de Virgile, sous le règne d'Auguste.

(416) Voir Пepí Kóouov, 394b, dans Festugière, Dieu cosmique, p. 466 et, de façon plus générale, sur les noms des vents, voir: K. Nielsen, Les noms grecs et latins des vents, dans Classica et Mediaevalia, VII, 1945, p. 1-113, (= Nielsen, Noms des vents), spécialement p. 16 sur les noms des vents employés pour désigner la direction. Sur l'inscription C.I.G., XIV, 1308, les noms latins et grecs des vents figurent en même temps que les désignations en latin des quatre régions du ciel: Occidens, Meridies, Oriens, Septentrio.

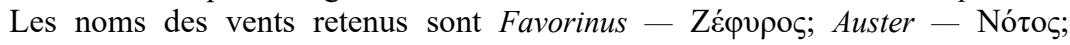

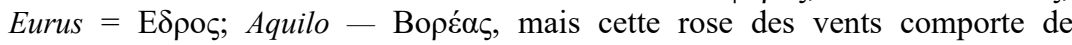
nombreux autres noms.

(417) Eurus est assez souvent associé au lever du soleil, voir VIRGILE, Géorgiques, III, 277.

(418) Nubs est employé ici pour Nubes (cf. Virgile, Géorgiques, I, 462). La graphie est très rare, comme en témoigne le matériel du Thesaurus: la forme Nubs n'apparaît que deux fois, chez Livius Andronicus (Apud SERv. Verg. Aen., 10, 636: «nubs» non dicimus, quod ait Livius Andronicus, qui primus edidit fabulam [latinam] apud nos) et dans Ausone, 345, 4, p. 162 (éd. PE IP ER) où le poète voulait terminer un vers ingénieux par un monosyllabe. La forme est donc excessivement rare.

(419) Nebula est plus souvent employé au pluriel et désigne la brume ou le brouillard automnal chez Virgile, Géorgiques, I, 401.

$\left({ }^{42}\right.$ ) Blanco-FreiJeiro, emploie, à tort, p. 162, Favorinus pour Zephyrus et Aquilo pour Boreas. Soulignons, au contraire, le parti pris du mosaïste de n'évoquer les vents que par les points cardinaux et d'ignorer les vents spécifiquement latins que l'on rencontre chez Virgile: Auster, Aquilo, 
Les quatre vents sont figurés sous les traits d'hommes adultes plus ou moins puissants - Boreas est beaucoup plus large d'épaules que Notus - mais d'âge égal. Leur corps est nu, leur visage est serein, quoiqu'un peu sévère. Ils ont une barbe courte mais abondante et deux ailes dans la chevelure.

Zephyrus et Nebula sont représentés en vol dans une position assez comparable à celle des deux vents hellénistiques - les adolescents jeunes et imberbes de la Tasse Farnèse -, alors que Nubs et Notus évoquent davantage les couples envolés des peintures pompéiennes de la Casa des Vettii( $\left.{ }^{421}\right)$.

La disposition sur 1 'emblema des trois vents subsistants, sans présenter de symétrie absolue, est assez clairement structurée pour nous permettre de supposer qu'Eurus, dont ne subsiste que la légende, était représenté seul (422), devant les chevaux d'Oriens, peut-être en vol comme Notus, si nous en jugeons par la jambe sombre, qui subsiste à côté de la légende Autumnus, le corps disparaissant partiellement derrière Aestas et Autumnus, comme celui de Boreas derrière les chevaux d'Occasus.

Ainsi, répartis à divers niveaux, au registre supérieur, les vents occupent dans la mosaïque de Mérida les quatre directions d'une rose des vents très simplifiée, proche de celle d'Homère, qui est définie dans l'espace du tableau par l'axe des pôles et la trajectoire * Il

Caunus, Favorinus... Maniluus emploie bien le mot Notos (Astronomica, I, 435) pour désigner le vent du Sud mais lorsqu'il cite les quatre vents, IV, 591-592, il emploie le mot Auster à côté de Boreas, Eurus, Zephyrus. Sur les noms des vents d'origine véritablement latine, sur les noms d'origine grecque et sur les noms traduits en latin, voir Nielsen, Noms des vents, p. 76-98.

Il note que le nom d'Eurus est passé directement en latin et que Favorinus s'employait de préférence à Zephyrus, Auster de préférence à Notos; Boreas et Aquilo se trouvent également.

(421) Sur l'exemple de la Tasse Farnèse, voir Blanco-FreiJeiro, p. 165 et pour leur fonction symbolique, voir R. Меrкецвасн, Eine astrale Deutung der Tazza Farnese, dans Les syncrétismes dans les religions grecques et romaines, (Colloque de Strasbourg, 1971), Paris, 1973, p. 67-78. Sur les couples pompéiens de la Casa des Vettii, voir C. L. Ragghianti, Pittori di Pompei, Milan, 1963, p. 64-66.

(422) Eurus, comme Boreas, est un vent qui chasse de gros nuages. La place manque devant les chevaux d'Oriens pour représenter à la fois la tête des saisons et une autre figure qu 'Eurus, si nous admettons que ce vent doit être représenté à la même échelle que les trois autres. Voir infra p. 33-34. 
des luminaires $\left({ }^{423}\right)$. Que les vents soient ainsi mis en relation avec quatre portions de l'espace n'est pas pour nous surprendre, mais nous pouvons constater à Mérida qu'aux quatre régions du ciel, délimitées par les deux lignes qui se coupent au niveau du pied de Caelum et de la main de Polum, semblent correspondre quatre régions de l'espace terrestre. Selon Ephore, cité par Strabon, les Anciens auraient eu l'habitude de «diviser le monde céleste et le monde terrestre en quatre portions: l'une vers VApeliotès serait occupée par les Indiens, la deuxième vers le Notos par les Ethiopiens, la troisième vers le Couchant par les Celtes, la quatrième vers le Borée par les Scythes» $\left({ }^{424}\right)$.

$\mathrm{Si}$ nous appliquons cette partition à l'espace de la mosaïque, au Notos correspond bien le Sud et le Nil, à Eurus l'Est et l'Euphrate, à droite, dans la partie ruinée du tableau, à Bóreas devaient correspondre le Nord et un fleuve qui le symbolise et à Zephyrus l'Ouest et un fleuve qui puisse caractériser cette direction et cette région de Voikouméné.

Les vents représentés semblent tous bénéfiques: Notos n'est pas le vent dangereux dont parle Virgile $\left({ }^{425}\right)$, il est ici le vent qui accompagne les pluies fécondantes, tel qu'il apparaît dans les hymnes orphiques (426) ; Zephyrus apporte les brumes de l'Ouest et semble ici associé au printemps, comme il l'était déjà chez Virgile $\left({ }^{427}\right)$; Boreas, s'il est bien associé à l'hiver dans la mosaïque,

(423) Sur la rose des vents d'Homère voir G. Aujac, Strabon et la Science, fig. VIII, reproduite ici pi. XIII. Sur l'axe des pôles et la trajectoire des luminaires, voir supra, notes $400-402$, et la figure de la rose des vents dans la mosaïque, pi. XII.

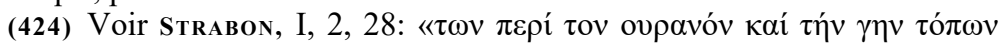

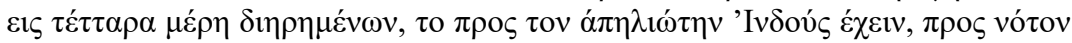

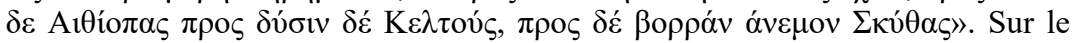
plan d'Ephore voir W.A. Heidel, The Frame, p. 17, pi. 7, reproduit pi. XIII. Sur la relation entre les noms des vents, les régions du ciel et les portions de la terre habitée, voir Nielsen, Noms des vents, p. 50-58; il précise que l'Europe est associée au Couchant.

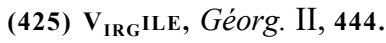

(426) Orphica, 82 cité par Blanco-Freijeiro, (p. 162). L. Robert, Hellenica, IX, p. 59, établit le même rapprochement entre les'O $\mu \beta \rho o r$ divinisés au Ile siècle et le Nó $\tau o \zeta$, en faisant la même citation.

$\left.{ }^{427}\right)$ VirgiLe, Géorg., II, 330. Mais Virgile n'attribue pas un vent à une saison, car il emploie souvent le mot au pluriel. 
n'est pas, malgré la proximité de Nix, le vent farouche et redoutable que dépeint Virgile $\left({ }^{428}\right)$; c'est un homme imposant, massif, mais son immobilité même n'est pas menaçante et son visage semble pacifique. Nix $\left.{ }^{429}\right)$, représentée en jeune femme endormie, n'évoque aucunement, sinon par sa légende, les frimas et le froid destructeur, comme c'est le cas chez Virgile $\left({ }^{430}\right)$; elle dit seulement la nature endormie et souligne la hauteur du mont (431) sur lequel elle est étendue. Ainsi le caractère bénéfique des vents-et des

(428) VirgiLe, Georg., I, 370; II, 315.

(429) $\mathrm{Y}_{0}$ ir supra I, p. 37-38 et note 98.

$\left(43^{\circ}\right)$ Virgile, Georg., Ill, 367 et $s q$.

(«i) Voir supra I, p. 59-60 et note 173. Le mot ne figure pas dans VIndex de Vermaseren et je ne connais pas d'autre exemple dans la mosaïque romaine de représentation allégorique de Morts. Les montagnes sont par contre fréquemment mentionnées par les poètes et souvent associées au lever des

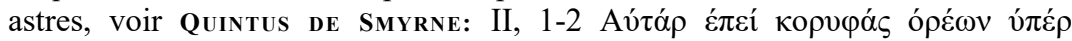

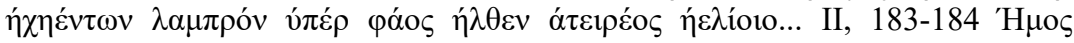

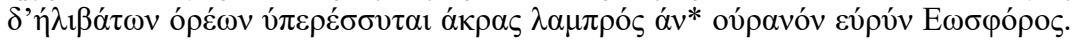
Elles constituent comme une super-terre, aux confins du monde terrestre et du monde céleste mais elles sont aussi un des éléments obligés de l'éloge

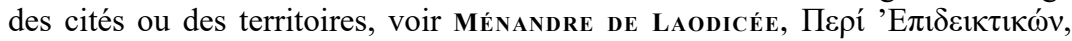

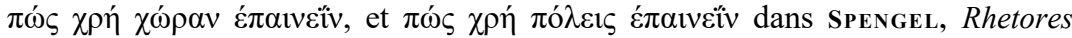
graeci, III, p. 344-345 et 350-351, et dans le Panégyrique de Maximien III, XIII, 4: «Vous qui assumez la charge d'un si grand Empire, vous qu'appellent ici et là tant de villes, de camps», "tôt limites, tôt circumiecta Romano Imperio flumina, montes, litora [vocant]». Dans l'éloge de l'harmonie du monde, les montagnes élevées se trouvent associées aux plantes, aux animaux, aux forêts, aux sources, aux rivières, aux villes, aux îles maritimes et aux continents, comme caractérisant l'ensemble terre et mer qui constitue le monde habité,

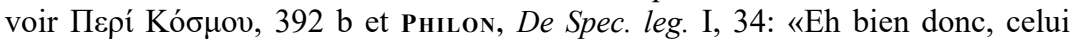
qui entre dans le monde qui est vraiment la grande cité, quand il a vu montagnes et plaines regorger d'animaux et de plantes, le cours des rivières nées de sources ou de pluies d'hiver, les mers largement épandues, les climats bien tempérés de l'air et les changements des saisons annuelles, puis le soleil et la lune qui président au jour et à la nuit, les circuits et les évolutions des autres astres errants et fixes et du ciel entier, n'est-il pas vraisemblable, n'est-ce pas de toute nécessité qu'il en viendra à la notion du créateur, du père et aussi du souverain maître de ces choses...» (traduction Festugière, Dieu Cosmique, p. 562). Nous pouvons supposer que, dans la mosaïque de Mérida, Nix caractérise Mons au registre terrestre comme Tranquillitas définit l'état d'Oceanus au registre marin. Manquent au registre terrestre, les plaines, les continents... peut-être disparus dans la lacune; nous y reviendrons. 
phénomènes atmosphériques en général-dans la mosaïque de Mérida s'oppose à ce que nous pouvons lire dans les Géorgiques $\left({ }^{432}\right)$

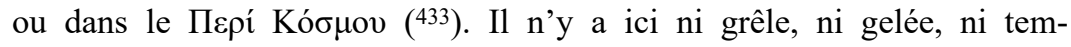
pêtes destructrices ( $\left.{ }^{434}\right)$; les quatre vents sont également favorables : quelle valeur symbolique attribuer à leur représentation?

G. M. A. Hanfmann (435) a souligné l'importance de leur figuration sur nombre de monuments des premiers siècles de l'Empire. L. Robert a pu dater l'apparition de leur culte, dans la partie grecque de l'Empire, du règne d'Hadrien $\left({ }^{436}\right)$. C'est, en tout cas, à partir de cette date qu'ils sont mentionnés dans les inscriptions, que des dédicaces leur sont consacrées, qu'ils sont appelés sauveurs, et qu'ils figurent à Athènes dans le calendrier sacré $\left({ }^{437}\right)$. C'est à la même date que sont divinisées les pluies nourricières $\left({ }^{438}\right)$. Les vents, comme les pluies ou les nuées, ne reçoivent pas alors un culte pour leur seul rôle bénéfique dans l'agriculture, ni pour répondre aux seules préoccupations personnelles de tel ou tel dédicant ${ }^{(439)}$. Comme en témoigne leur rapprochement dans les inscriptions et dans les sanctuaires avec des abstractions qui appartiennent au registre moral ou politique - Arété, Homonoia, Sophrosyné, Pistis... $\left({ }^{44 \circ}\right)$, ils sont les garants, comme les saisons $\left({ }^{441}\right)$, de

(432) $\mathbf{y}_{0} \mathbf{i}_{\mathbf{r} \text { no }} \mathbf{j}_{\mathrm{e}} 408$.

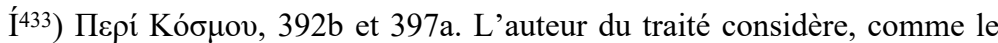
font aussi les stoïciens, qu' «une harmonie unique, qui révèle l'ordre universel, naît des contraires» et il mentionne «les vents qui soufflent en tourbillons et s'entrechoquent, les orages et les tempêtes» comme des conditions de la conservation du monde.

(434) Gela renforce le caractère idéologique de la représentation. Voir sur ce thème de l'éternel printemps, VirgiLe, Géorg. II, 338-39: «ver illud erat, ver magnus/agebat orbis» et pour la beauté paisible de l'Empire, DION DE Pruse et Aelius Aristide cités supra, p. I, 73, 75, 76.

${ }^{(435)}$ Hanfmann, Season Sarcophagus, p. 121.

(436) Roвert, Hellenica, IX, p. 60.

$\left.{ }^{437}\right)$ ID., ibid., IX, p. 60 et I.G., II², 1367.

(438) ID., ibid., IX, p. 59.

${ }^{(439)}$ ID., ibid., IX, p. 61.

${ }^{440}$ ) ID., ibid., IX, p. 60-61.

(441) ID., ibid., IX, p. 61. Les quatre saisons sont d'ailleurs nommées, non comme «les antiques divinités de la fertilité qui favorisent la croissance des plantes, l'éclosion des fleurs et la matuiation des fruits, les Heures mais comme Printemps, Eté, Automne et Hiver». 
l'ordre divin, qui se manifeste dans l'Univers (442). Nous retrouvons trace de cette conception tant dans la théologie cosmique $\left({ }^{443}\right)$, que dans la symbolique de nombreux cultes et en particulier dans la cosmologie du culte de Mithra $\left({ }^{444}\right)$.

Pourtant, dans la mosaïque de Mérida, les vents ne peuvent renvoyer ni à la cosmologie $\left({ }^{445}\right)$ ni à l'iconographie mithriaque. Si la disposition, le nombre des vents et leur figuration varient dans l'iconographie du culte de Mithra, deux vents seulement sont ordinairement retenus, qui ne sont jamais accompagnés ni de nuages, ni de neige (446): Boreas, le vent du Nord, qui est placé à côté de Sol et Notus, le vent du Sud, qui est placé à côté de $\mathrm{Lw}^{\wedge} \mathrm{a}\left({ }^{447}\right)$; ils sont alors figurés en buste; si les quatre vents sont représentés, n'apparaissent le plus souvent que leurs têtes, aux quatre coins de la scène ( $\left.{ }^{448}\right)$. Ordinairement, il $y$ a deux vents âgés et deux vents plus jeunes, les uns figurés barbus, les autres imberbes; ils sont représentés, tantôt avec des ailes, tantôt sans ailes $\left({ }^{449}\right)$.

(442) Voir Hanfmann, Season Sarcophagus, p. 148. Ainsi s'expliquerait que dans le chant II des Dionysiaques de nonnos de Panopolis les quatre vents, Eurus, Notus, Zephyrus, et Boreas soient désignés comme les bons vents, alliés de Zeus (v. 273-274; 392-393; 640-645) qui l'aident à lutter contre les vents mauvais, alliés de Typhée. Notons que, dans ce même chant (v. 258-280), Nonnos présente un tableau inversé de celui que représente la mosaïque de Mérida, le bouleversement du Cosmos; il est l'oeuvre de Typhée, l'adversaire acharné de l'Harmonie universelle (I, v. 397-399).

(443) Voir Festugière, Dieu cosmique, p. 468 et sq.

(444) Je m'arrête plus précisément à ce culte, que mentionnent BLANCO-

-Freijeiro, p. 161 et G. Ch. PiCard, Mosaïque Cosmologique, p. 124.

(445) Voir Leroy A. Campbell, Mithraic Iconography and Ideology, Leyde, 1968, chap. Y., p. 162-163; et M. J. Vermaseren, Mithra, ce dieu mystérieux (traduction M. Léman et L. Gilbert), Paris, 1960, p. 50-100 et p. 127-148.

(446) Voir, sur l'iconographie des vents, M. J. Vermaseren, C.I.M.R.M. (références citées supra note 413). Les mots Nubs, Nebula et Nix ne figurent pas dans l'index de Vermaseren.

$\left({ }^{447}\right)$ Voir Vermaseren, C.I.M.R.M., I, $\mathrm{n}^{\circ}$ 966; II, 1292, 2; 1292, 3;

Cumont, T. M. R. M. M. $\mathrm{n}^{\circ} 245$ ter, c; 246d; $267 \mathrm{a}$.

(448) Vermaseren, C.I.M.R.M., I n ${ }^{\circ} 339 ; 985$; II, 1083 A, 10; 1127 ;

$1247 \mathrm{~B} ; 1283 ; 1300 ; 1388$.

(449) Ni Cumont ni Vermaseren n'expliquent ces variations.

Conimbriga, 19 (1980), 5-127 
Sur les reliefs mithriaques, les vents ne sont généralement pas mis en relation avec les saisons $\left({ }^{450}\right)$.

Les vents dans la mosaïque de Mérida n'évoquent pas davantage les spéculations néo-pythagoriciennes dont nous retrouvons trace dans certaines conceptions cosmologiques, bien attestées aux Ier et $\mathrm{II}^{\mathrm{e}}$ siècles, qui établissaient des correspondances entre les vents et les saisons $\left({ }^{451}\right)$ : vent du Sud et printemps; vent du Nord et automne; vent d'Est et été; vent d'Ouest et hiver. Nous n'avons rien de tel ici. A Notus, le vent du Sud, correspondent l'été, Aestas, et le Nil; à Eurus, le vent d'Est, correspondent l'automne, Autumnus, et l'Euphrate dans la partie conservée de la mosaïque. Nous pouvons supposer, de façon sûre, qu'à Boreas, le vent du Nord, correspondaient dans la lacune Hiems, l'hiver et Tandis, le Don, ou peut-être Ister, le Danube ( $\left.{ }^{452}\right)$, et qu'à Eurus, le vent d'Ouest, correspondaient $\mathrm{Ver}$, le printemps $\left({ }^{453}\right)$ et un fleuve de l'Ouest. Ce seul critère ne permet pas de préciser s'il s'agissait de Tiberis, le Tibre, ou de Rhenus, le Rhin $\left({ }^{454}\right)$, ou de Eridanus, le Pô, le seul fleuve de l'Ouest mentionné par Manilius et mis en relations dans sa rose des vents avec la zone impartie à Corus et à Zephyrus $\left({ }^{455}\right)$, ou bien de Anas $\left({ }^{456}\right)$ — le Guadiana — qui relie

$\left(45^{\circ}\right) \mathrm{y}_{\text {oir }}$ F Cumont, T.M.R.M.M., p. 93 et Vermaseren, C.LM.R.M., II, 1083 A, 10; 1137, A 2b; 1282; 1685; 1727. Sur ces reliefs les saisons sont le plus souvent représentées en buste, tantôt comme des jeunes femmes, tantôt comme des jeunes gens. L'hiver est le plus souvent un vieillard barbu. Sur les saisons dans la mosaïque, voir infra p. 33-45.

(*51) Hanfmann, Season Sarcophagus, p. 121 et p. 155-156.

$\left({ }^{* 52}\right)$ Voir supra I, p. 57. Sur l'iconographie du Danube, voir L. Rossi, Il Dânubio nella storia, nella numismática e nella scultura romana, dans Num. ant., 1972, p. 111-143 avec planches.

$\mathrm{fl}^{53}$ ) Le printemps est la saison habituellement associée à l'Italie quand on ne lui accorde pas les bienfaits des quatre saisons. De façon générale l'Empire jouit d'un climat favorable, par opposition aux climats des régions situées au-delà des frontières de l'Empire et où les Romains n'ont pas voulu s'établir (cf. Strabon, IV, 5,5; XI, 2, 1 et Virgile, Géorg. III, 350-384). Pour la valeur idéologique de cette représentation, voir R. DIon, Aspects politiques de la géographie antique, p. 266 sq..

(454) Voir pour le Tibre supra I, p. 57-58, note 168, et pour le Rhin, I, p. 57, note 167 .

(455j Voir Manilius, Astronomica, IV, 585-817, particulièrement v. 610 et la carte dressée par G. P. GooLd, page de garde de l'édition et traduction 
Mérida à l'océan, ou même encore du Tartessos mythique (457)

Je Douro, le Tage ou le Guadalquivir — qui a été parfois associé

à Y Ister. Un fleuve espagnol conviendrait mieux à Mérida pour symboliser l'Ouest et l'extrême-Occident, mais nous ne pouvons, en ce domaine, que formuler des hypothèses. Constatons cependant que, dans la partie gauche du tableau, l'Euphrate se jette dans l'Océan et le Nil dans la Méditerranée; nous pouvons supposer qu'à droite, de manière parallèle, figuraient le Tanaïs ou VIster qui se jettent dans le Pont-Euxin, et le $T, 1$ Anas, ou le Betis qui, comme le Rhin, se jettent dans l'Océan. Le Rhin est à écarter, quoiqu'il soit un fleuve frontière comme l'Euphrate $\mathrm{i}^{458}$ ), parce

anglaise des Astronomica, Loeb c'ass. Lib., 1977. Outre 1

figurent les fleuves Tanais, Tigris, Euphrates, Ganges, Nilus. Le mosaïste de Mérida a délibérément limité Yoikouméné à YEuphrate.

$(4 ;>6)$ On a pu hésiter à identifier dans le Mithraeum de Mérida la figure masculine, couchée dans l'attitude caractéristique des divinités fluviales, avec Anas, le Guadiana, avant d'y reconnaître Oceanus (voir García y Bellido, Les religions Orientales, p. 32). L ${ }^{9}$ Anas est mentionné par Strabon (III, 4, 12) avec le Tage, comme «l'un des fleuves nombreux, qui, prenant leur source sur le territoire de Celtibérie, descendent vers 1 Océan». L Anas est par excellence un fleuve de l'extrême Ouest et pourrait former couple avec Zephyrus, s'il pouvait être rapproché des grands fleuves que sont le Nil et l'Euphrate. Ce travail était achevé lorsque j'ai pu prendre connaissance du livre de J.-G. Gorges, Les villas hispano-romaines, Inventaire et problématique archéologiques, Paris, 1979 (Publications du Centre Pierre Paris, 4). L'auteur mentionne, p. 355 , des restes de pavements bien conservés dans une villa de Tarraconaise, proche de Ségovie, la villa d'Aguilafuente, dont «un emblema rectangulaire, situé non loin du péristyle et décentré vers l'Est, où sont représentés quatre chevaux, attachés deux à deux à un petit arbre». On distingue nettement l'un des chevaux et les légendes, Tagus et Eufrata. Cette mosaïque, datée il est vrai du IVe siècle, semble confirmer mon hypothèse de la présence d'un fleuve espagnol à droite dans la lacune pour représenter l'Occident, comme l'Euphrate représente à gauche l'Orient.

$\left.{ }^{457}\right)$ Sur les difficultés d'identification du Tartessos, voir Heidel, Frame, p. 39-44. Le Tartessos est associé à Ylster dans les Météorologiques

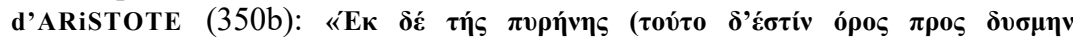

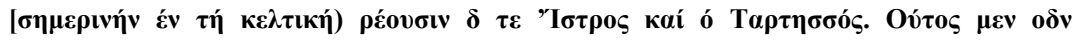

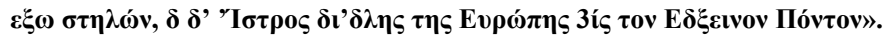

(458) Le Rhin est mentionné avec l'Euphrate, le haut et bas Danube, les Pyrénées, les Baléares et le désert de Nubie dans les Questions naturelles de SÉnÈque, I, Praef. 9, où le philosophe montre que l'âme ne peut atteindre 
qu'il est plus facilement associé au Nord. Restent $Y$ Anas et les autres fleuves hispaniques mentionnés par Strabon, à la place de l'antique Tartessos, entre lesquels nous ne choisirons pas.

Dans tous les cas, dans la mosaïque de Mérida, les vents, par la présence des nuages et des brumes, annonciateurs de pluies fécondantes, sont signes de prospérité, garantissent, par leur rapprochement avec les saisons et avec les deux luminaires, la régularité des cycles cosmiques, évoquent par leur dénomination d'après les quatre points cardinaux la totalité du monde sublunaire. Ils contribuent ainsi à exprimer, de façon métaphorique, l'ubiquité et la prospérité de l'Empire. Nous disons bien l'Empire, et non le Cosmos, parce que la juxtaposition des figures que nous venons d'étudier \{Notus, Nubs, Zephyrus, Nebula, Boreas, Nix, Eurus, Tonitrum même) — phénomènes atmosphériques dont nous avons vu qu'ils garantissaient avec les cycles cosmiques l'ordre divin et la bienveillance du Dieu créateur - et des figures qui renvoient, non à la fécondité naturelle de la terre (animaux, fruits, moissons,

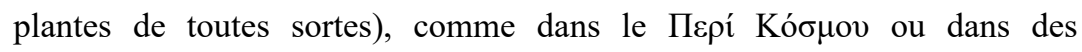
textes plus spécifiquement stoïciens ou seulement cosmologiques $\left({ }^{459}\right)$, mais à la prospérité et aux richesses procurées ou transformées par l'activité humaine (Copiae, Navigia) dans le port du monde (Portus, Pharus), ne peut s'expliquer que dans une seule perspective idéologique et religieuse: glorifier le monde romain en même temps que vénérer l'ordre et la beauté du Cosmos $\left({ }^{\circ}{ }^{\circ}\right)$ et y reconnaître la volonté de son créateur $\left({ }^{461}\right)$.

à la plénitude du bonheur qu'après avoir fait le tour du monde du haut du ciel et jeté un regard dédaigneux sur l'étroite terre qui constitue l'Empire romain. Voir un développement semblable dans Maxime DE Tyr, XXII, 6, cité par Festugière, Dieu Cosmique, p. 454-455.

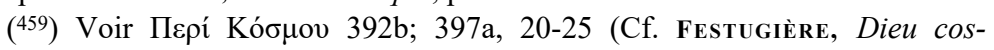
mique, p. 463 et 469); voir aussi Dion de Pruse, Or. 3, 72 et Or. 36, 56-57); même association chez Plutarque, Mor. 447c. Il est peu vraisemblable que le mosaïste, qui ne fait figurer à côté de l'automne et de l'été ni animaux ni plantes ni fruits, excepté la grappe de raisin tenue par Autumnus et les épis de blés tenus par l'enfant, ait pu les disposer dans la partie droite, ruinée aujourd'hui, à côté de l'hiver et du printemps.

$\left(4^{\circ}\right)$ Pour Manilius, sous le règne d'Auguste, l'ordre de l'Univers est bien divin (Astronomica, I, 523: «deus est qui non mutatur in aevo»), mais il ne met pas le Cosmos en relation avec le monde romain pour en souligner 
Cette démarche, qui était déjà perceptible chez Dion de Pruse à la fin du I ${ }^{\text {er }}$ siècle de notre ère $\left({ }^{462}\right)$, s'expiime officiellement, dès le règne d'Hadrien, dans l'iconographie impériale! ${ }^{463}$ ), oriente la théologie et l'iconographie de nombreux cultes, particulièrement du mithriacisme ${ }^{464}$, avant de devenir au III ${ }^{\mathrm{e}}$ siècle de notre ère l'objet d'une codification rhétorique.

Le rhéteur Ménandre de Laodicée, définissant les règles de l'éloge du souverain, recommande de «demander aux Dieux le salut du souverain, car les pluies qui viennent au bon moment, et les vents favorables sur mer, et l'abondance des productions de la terre se produisent, avec leurs effets heureusement favorables pour nous, grâce à la justice du souverain»!465).

Le panégyriste Mamertin, à la fin du III $^{\mathrm{e}}$ siècle, qui suit avec un soin minutieux les règles qui régissent le discours $\mathrm{d}$ anniversaire $\left({ }^{466}\right)$, n'hésite pas à franchir une étape nouvelle en assi-

la stabilité et l'éternité, comme le fait au II ${ }^{\mathrm{e}}$ siècle Aelius Aristide. Il établit seulement un parallèle, à l'extrême fin du poème ( $Y, 734$-fin), entre la place des astres et les catégories sociales et semble promettre à Rome la domination même du firmament.

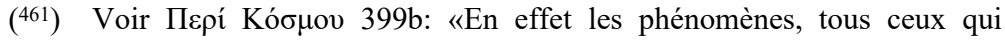
se produisent dans l'air comme sur la terre et dans l'eau, on peut bien dire qu'en toute réalité ils sont l'oeuvre du Dieu qui règne sur le monde» (dans Festugière, Dieu cosmique, p. 437), et Manilius, Astronomica, I, 531. «non casus opus est, magni sed numinis ordo»».

(462) voir M.-H. QueT, D.H.A., IV, p. 69

(463) Voir Hanfmann, Season Sarcophagus, p. 163-184 et particulièrement p. 172 .

(464) Voir Campbell, Mithraic Iconography, p. 121 et R. Turcan, Mithras Platonicus, Leyde, 1975, p. 12 et 128 qui mettent, après F. Cumont, Les religions orientales, p. 28-30, l'accent sur l'influence des spéculations astrologiques sur le mithriacisme. Seul R. Merkelbach propose d'y voir un reflet de la propagande impériale et souligne l'importance de la cosmologie platonicienne du Timée dans ces spéculations (Die Kosmogonie der MithrasMysterien, dans Eranos-Jahrbuch, 1966, p. 219-257), dès la fin du II siècle, R. Turcan ne constate d'influence de l'idéologie impériale sur le mithriacisme qu'au III' siècle.

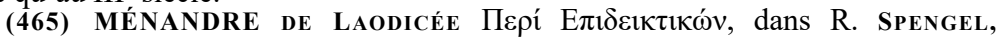

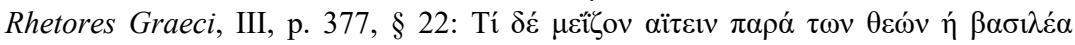

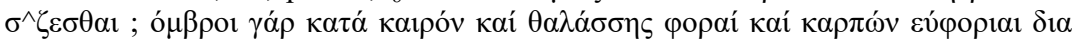

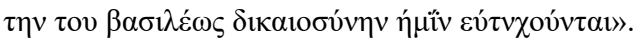

(466) Voir Panégyriques Latins (C.U.F.), Paris, 1949, traduction E. GaLLETIER, p. 17. 
milant l'oeuvre des souverains Dioclétien et Maximien à celle des dieux souverains, Jupiter et Hercule $\left.{ }^{467}\right)$ et il utilise, de la même façon, la mention «des brises paisibles qui glissent silencieusement» et qu'il associe à «la révolution du ciel» comme symboles d'Eternité $\left.{ }^{468}\right)$.

Ainsi, en cinq siècles, de Yhymne de Melimno au Panégyrique de Maximien, les vents n'ont cessé de voir croître leur importance dans le domaine idéologique. Le vent toujours favorable mais unique de l'hymne hellénistique a fait place aux brises paisibles garantes de l'ordre et de l'éternité du monde, comme delà volonté des Dieux.

Aussi comprenons-nous que la présence des vents ait pu être réinterprétée dans la religion mithriaque, si l'on en croit ce qu'écrit Porphyre ${ }^{469}$ ), et qu'on les ait considérés comme «les conducteurs des âmes qui vont vers la génération ou en reviennent». Mais, dans la mosaïque de Mérida, malgré la beauté plastique des couples envolés dans le ciel, les vents ne sont pas des génies psychopompes et nous ne saurions identifier Nubs, Nebula ou Nix avec des âmes, même si, postérieurement, le motif du couple en vol a connu une grande vogue dans l'iconographie funéraire $\left({ }^{470}\right)$ comme symbole de salut éternel.

Dans la mosaïque de Mérida, les vents expriment, comme nombre d'autres figures, de manière métaphorique, cette relation d'étroite correspondance entre les phénomènes de l'ordre cosmique et l'harmonie du monde romain et laissent entendre que l'on peut identifier la volonté du Dieu créateur de l'Univers à la sagesse du Souverain $\left({ }^{471}\right)$.

(467) Panégyrique de Maximien, III, III, 1-6.

(468) Ibid., Ill, III, 3 et III, IX, 2: «vous seuls étiez accompagnés (même en hiver) par les rayons du soleil, par de douces brises, des souffles printaniers».

$\left({ }^{469}\right)$ Porphyre, $U$ antre des Nymphes, trad. Trabucco, Paris, 1918, $\S$ 25-26. R. Turcan explique dans Mithras Platonicus, p. 86-89, comment a pu se produire une contamination entre les doctrines orphiques et les mystères iraniens. Pour une relecture de Porphyre, De antro Nympharum, 24, voir R. ВECK, The seat of Mithras at the Equinoxes, J. M. S., 1976, I, 1, p. 95-98.

${ }^{\left.47^{\circ}\right)}$ Voir F. Cuмоnт, Recherches sur le symbolisme funéraire des Romains, Paris, 1942, p. 104-141; 191-197 et C. R. Chiarlo, Un sarcófago, I venti ed Aion, dans S.C.O., 1977, 26, p. 69-78.

(471) Il est intéressant de constater sur ce sujet l'évolution qui se manifeste entre les conceptions du Пєрí Kóø̆ov (400b) où l'auteur met en relation

Conimbriga, 19 (1980), 5-127 
Pour conclure sur ces phénomènes atmosphériques, il convient de souligner davantage la beauté et l'harmonie qui se dégagent de ces flgures et remarquer que la facture du corps de $N u b s$ et de $N$ ebula est bien proche de celle du corps de la Vénus de Timgad $\left({ }^{472}\right)$ datée $\mathrm{du}$ règne d'Hadrien, assez voisine de celui de la Vénus de Boscéaz $\left.{ }^{473}\right)$, datée de la fin du II ${ }^{\mathrm{e}}$ siècle ou du début du III ${ }^{\mathrm{e}}$. Ceci nous permet de constater que les similitudes plastiques ne contredisent pas les nombreux rapprochements que nous avons pu établir dans les domaines cosmologique, épigraphique et idéologique $\left({ }^{474}\right)$ et nous invitent à proposer, sinon pour la date exacte de réalisation de ce pavement, du moins pour l'univers culturel auquel renvoie Vemblema, une même période postérieure au règne d'Hadrien: la seconde moitié du $\mathrm{II}^{\mathrm{e}}$ siècle $\left({ }^{475}\right)$.

\section{B) Les deux luminaires}

Les légendes Oriens et Occasus ${ }^{476}$ ) désignent, dans la mosaïque de Mérida, les figures du soleil et de la lune.

la loi du Cosmos et la «loi civique qui, immuablement fixée dans l'âme de ceux qu'elle régit, gouverne la vie de l'Etat.. » et celles que développent DıoN de Pruse ou Aeius Aristide, pour lesquels la loi de l'Univers se confond avec la juste volonté du souverain [Dıon, Or. 36 30-32; 75, 4; Piutarque Mor., 720 E); Cf. M.-H. Quet, D.H.A., IY, p. 76 et supra I, p. 78, 95-96.

(472) Voir J. Lassus, Vénus marine, dans La mosaïque gréco-romaine, I, (Colloque C.N.R.S., 1963), Paris, 1965, p. 175-192.

[473] Voir V. Von GonzenbacII, Fliegende Gotter, dans Schweizer Münzblatter, 8, 1958, p. 110 sq. Cette mosaïque est citée par Bıanco-FrelJEıro, fig. Xa.

(474) Dans le domaine idéologique, le thème continue à se développer au cours du IIIe siècle, comme nous l'avons vu dans le Panégyrique de Maximien, mais la sérénité du tableau dans la mosaïque de Mérida suppose une période prospère où l'on pouvait croire réalisée la perfection de 1 âge $\mathrm{d}$ or.

$\left({ }^{47 \delta}\right)$ Nous reviendrons sur le problème de la datation du pavement infra, p. 101-103.

[476] Voir sur Oriens et Occasus, Gareía-Sandoval, p. 14 et 19, qui identifie seulement les figures du soleil et de la lune. Les rapprochements, fondés sur les termes seuls, avec les Géorgiques (p. 23-24), quoique sans références précises, sont intéressants. On peut constater que, dans tous les cas, le poète note la course divine (I, 250 et III, 357-359) ou annuelle (II, 323-324) du soleil; le char ou les chevaux sont mentionnés chaque fois. La lune 
Oriens est ici représenté à l'extrême gauche, au-dessus de Natura, au registre inférieur de celui où se trouve Polum, sous les traits d'un adolescent imberbe, debout sur un quadrige dont on aperçoit, partiellement, de profil, une roue et la caisse et qui semble apparaître dans le tableau. Oriens est vêtu d'une longue tunique rose clair et porte sur les épaules une chlamyde flottant au vent, grenat sombre avec des reflets cuivrés. Son visage, aux traits réguliers mais sévères, est légèrement incliné vers le bas. La chevelure, coiffée en arrière, dégage le front et les tempes et retombe en ondulations souples sur la nuque. La figure est nimbée $\left.{ }^{477}\right)$. Du nimbe radié se détachent onze rayons en glaives. Le personnage tient un fouet de la main droite, de l'autre - qui a disparu dans la lacune - les rênes de son attelage de quatre chevaux blancs qui semblent immobiles. Ne restent des chevaux que les quatre têtes, un arrière-train et une queue. Cette représentation est iconographiquement assez voisine de celle d'un soleil en médaillon, figurant sur la mosaïque aux divinités d'Orbe, près de Boscéaz ( ${ }^{478}$ ), (pi. XV), malgré plusieurs différences sensibles de détail dans la position des bras, le mouvement et la couleur du

est mentionnée le plus souvent seule; Virgile note (I, 395) qu'elle est redevable de sa clarté aux rayons de son frère. Voir aussi Blanco-Freijeiro, p. 161, qui établit les rapprochements Oriens-Anatolé, Occasus-Dysis et mentionne les inscriptions au soleil naissant dans le culte de Mithra.

$\left({ }^{477}\right)$ Sur le Nimbe d'Oriens voir M. Collinet-Guérin, Histoire $d u$ Nimbe, Paris, 1961 : p. 116-127, sur le pré-nimbe de Sol dans le culte de Mithra; p. 203-217, sur le nimbe romain. Retenons comme caractéristiques de l'art romain, la forme circulaire, les rayons en glaives, la position du nimbe derrière les épaules et la tête, par opposition au nimbe «feu-follet* des Grecs, p. 204-205. L'auteur souligne que le nimbe s'introduit dans l'iconographie romaine dès le $\mathrm{II}^{\mathrm{e}}$ siècle, qu'il caractérise des hommes aussi bien que des divinités, puisqu'on connaît même un médaillon d'Antonin le Pieux nimbé p. 208-209, et qu'il n'est pas caractéristique du culte de Mithra.

$\left({ }^{478}\right)$ Voir note 473 et V. Von Gonzenbach, Romische Mosaïken, p. 187 et pl. 61 et pour l'ensemble de la mosaïque p. 184-194; pour une interprétation pythagoricienne de ce pavement voir M. RENARD, La mosaïque aux divinités de Boscéaz, près d'Orbe, dans Mélanges J. Carcopino, Paris, 1966, p. 803-818, fig. 1-3, qui concerne plus particulièrement les mythes de Narcisse et de Ganymède, et en dernier lieu, sur l'importance du complexe gallo-romain de Boscéaz, D. Weidmann, L'établissement romain d'Orbe-Boscéaz dans Archéologie Suisse, 1, 1978, 2, p. 84-86. 
manteau, l'attitude générale du personnage, sa coiffure, avec une couronne radiée plutôt qu'un nimbe, la représentation du quadrige, le mouvement de l'attelage. A Boscéaz, chaque personnage est traité pour lui-même et, quoique la mosaïque représente les sept planètes, dans un ordre qui n'est pas celui de Vheptazonos $\left({ }^{479}\right)$, le soleil est associé comme à Mérida à la lune.

Occasus est à Mérida une jeune femme représentée à droite du tableau un peu plus haut qu"Oriens, au niveau de Polum. Elle est assise sur un bige de deux chevaux blancs $\left({ }^{48}\right)$, qu'elle conduit sans regarder l'attelage, en tournant la tête vers l'arrière. Elle ne montre à qui regarde la mosaïque que son dos, comme si elle n'illuminait désormais que la nuit. La caisse du char, à l'exception de Yantyx arrondi à l'avant $\left({ }^{481}\right)$, a disparu dans la lacune ainsi, sans doute, que l'arrière-train des chevaux, que le mosaïste a pu

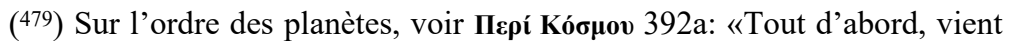
le cercle du Lumineux, qui est dit en même temps cercle de Saturne, puis le cercle du Resplendissant dit cercle de Jupiter, ensuite le Rutilant, dénommé cercle d'Hercule ou de Mars, à la suite le Scintillant, que certains disent consacré à Mercure, d'autres à Apollon, après lui le cercle du Porte-Lumière que les uns nomment cercle de Vénus, d'autres cercle de Junon, ensuite le cercle du soleil et en dernier lieu le cercle de la lune, dont la frontière se termine à la terre (traduction Festugière, Dieu cosmique, p. 462-463). A Boscéaz le mosaïste a fait figurer Vénus au centre de la mosaïque planétaire.

$\left({ }^{48^{\circ}}\right)$ Sur le bige d'Occasus, voir F. Cumont, T.M.R.M.M., t. I, p. 121-128. L'auteur souligne que «la poésie de l'âge d'Auguste représentait comme ses modèles grecs la lune parcourant le ciel étoilé sur un bige traîné par des chevaux. Ce n'est qu'au II ${ }^{\mathrm{e}}$ siècle de notre ère et pour la première fois sous le règne d'Hadrien qu'on substitue à ceux-ci des taureaux d'une blancheur éclatante. A la fin de l'Empire, c'est un attelage de taureaux qui sera habituellement prêté à la déesse dans les oeuvres littéraires comme dans les oeuvres artistiques». Nous en retiendrons les indices du caractère non mithriaque de la représentation du bige, l'origine vraisemblablement hellénistique de la figure et la date assez haute dans le deuxième siècle. Voir sur les chars célestes, Vermaseren, C.l.M.R.M., t. II, s. v. chariot et ID., Two Unknown Mithraïc Reliefs, dans Hommages à M. Renard, Bruxelles, 1969, t. III, (col.. Latomus, $\mathrm{n}^{\circ}$ 193), p. 644-645 et pl. CCXXX et CCXXXII, où l'auteur étudie le quadrige de Sol et le bige de Luna, tirés l'un et l'autre par des chevaux sur un relief qui date du II" siècle ap. J.-C.

(481) Sur les caisses des biges et quadriges et les modes d'attelage, voir Edm. Saglio, dans DA., s. v. Currus, t. 1, p. 1636 à 1642. Le timon du bige n'est pas visible ici. 
également ne pas dessiner pour alléger la composition (482). Iconographiquement Occasus est très proche de la figure de la lune en médaillon de Boscéaz (pi. XVI): même draperie jetée sur l'épaule gauche, qui suit le mouvement du corps, sans le dissimuler, même nudité absolue, même position du dos. A Boscéaz, le bras gauche, qui repose sur les genoux, tient les rênes; le bras droit, plié à hauteur du coude, est dirigé vers le haut et la main droite tient, comme celle du soleil, un fouet. A Mérida, le bras droit, légèrement incliné vers le bas, tient les rênes, le gauche n'est pas visible. La tête s'inscrit, dans les deux cas, à l'intérieur du disque lunaire $\left({ }^{483}\right)$ représenté dans sa totalité. A Mérida, le mosaïste a distingué les cornes $\mathrm{du}$ croissant $\mathrm{du}$ reste $\mathrm{du}$ disque dont l'existence se révèle seulement par l'ombre portée sur les corps de Zephyrus et Nebula et par la disposition des tesselles, dont la couleur seule — bleu clair - ne se distinguerait pas, sans cela, de celle du fond du tableau. Les deux cornes du croissant, très effilées et lumineuses, sont représentées par trois rangs de tesselles dorées et se détachent des épaules, à la naissance du cou. A Boscéaz, le disque est plus complètement visible - il est traité en tesselles argentées; le croissant, plus plein, quoiqu'il soit stylisé, dégage le cou. Le visage est tourné de profil à Boscéaz et la lune regarde devant elle. La tête, présentée de trois quarts et de dos, est tournée vers l'arrière à Mérida. Les cheveux sont noués en chignon à Boscéaz, portés courts à Mérida. Mais le modelé du corps féminin — hanches larges, moelleux des épaules, gonflement du buste et chute des reins - est traité de la même façon par les deux artistes. Dans les deux cas, le personnage est assis sur un pan de manteau, vert à Boscéaz, rouge à Mérida. Les deux figures semblent manifestement renvoyer à un même type: Occasus, malgré la légende masculine, ne peut être à Mérida qu'une représentation féminine ( $\left.{ }^{484}\right)$ de la lune,

(4ß2) C'est le procédé retenu dans la mosaïque de Boscéaz pour l'arrièretrain des chevaux du quadrige de Sol (pi. XV). Voir Gonzenbach, Rômische mosaiken, pl. 61.

(483) Sur la forme réelle du disque lunaire, voir Manilius, Astronomica, I, 208: «Solisque orbem lunaeque rotundum aspicimus...». Le choix du mosaïste n'est pas ici cosmologique. Il témoigne d'un choix iconographique qui semble correspondre au goût d'une époque donnée (voir mosaïque de Boscéaz).

(484) Il arrive dans l'iconographie mithriaque que la lune soit dépourvue de tout signe distinctif de son sexe: F. Cumont, T.M.R.M.M., t. I, p. 122. 
issue d'un carton très proche de celui de la mosaïque de Boscéaz.

Il semble donc $y$ avoir comme une contradiction entre les figures représentées, le soleil et la lune, et les légendes qui les désignent; Oriens et Occasus $\left({ }^{485}\right)$ évoquent moins les astres euxmêmes que leurs mouvements.

Oriens n'est pas, à proprement parler, l'astre solaire. Le mot désigne ordinairement le moment et le lieu de son lever, mais il arrive qu'il désigne le soleil naissant et qu'on lui rende un culte sous ce nom( $\left.{ }^{486}\right)$.

$\mathrm{Au}$ contraire Occasus ne désigne pas d'ordinaire la lune. Le mot est habituellement employé pour désigner le coucher du soleil et par extension le coucher des astres. Il ne peut donc désigner la lune que par référence à l'apparition du soleil, qui est le moment de sa propre disparition. D'ailleurs, en latin, Oriens fait plus volontiers couple avec Occidens $\left({ }^{487}\right)$, dans un sens spatial, pour désigner l'Orient, par opposition à l'Occident; Occasus avec Ortus $\left({ }^{488}\right)$, dans un sens temporel, pour évoquer le moment du lever et du coucher de l'astre solaire, mais la spécialisation n'est pas absolue.

(485) Sur Oriens, du point devue lexical, voir les exemples donnés par Ernout-Meillet, Dictionnaire étymologique, p. 468. Sur Occasus, voir Thesaurus linguae latinae, vol. IX, 2, fase. Ill, col. 337-338. Le mot Occasus, comme Ortus, s'applique le plus souvent au soleil mais il désigne aussi le coucher des astres en général comme Ortus leur lever. Voir Manilius, Astronomica, I, 827.

(486) Voir GuMont, T.M.R.M.M., t. I, p 128 et G. H. Halsberghe The Cult of Sol Invictus (.E.P.R.O., 28), Leyde 1972, p. 48. L'auteur note l'importance du culte de Sol invictus en Espagne et son expansion à partir du règne de Septime Sévère, dont la femme est assimilée à Luna.

(487) Voir Panégyrique de Maximien, III, IV, 2: «Cum ad Orientem Occidentemque occupari putaremini»; mais Mamertin emploie aussi dans ce même sens Ortus et Occasus: «ab solis Ortu... sub ipso lucis Occasu» (III, XVI, 4-5).

(488) Voir Manilius, Astronomica, I, 174-176; le poète évoquant le renversement impossible des phénomènes de l'ordre cosmique applique les mots Occasus, Ortus au soleil: «Non ageret currus Phoebus ab Occasu et nunquam remearet ad Ortus», et évoque par une périphrase la marche de la lune: «Lunave summersos regeret per inania cursus». Manilius utilise la même expression Ortus-Occasus en I, 192-193 et 242, toujours appliquée au soleil. Pour la lune il emploie en I, 232, Exoriens. 
Le faux parallélisme Oriens /Occasus semble donc renvoyer à un double registre spatio-temporel et rend sans doute compte de l'effort du mosaïste, soit pour traduire en latin des termes grecs qui lui échappaient — ce qui est peu vraisemblable —, soit pour conférer aux images du soleil et de la lune une double signification.

Aussi devons-nous nous interroger sur la nature de ces deux figures et sur leur rôle dans le tableau.

Oriens et Occasus ne représentent pas ici les deux luminaires comme des astres évoluant dans l'ether ( ${ }^{489}$ ) ni comme deux des sept planètes évoluant chacune sur son cercle propre, entre le firmament et la terre $\left({ }^{49}\right)$. Leur disposition dans l'espace de la mosaïque, sous Zephyrus et Nebula à droite, sous Nubs et Notus à gauche, montre qu'ils appartiennent ici au monde humain que nous appelons habituellement sublunaire, au registre de l'air et des phénomènes atmosphériques $\left({ }^{491}\right)$. Cette constatation nous permet d'affirmer, à nouveau, que la mosaïque de Mérida n'est pas une représentation de la totalité du Cosmos; manquent l'éther et le ciel étoilé qu'a longuement décrits, après Aratos, Manilius, dans son poème cosmologique $\left({ }^{492}\right)$ et que nous retrouvons dans toutes les descriptions de l'Univers de caractère astronomique, même lorsque l'ouvrage privilégie les considérations religieuses $\left({ }^{493}\right)$. Le mosaïste de Mérida ne s'intéresse pas aux astres pour eux-mêmes, il privilégie le monde visible par les hommes, celui de la tene, de la mer, de l'air, du soleil et de la lune. Mais cette simplification lui est sans doute imposée aussi par la nature de son art. Son

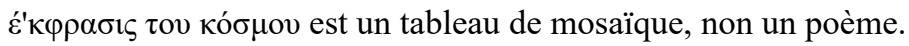

Dans la mosaïque de Mérida, Oriens et Occasus symbolisent donc, dans une sorte de raccourci spatial, les lieux de lever et de

(489) Le soleil et la lune évoluent précisément entre le ciel des fixes

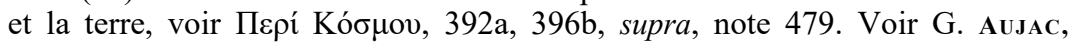
La géographie dans le monde antique, Paris, 1975, (= Ausac, Géographie) p. 27-28.

$\left(4^{\circ}\right)$ Voir Manilius, Astronomica, I, vers 539 ou 805, p. 46 (éd. G. P.

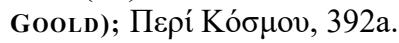

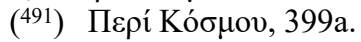

(492) Astronomica, I, 255-538.

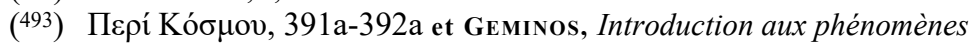
(I, 23-38), cité par AuJac, Géographie, p. 27-28 et 31. 
coucher des astres: l'Orient et l'Occident $\left({ }^{494}\right)$. Ils renvoient aussi à un registre temporel et expriment l'écoulement du temps, écoulement quotidien par l'alternance du jour et de la nuit, annuel par le mouvement des astres à travers les signes zodiacaux, qui permet l'alternance des saisons dans l'année ( $\left.{ }^{495}\right)$.

L'influence qu'exercent le soleil et la lune sur la terre avait retenu l'attention des savants hellénistiques (496). Dès le Ier siècle de notre ère, l'accent est mis, dans le poème de Manilius, comme dans

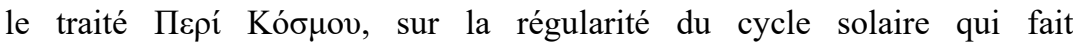
alterner le jour et la nuit et se succéder les quatre saisons comme signe et source de l'harmonie de l'Univers $\left.{ }^{497}\right)$. Le rôle du soI|il n'est pas exagérément valorisé dans la mosaïque de Mérida, comme cela a pu être le cas dans le traité cosmologique de Cléomède $\left({ }^{498}\right)$ dès

(4®4) Voir cet emploi d'Occasus pour l'Occident dans Manilius, Astronomica, I, 242: «Hanc ubi ad Occasus nostros sol aspicit actus». Sur les lieux de lever et de coucher du soleil comme limites de l'Empire, voir Aelius ArisTIDE, Eloge, § 10 cité note 142; Panégyrique de Maximien, cité note 487, et Quintus de Smyrne, XIII, 339-341: "Il[Enée] régnera lui-même sur un vaste peuple et sa race étendra plus tard son empire jusqu'aux confins immuables du Levant et de l'Occident».

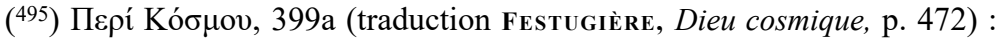
«C'est en effet par une unique révolution du ciel entier dans les limites d'un jour et d'une nuit que sont produits les trajets de tous les corps célestes, trajets qui tous diffèrent...» et plus loin: «Le soleil qui brille sur toutes choses entreprend sa double course, soit que par son lever et son coucher il divise le jour et la nuit, soit que glissant à travers les signes zodiacaux en avant vers le nord, en arrière vers le sud, il amène les saisons de l'année...». Voir aussi Manilius, Astronomica, I, 259 et Virgile, Géorg., I, 231-233; 463-465. Voir sur cette conception du temps et sur sa représentation: Hinks, Myth, p. 49-51.

(4»e) Voir Aujac, Géographie, p. 89-93.

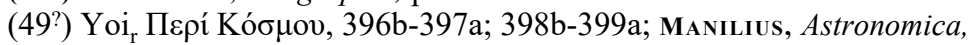
1,173-193, et Pтolémée, Apotelesmatica (Tetrabible) 1, 18, 3.

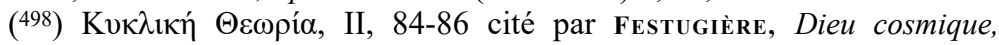
p. 484-485. Il faudrait pouvoir tout citer: «D'abord que le soleil illumine tout l'univers bien que celui-ci soit d'une grandeur, pour ainsi dire infinie... que c'est lui qui par sa force énorme produit la vie sur la terre, en sorte qu'elle porte fruits et crée des être vivants; que c'est lui... ; que c'est lui qui fait non seulement le jour et la nuit, mais l'été, l'hiver et les autres saisons; qui est cause...; c'est la force du soleil... D'un mot, presque toute la diversité des choses terrestres a pour cause le soleil... Bref, toutes les différences, toutes les propriétés particulières qui se font voir d'objet à objet, de tout cela, c'est 
le $\mathrm{II}^{\mathrm{e}}$ siècle, et dans la religion et l'iconographie au $\mathrm{III}^{\mathrm{e}}$ siècle $\left({ }^{499}\right)$. Il occupe dans la mosaïque moins de place que Natura ou Aeternitas], moins de place même que les deux fleuves encore visibles. Le soleil à son lever et la lune à son coucher ne sont ici que des éléments de l'harmonie cosmique $\left({ }^{50}\right)$. Leurs images, plastiquement très belles, concourent à exprimer la beauté de la loi de l'Univers et à la faire aimer.

Une pareille symbolique n'est pas caractéristique d'un culte en particulier. Le soleil et la lune sur leurs chars célestes se retrouvent dans l'iconographie de nombreux cultes, sur de très nombreux documents figurés ( $\left.{ }^{501}\right)$. On y a vu des symboles d'éternité ( ${ }^{502}$ ), d' universalité $\left({ }^{503}\right)$, ou une sorte de «commentaire théologique» de la scène qu'ils accompagnent (504) et cela est sans doute vrai lorsqu'ils sont les seuls éléments de caractère cosmologique du tableau. On les a surtout associés au mithriacisme depuis que F. Cumont a affirmé «qu'ils ne font défaut sur presqu'aucun des

la force du soleil qui est la cause. Davantage, telle est la surabondance de cette force que la lune elle-même, qui reçoit sa lumière du soleil, tire de cette lumière empruntée tout ce qu'elle a de puissance...».

(4") Voir F. Cumont, Théologie solaire du paganisme romain, Bruxelles, 1909; Les religions orientales, p. 197 et sur l'influence de cette foi sur les emblèmes monétaires, IDEM, L'éternité des empereurs romains dans Hist, etlitt. relig., I, 1896, p. 435-447. Sur la représentation du soleil sur les monnaies de Septime Sévère, voir Mattingly-Sydenham, R.I.C., IY, 1, p. 79, 126 en buste radié; p. $103,105,119,157,158,192$, debout avec un fouet. Sur le rôle de l'astrologie et l'importance du culte solaire à la fin du principat, F. H. Cramer, Astrology in Roman Law, p. 217-231. Sur les spéculations des néo-platoniciens, voir Hanfmann, Season Sarcophagus, p. 152-154; sur la représentation de Sol invictus sur la mosaïque aux chevaux de Sens, voir J.-P. Darmon, La mosaïque gréco-romaine, t. II, p. 307-316. Sur la prééminence du rôle solaire sous les Sévères, voir Festugière, Hermétisme, p. 117 sq.

$\left(5^{\circ \circ}\right)$ Voir $_{\text {sur }}$ cette conception, Festugière, Dieu cosmique, p. 418-419 et 504-506.

(501) Voir W. Deonna, R.H.R., 1946, 132, p. 5-47.

$\left(5^{\circ 2}\right)$ Voir H. Seyrig, Syria, 12, 1931, p. 55; 13, 1932, p. 63; F. Cumont, T.M.R.M.M., t. I, p. 125 et Recherches, p. 79 et sq. et W. Deonna, Eternité, dans Hommages à J. Ridez et à F. Cumont, Bruxelles, 1948 (coli. Latomus, 2), p. 71-76.

(503) Voir Cumont, T.M.R.M.M., t. II, p. 90 et D. Levi, Aiôn, dans Hesperia, XIII, 1944, p. 293-294, à propos de la Patère de Parabiago.

$\left(5^{\circ} 4\right) \mathrm{Voi}_{\mathrm{r}} H \mathrm{~s}_{\mathrm{EYRIGj}}$ Syria, 14, 1933, p. 243. 
monuments consacrés au culte du Dieu tauroctone» $\left.{ }^{505}\right)$. Leur rapprochement s'imposait, sans doute, d'autant plus facilement que les images du soleil et de la lune sont associées sur quelques reliefs mithriaques à la terre, à l'océan, au ciel, aux vents et peut-être même aux saisons (506). Pourtant, contrairement à ce que laisse entendre A. Blanco-Freijeiro (507), la légende Oriens ne renvoie pas au mithriacisme dans la mosaïque de Mérida, non plus que l'iconographie des deux luminaires.

Le mot Oriens n'est employé que quatre fois dans les inscriptions mithriaques et dans un des cas au moins l'expression a un caractèie spatial— «ab oriente ad occidente $(m) »-\left({ }^{508}\right)$. Le soleil est représenté, très souvent, sur nombre de reliefs mithriaques et sur les parois des antres d'initiation $\left({ }^{509}\right)$, sous les traits d'une figure très peu différente de celle d'Oriens, debout, devant ou dans son quadrige: le soleil apparaît quarante trois fois dans le Corpus des inscriptions et monuments relatifs au culte de Mithra de M. J. Vermaseren $\left({ }^{5}{ }^{\circ}\right)$. Il a ordinairement les traits d'un homme jeune, la tête coiffée d'une couronne radiée de neuf, onze ou douze

(55) Cumont, T.M.R.M.M. t. I, p. 121.

(506) C'est le cas de la stèle de Carnuntum (Pannonie) étudiée par Cumont, T.M.R.M.M., t. I, p. 90 et sq., II, $\mathrm{n}^{\circ} 246 \mathrm{e}, 2$, p. 349, pi. VI, n 228 bis, c, 1, p. 497, fig. 432, et D. Levi, Hesperia, p. 298 et Vermaseren, C.I.M. R.M., t. II, $\mathrm{n}^{\circ} 1685,1$, p. 216 fig. 431-434. Voir aussi le relief de Virunum (Norique): Vermaseren, C.I.M.R.M., t. II n ${ }^{\circ}$ 1430, B2, p. 159.

(so?) $\mathrm{y}_{0}$ ir BLANCO-FreiJEIRo, p. 161.

(sos) Voir Vermaseren, C.I.M.R.M., t. I, 518: «Orienti»; 480: «Oriente»; t. II, 1469: «invicto deo Orienti omnipotenti»; 2213: «invicto deo Orienti ab Oriente ad Occidente $(\mathrm{m}) »$.

$\left({ }^{509}\right)$ Voir la représentation de la voûte céleste avec tout le zodiaque sur la voûte du Mithraeum de Ponza, Vermaseren, Mithriaca II, 1974, planches VI et VII, p. 8-9. L'auteur date de la période antonine la décoration de la voûte de Ponza. Le soleil est bien représenté debout avec un fouet et une couronne nimbée de 11 rayons. Il voisine avec Océan qui a des écrevisses dans la chevelure et avec la Terre.

$\left(51^{\circ}\right)$ Nous ne retiendrons que les exemples où Sol figure sur un quadrige : t. I, $212 ; 332 ; 335 ; 337 ; 390 ; \mathrm{r}, 4 ; 415 ; 532 ; 554 ; 556 ; 609 \mathrm{a} ; 736 ; 810 ; 878$; 942; 966a. T. II, 1137 A 3 c; 1174; 1247 A, 12; 1283, 3; 1292, 2; 1292, 5c; $1359 ; 1400,12 ; 1430$, с $3 ; 1458 ; 1579,4 ; 1591 ; 1599 ; 1879 ; 1935,11 ; 1972,9$; 2036, 10; 2044, 4; 2048; 2048, 3; 2055; 2166, 3; 2176; 2216; 2245, 3; 2298, 2; 2320,$5 ; 2361$. 
rayons, parfois nimbée, avec de longs cheveux qui tombent sur les épaules. Il tient un fouet de la main droite, de l'autre les rênes de son attelage qui s'élève vers le ciel. Sol se trouve ordinairement placé dans l'angle gauche du relief et semble le plus souvent associé à Luna, qui est généralement placée à droite.

Le mot Occasus n'apparaît dans aucune inscription mithriaque, quoique la lune soit représentée sur dix-sept monuments mithriaques ( $\left.{ }^{511}\right)$, assise, debout ou en buste sur un bige. Elle a un croissant placé derrière la tête, attaché aux épaules de façon que les extrémités seules des cornes soient visibles. Elle porte quelquefois un diadème, tient parfois un fouet de la main droite et semble fougueusement descendre une pente rapide, à droite de la scène. Son bige, tiré le plus souvent par des boeufs, rarement par des chevaux, se dirige tantôt vers la droite, tantôt vers la gauche, mais, dans tous les cas, il descend tandis que le quadrige de Sol s'élève vers le ciel.

Dans la mosaïque de Mérida, le quadrige du soleil est bien situé à droite mais plus bas que le bige de la lune qui semble, dans un mouvement ascendant, s'éloigner à regret du centre du tableau, tandis que le soleil vient juste d'y pénétrer. Le mouvement de rotation $\mathrm{du}$ soleil et de toute la sphère céleste autour de l'axe $\mathrm{du}$ monde s'effectue selon la ligne droite imaginaire qui relie les disques d'Oriens et d"Occasus. Ainsi la trajectoire des luminaires semble décrire, comme nous l'avons vu plus haut, l'un des cercles parallèles, mis à plat dans la mosaïque, que parcourt le soleil en un jour et une nuit ${ }^{(512)}$. Des parallèles à cette droite définissent dans l'espace du tableau des zones qui correspondent aux divers registres, céleste, terrestre, maritime. La disposition oblique de ces registres par rapport à l'axe absidial montre clairement qu'ont disparu, dans la grande lacune de droite, des figures appartenant au registre terrestre. Gela explique, sans doute, que le registre maritime puisse paraître privilégié, mais témoigne surtout de l'importance accordée à la cosmologie dans ce tableau.

(su) Nous ne retiendrons que les exemples où Luna figure sur un bige, Vermaseren, C.LM.R.M., t. I, 184; 335; 415; 532; 332, 3; 810; 952?; 966A; t. II, 1283,$4 ; 1292,3 ; 1292,3 ; 1359 ; 1521 ; 1972,7 ; 2215 ; 1458 ; 2046,7 ?$ ?

(512) Voir supra, note 401. 
Ainsi, les noms choisis par le mosaïste, Oriens et Occasus, le traitement plastique réservé aux images des deux luminaires, leur disposition dans l'espace $d u$ tableau sur une ligne perpendiculaire à l'axe des pôles, le voisinage même des autres figures (513), tout nous interdit d'accepter l'hypothèse d'une atmosphère mithriaque, même si la symbolique du culte de Mithra est, à cette date, nourrie de références cosxnologiques dont nous connaissons, par ailleurs, l'importance au II' siècle $\left({ }^{514}\right)$.

Le culte de la puissance qui anime l'Univers et circule à travers l'ensemble du monde caractérise la théologie cosmique et relève du mysticisme astral $\left.{ }^{515}\right)$ en général, plus que d'un culte particulier.

Dans la mosaïque de Mérida, les luminaires sont les garants de l'harmonie des cycles cosmiques; ils expriment l'éternité et l'universalité de l'ordre cosmique et, sans doute aussi, de l'ordre romain dans un empire qui s'étend de l'Orient à l'Occident (516) et dont on veut enraciner l'éternité dans la régularité des phénomènes naturels ${ }^{(517)}$. L'amour pour le Cosmos que suscitent l'ordre et la beauté de l'Univers semble indissociable, dès la fin du Ir siècle de notre ère, de l'amour pour Rome $\left({ }^{518}\right)$.

(513) Dans l'iconographie mithriaque il n'y a rien dans l'index de Vermaseren s.v. Mons, Nix, Portus, Pharus, Copiae, Navigia, Tranquillitas, Nilus, Euphrates, Tonitrum, Pontus, Saeculum.

${ }^{\left({ }^{14}\right)}$ Sur l'importance de la cosmologie en général, voir A. BouchéLeclerce, Histoire de la divination, I, Paris, 1879, p. 253 et sq., et dans le mithriacisme en particulier, voir CAMpbell, Mithraic Iconography, p. 121 et déjà chez F. Cumont, dans Les religions orientales, p. 28 :«La dogmatique des mystères de Mithra est, à certains égards, une expression religieuse de la physique et de l'astronomie romaines». Pour une nouvelle interprétation de la cosmologie mithriaque, voir Мerкelbach, Die Kosmogonie, p. 219-257 et pour l'interprétation de la voûte du Mithreum de Ponza cf. M. J. Vermaseren, Mithriaca II, The Mithreum at Ponza, Leyde, 1974 et pour l'interprétation du zodiaque et l'importance de sa figuration, voir R. BEck, Interpreting the Ponza Zodiac, dans J.M.S., 1976, I, 1, p. 1-19 et le compte rendu du Colloque de Rome, 23-31 mars 1978, dans J.M.S. 1978, II, 2, p. 241-242.

(515) Voir Festugière, Dieu cosmique, p. 504-505. Sur le mysticisme astral, voir F. Cumont, La théologie solaire, $2^{\mathrm{e}}$ part. p. 256-286.

(516) Aelius Aristide, Eloge, § 10, cité note 142.

(517) ID., ibid., § 109, cité note 253.

(518) Voir Klingner, Rom ais Idee, p. 570. 


\section{G) Les saisons}

Dans la mosaïque de Mérida, deux légendes de saisons seulement subsistent, Aestas et Autumnus. Elles sont disposées dans l'espace de Yemblema, verticalement, entre les figures des fleuves et la lacune où disparaissent les chevaux d'Oriens à gauche, horizontalement, entre le voile de Natura et la grande lacune de droite. Une lacune de moindre importance empêche de distinguer clairement la composition originale du groupe. Nous essaierons d'abord $4 \mathrm{e}$ décrire très exactement les fragments qui subsistent, avant d'en proposer une interprétation.

Au-dessus du voile de Natura, tout près de l'emplacement où devraient se trouver les pattes de devant des chevaux d'Oriens, on distingue le mollet et le pied d'une jambe gauche, traitée en tesselles sombres et coupée au niveau du genou par la lacune. Cette jambe, iconographiquement, dans le tableau, vu sa taille et sa couleur, devait appartenir à un adolescent. Ce pourrait être l'étoile du matin, Phosphorus, le vent d'Est, Eurus, ou une saison masculine.

Phosphorus est bien habituellement placé devant les chevaux $\mathrm{du}$ soleil sur les bas-reliefs mithriaques $\left({ }^{519}\right)$ et figure à côté des

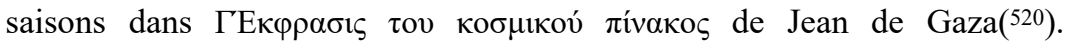
Nous ne retiendrons pas cependant cette hypothèse. Le mosaïste de Mérida n'a pas fait figurer Hesperus ( $\left.{ }^{521}\right)$, l'étoile du soir, dans son tableau et les figures $\mathrm{d}^{\prime}<9$ riens et $\mathrm{d}^{\prime}$ Occasus, comme nous l'avons montré plus haut, n'ont rien de mithriaque. Enfin, il semble difficile de loger dans si peu d'espace Phosphorus, Eurus, Autumnus et Aestas en respectant l'échelle choisie par le mosaïste.

Eurus serait mieux à sa place ici $\left.{ }^{522}\right)$. Le mouvement de la jambe est bien celui d'un personnage en vol dont le pied ne repose pas sur le sol. Mais la position de cette jambe semble, au premier abord, sans relation avec la légende qui est située sous les naseaux

(519) Sur Phosphorus dans les bas-reliefs mithriaques, voir VermaSEREN, CJ.M.R.M., t. I, $\mathbf{n}^{\circ} 415$.

$\left(52^{\circ} \mathrm{j}\right.$ Voir planche IX.

$\left.{ }^{521}\right)$ Il figure à côté de Séléné dans la description de Jean de Gaza, voir planche IX, et devant le bige de Luna sur les bas-reliefs mithriaques, voir CJ.M.R.M., t. I, $\mathrm{n}^{\circ} 415$.

(522) $\mathrm{V}_{0} \mathrm{i}_{\mathrm{r}}$ supra, I, p. 23, 56 et notes $417,422$.

Conimbriga, 19 (1980), 5-127 
des chevaux. A y regarder de plus près, pour peu que le personnage soit incliné dans une position voisine de celle de ,et en tenant compte de la place occupée par les ailes, rien $\mathrm{n}$ empêche d'attribuer à Eurus cette jambe, tout en respectant la taille du personnage et la distance que le mosaïste laisse le plus souvent entre la figure d'un personnage et la légende qui le désigne.

Aussi pouvons-nous penser, avec quelque vraissemblance, qu'Eurus figurait bien à cette place et refuserons-nous de voir dans la couleur de la jambe l'indice de la présence $d$ une saison masculine et d'admettre, comme A. Blanco-Freijeiro, que l'hiver a disparu dans la lacune ${ }^{(523)}$. Nous reviendrons sur ce problème, quand nous aurons fini de décrire le groupe des saisons.

En poursuivant l'examen du tableau vers la droite, nous distinguons, à côté de la jambe brune, inscrite sur deux lignes c'est le seul exemple dans ce qui subsiste de la mosaïque de Mérida $\left({ }^{524}\right)$ - la légende Autum/nus et un bras traité en tesselles claires, avec un bracelet au-dessus du coude, un bras féminin donc, dont la main tient deux grappes de raisins, puis une lacune verticale assez étroite, très circonscrite, de 10 à $12 \mathrm{~cm}$ de large sur $50 \mathrm{~cm}$ de hauteur. A droite, au-delà, une jeune femme voilée dont manquent la tête, l'épaule et le bras gauche. Elle s'appuie, du pied gauche, sur un support rocheux où s'inscrit la légende Aestas dont les caractères, aussi importants que les lettres de la légende Nilus, sont peu distincts $\mathrm{du}$ fond $\mathrm{du}$ tableau $\left({ }^{525}\right)$. La jambe droite n'est pas visible, le corps est incliné vers l'avant, l'épaule et le sein droits sont nus. Un vetement cache le corps et la jambe gauche jusqu'au genou. Le tissu, épais, semble être réversible, d'un rouge orangé sur le dessus et vert bleute à 1 intérieur. La jambe droite n'est pas visible. La jeune femme tient de la main

(52s) BLAnCo-Freijeiro, p. 165 et infra p. 36 et sq.

$\left.{ }^{524}\right)$ Notons cependant que le même procédé est utilisé au IVe s. dans la mosaïque constantinienne de la Villa «el Hinojal», conservée aujourd hui au musée de Mérida où quatre saisons féminines en buste sont représentées: Vira/n. Hestas, Autum/nus, Hib. Voir J. G. Gorges, Les villas romaines, Inventaire et Problématique archéologiques, Paris, 1979 (Publications du Centre Pierre Paris, 4) p. 193-194, (non consulté au moment de la rédaction).

(525) Notons que le mosaïste a employé, quelle que soit la couleur du fond, des tesselles de même couleur, blanches, pour les légendes. 
droite par le bras gauche, un enfant de petite taille (ô26) qui semble suspendu dans les airs et qui se trouve très exactement situé dans le prolongement de la lacune où avaient disparu son corps et sa tête, lorsque E. Garcia^Sandoval a relevé le dessin de $Y$ emblema. A en juger par son croquis $\left.{ }^{527}\right)$, il ne subsistait, alors, de la figure que les bras, les jambes et une mince portion du corps.

Aujourd'hui, après restauration sans doute $\left.{ }^{528}\right)$, l'enfant est complètement visible, à l'exception de la tête. Il porte une sorte de tunique-pantalon, courte, rayée verticalement et coupée par une étroite ceinture. Le vêtement bleu sans manches, très ajusté, est souligné par une ligne de tesselles marron foncé au niveau du du corsage et semble formé de plis plats soulignés de brun ocre, au niveau de la culotte. C'est un costume extrêmement recherché qui surprend par sa conception, et forme hapax dans la mosaïque où les corps des autres personnages sont seulement plus ou moins dissimulés par une draperie ou un voile et non vêtus $\left.{ }^{529}\right)$. On comprend mal pourquoi cet enfant est traité différemment des autres adolescents du tableau, Pharus et Tonitrum. Il tient dans la main droite un bouquet difficile à décrire: ce ne sont ni des fleurs, ni un rameau de feuillages, ni une palme, comme pourrait le laisser croire le dessin de E. Garcla-Sandoval. Sur la mosaïque, et par agrandissement photographique, on peut reconnaître un bouquet de tiges dorées à longues barbes $\left({ }^{53^{\circ}}\right)$, un bouquet stylisé * 15

(526) Il mesure $45 \mathrm{~cm}$ de la pointe des pieds à la naissance du cou;

$15 \mathrm{~cm}$ de tour de poitrine; $14 \mathrm{~cm}$ de longueur de bras et $23 \mathrm{~cm}$ de longueur de jambe, mais il est situé à un registre où le bras à'Autumnus mesure $28 \mathrm{~cm}$ et celui de l'autre saison féminine $28 \mathrm{~cm}$; son tour de buste, $32 \mathrm{~cm}$ environ; sa jambe, du pied au genou, $38 \mathrm{~cm}$.

${ }^{(527)}$ Voir planche I.

(528) A. Blanco-FreiJeiro ne dit pas sur quels indices repose la restauration, ne mentionne même pas qu'il y ait eu restauration, ce que prouve je dessin de E. Garcia-Sandoval.

(529) On peut considérer que Navigia porte un soutien-gorge de nageuse. Ce n'est pas un vêtement comparable à la tunique de l'enfant, qui est très élaborée.

$\left(5^{\circ}\right)$ Assez comparable au bouquet d'épis de l'été dans la mosaïque de Daphné d'Antioche, voir Hanfmann, Season Sarcophagus, t. II, $\mathrm{n}^{\circ} 34$ pl. 137. 
d'épis de blé, comme l'a noté aussi A. Blanco Freijeiro (531). Nous ne suivrons pourtant pas celui-ci dans son interpretation du groupe des saisons.

A. Blanco-Freijeiro, rappelons-le $\left.{ }^{532}\right)$, suppose que les lettres de la légende Fer, qui désignerait la figure féminine située à droite, ont disparu dans la lacune et identifie trois saisons. Autumnus «una muchacha», Aestas «un niño», et Fer «una joven». La légende et la figure de [Hierns], dont il ne précise pas le sexe, situées au-dessus de l'enfant [Aestas], auraient, de plus, disparu dans la lacune. Ces suppositions conduisent le savant espagnol a formuler des remarques stylistiques sur la représentation des saisons dans la mosaïque de Mérida. Autumnus et [Fer] seraient des saisons féminines, de type hellénistique, encore proches des Horai grecques; Aestas une représentation masculine de «type populaire qui se répandrait dans les scènes mythologiques à l'époque antonine» (533). Ainsi la mosaïque de Mérida présenterait une synthèse de types iconographiques variés, associant des saisons masculines et des saisons feminines, des saisons adultes et des saisons enfants.

G. M. A. Hanfmann a souligné que le type iconographique des saisons n'est pas fixé sous l'Empire (534), que la vogue des saisons féminines dansant, de type hellénistique, qui a caractérisé le 1er siècle de notre ère et s'est prolongée au $\mathrm{II}^{\mathrm{e}}$ siècle $\left({ }^{535}\right)$, a pu s'effacer devant la popularité des saisons féminines en bustes $\left(536^{* * *}\right)$,

(531) BlanCo-FreiJeiro, p. 165.

(532) Voir supra, I, p. 26.

(533) BlanCo-FreiJeiro, p. 166.

(534) Voir Hanfmann, Season Sarcophagus, t. I, p. 134-136. L'auteur souligne, t. I, p. 173 n. 193, que le genre de chaque saison n'influe en rien sur la représentation qui en est donnée. En grec, trois saisons sont de genre neutre, une de genre masculin, mais les Horai sont toutes figurées en jeunes filles. En latin, deux saisons sont féminines, une neutre, une masculine, sans entraîner de différences de sexe dans la représentation qui en est donnée.

(535) Voir Hanfmann, Season Sarcophagus, t. I, p. 136 et 173 et t. II, p. $137-144$

(536) ID., ibid., t. II, p. 147-158. Les bustes ou les têtes des saisons confèrent à la scène qu'elles cantonnent un caractère de permanence, sinon d'immortalité. Voir P. Voûte, M.E.F.R.A., 84, 1972, p. 668; Hanfmann, Season Sarcophagus, t. I, p. 137; 212-214; et Hinks, Myth, p. 52-53. 
des saisons masculines $\left({ }^{537}\right)$ et des saisons enfants $\left({ }^{538}\right)$, sous diverses influences et particulièrement pour le type masculin sous la pression de l'icoïiographie impériale, diffusée par les monuments officiels et par les types monétaires $\left.{ }^{539}\right)$. Pourtant, sans être absolument unique $\left(^{54 \circ}\right)$, l'association de saisons féminines et d'un enfant de sexe masculin est extrêmement rare dans l'iconographie des saisons. Une pareille lecture, qui nous conduirait à identifier [.Hiems] avec une saison masculine, risque de nous faire commettre plusieurs erreurs: soit établir des rapprochements avec l'iconographie mithriaque, où sont le plus fréquemment associées saisons masculines et saisons féminines $\left({ }^{(51)}\right)$; soit reconnaître dans la ${ }^{*} 54$

(537) Voir Hanfmann, Season Sarcophagus, t. II, p. 159-185.

(538) ID., ibid., t. II, p. 160-161; p. 169-171. Sur leur apparition strictement romaine et relativement tardive, voir Hinks, Myth, p. 48.

$\left.{ }^{539}\right)$ Voir Hanfmann, Season Sarcophagus, t. I, p. 163; 171 et 179-180 ; l'auteur note que le premier exemple officiel de saison masculine date du règne de Trajan (Arc de Bénévent, t. II, n 307, pl. 123 et 124); il souligne qu'au $\mathrm{II}^{\mathrm{e}}$ siècle sur les monnaies alternent les types de saisons masculines et de saisons féminines. Le type masculin s'est imposé en Occident à l'époque des Sévères et maintenu postérieurement.

(54) ID., ibid., t. II $\mathrm{n}^{\circ} 176$, p. 67; sur le sarcophage de Triptolème on voit à côté de trois saisons féminines, été, automne, hiver, un jeune garçon nu qui pourrait être la quatrième saison, le printemps, mais l'identification est douteuse; et $\mathrm{n}^{\circ} 73$, p. 141, sur le vase d'Onyx de Braunschweig, à côté d'un empereur romain sous les traits de Triptolème, Déméter, des figures dionysiaques et trois Horai, deux debout, le printemps et l'hiver, une assise, l'été; à côté, un adolescent debout qui porte une corbeille de fleurs; on hésite à voir en lui l'automne ou un personnage dionysiaque. Notons que ces deux exéifiples ne sont pas sûrs et qu'on ne connaît pas d'exemples semblables dans les mosaïques.

(54i) Voir sur $\mathbf{i}_{\text {es }}$ saisons dans l'iconographie mithriaque, Hanfmann, Season Sarcophagus, t. I, p. 180-181; F. Cumont souligne que sur les monuments du dieu iranien les saisons sont souvent associées aux vents, T.M.R. M.M., p. 92-93. Elles étaient primitivement conçues comme des divinités masculines et auraient évolué sous l'influence de la cosmologie stoïcienne. Dans l'index de Vermaseren figurent sept exemples de saisons qui sont presque toutes représentées en buste, (voir C.I.M.R.M., t. II, $\mathrm{n}^{\circ} 1083$, A, 10, les 4 saisons en buste associées aux vents; 1137 A, 2 b, deux bustes de saisons, l'hiver barbu et une femme; 1282, 4 bustes de saisons à longue chevelure; 1685 , les saisons sont représentées au milieu d'autres figures comme des jeunes gens et un vieillard; 1727, 4 bustes de saisons en médaillons aux angles de 
facture de «l'enfant Aestas» une influence de l'art plébéien et chercher une origine africaine ou occidentale au mosaïste (542), alors que la conception d'ensemble du tableau, le traitement réservé à toutes les autres figures renvoient à une culture et à des modèles d'origine hellénique et laissent supposer que, s'il n'est réellement grec, ce mosaïste est pénétré de culture grecque et a reçu, comme l'a souligné G. Ch. Picard, «sa formation dans un grand centre de la Méditerranée orientale» $\left({ }^{543}\right)$.

Dans son article consacré aux mosaïques romaines de Mérida (544), A. Blanco-Freijeiro, mentionnant les légendes des saisons, ne cite pas $V e r$, mais il ne dit pas qu'il renonce à sa première hypothèse qui lui faisait reconnaître le printemps dans la jeune femme au sein nu, et semble toujours admettre que les quatre saisons sont toutes placées à gauche dans le tableau.

G. Ch. Picard a refusé de suivre A. Blanco-Freijeiro dans ses conclusions et ne découvre dans la mosaïque ni influence de «l'art plébéien», ni «reflet de l'idéologie impériale» (545). La nature de son exposé l'empêche de s'intéresser précisément aux problèmes que pose le groupe des saisons.

Pour notre part, nous ne saurions identifier $\mathrm{Ver}$ avec la jeune femme placée à droite près de la lacune et Aestas avec l'enfant auquel elle donne la main; nous ne croyons pas davantage que les quatre saisons aient figuré ensemble, réunies dans un même groupe, à côté de Natura, dans la partie gauche du tableau. Ver pourrait bien être une jeune femme, semblable aux Heures hellénistiques, mais nous remarquerons que la légende Aestas s'inscrit, en partie, sur le socle sur lequel la jeune femme appuie le pied et très exactement dans l'axe de son corps. Si le mosaïste avait voulu désigner

la scène: en haut un jeune homme, le printemps, une femme très habillée, l'hiver, en bas une femme, l'été, un homme, l'automne; 1797, 5, l'identification douteuse d'un buste avec une saison).

(542) $\mathrm{y}_{\mathrm{j}} \mathrm{j}_{\mathrm{r}}$ BLANCO-FreiJeIro, p. 174. Dans la partie grecque de l'Empire, au $\mathrm{II}^{\mathrm{e}}, \mathrm{III}^{\mathrm{e}}$ et même au $\mathrm{V}^{\mathrm{e}}$ siècle, c'est toujours le type des saisons féminines qui prévaut (voir Hanfmann, Season Sarcophagus, t. I, p. 148-149; t. II $\mathrm{n}^{\circ} 50$, p. 71$)$.

$\left(\mathrm{ot}^{3}\right)$ Voir G. Ch. Picard, Mosaïque Cosmologique, p. 123.

(544) Blanco-FreiJeiro, Emerita, p. 195.

(545) Voir G. Ch. Picard, Mosaïque Cosmologique, p. 123. 
par Aestas l'enfant, la place ne lui aurait pas manqué à gauche sous la main de l'enfant le long de sa jambe droite. Il est, au surplus, tout à fait habituel de représenter l'été, de préférence aux autres saisons, en jeune femme dénudée ( $\left.{ }^{546}\right)$ alors qu'un type d'été, enfant, au milieu de saisons féminines, serait un hapax dans l'iconographie des saisons. Je crois donc qu'il faut nécessairement identifier l'été avec la jeune femme au sein nu.

L'enfant auquel elle donne la main ne fait pas moins problème. Peut-on le considérer comme une troisième saison, distincte des deux saisons désignées par les légendes Aestas et Autumnus et supposer qu'une légende s'est perdue, qui serait obligatoirement alors Ver ou Hiems? Ce serait faire de cet enfant, unique dans le groupe $\left({ }^{547}\right)$, une saison semblable aux $\mathrm{j}^{\wedge}$ wtó-saisons ${ }^{548}$ ) qui accompagnent, par couple ou groupe de trois ou quatre, Terra Mater ou Italia ${ }^{549}$ ) sur des monnaies et des monuments figurés des $\mathrm{I}^{\mathrm{er}}$, II ${ }^{\mathrm{e}}$ et $\mathrm{III}^{\mathrm{e}}$ siècles, ce qui est impossible. L'enfant par sa position n'est pas dissociable, ici, de la jeune femme qui lui tient le bras; il porte le bouquet d'épis mûrs caractéristique, avec la faucille, de l'été $\left({ }^{5}{ }^{\circ}\right)$. Aussi pouvons-nous affirmer que l'enfant

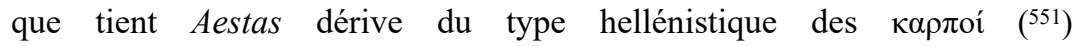
de la terre et qu'il est symbole de vie, d'abondance et de prospérité. Il redouble en quelque manière les autres expressions de la fécondité qui caractérisent les saisons $\left(552 *{ }^{554}\right)$. Plastiquement, nous

(843) Voir Hanfmann, Season Sarcophagus, t. I, p. 135.

(547) Autant que la lacune nous permet d'en juger.

(548) Sur tes saisons-/? $i_{i} £ £ i$, voir HanfmanN, t. II, p. 160 et 170 sq. et ToynbeE, Hadrianic School, p. 142-143, pour un bronze d'Hadrien avec la légende Tellus stabilita et des bronzes d'Antonin et de Commode, planche XIX, $\mathrm{n}^{\text {os }} 6,10,11$. Mais lesputti sont tantôt masculins, tantôt féminins (cf. ToYNBEE Roman medallions, p. 93).

(549) Sur ce thème voir, outre les références de la note précédente, E. Strong, Terra mater or Italia, dans J.R.S., 27, 1937, p. 114-126 avec planches nombreuses, spécialement p. 117, 119-120.

$\left(55^{\circ}\right)$ Voir Hanfmann, Season Sarcophagus, p. 135. Rien dans la mosaïque n'indique que la jeune femme au sein nu tient un bouquet de fleurs de la main gauche, quoi que dise Blanco-FreiJeiro, p. 165.

(554) $\mathbf{y}_{\text {oir E }}$ Strong, J.R.S., 1937, p. 116 et 120.

(552) Sur la double présence d'une saison et d'un génie enfant pour redoubler la force du thème, voir R. ETIEnNe, Une mosaïque de Volubilis, M.E.F.R., 62, 1950, p. 93-118, particuièrement p. 104-108. A Volubilis, 
remarquerons qu'il appartient au même registre que les grappes de raisin et les épis et que, situé comme eux dans la proximité de Natura, il réaffirme le thème de la prospérité que les poètes et ]es panégyristes cnt toujours associé sous l'Empire au bonheur de l'âge d'or ( $\left.{ }^{553}\right)$.

Nous pouvons donc affirmer, avec certitude, que deux saisons seulement sont représentées, à gauche, dans le tableau. Les deux autres saisons n'ont pas disparu dans la lacune de gauche, elles devaient figurer, à droite, dans la partie ruinée de la mosaïque. L'été et l'automne figurant du côté du vent du Sud et du vent d'Est, nous pouvons supposer, comme nous l'avons indiqué plus haut $\left({ }^{554}\right)$, que le printemps et l'hiver étaient situés du côté du vent du Nord et de la neige, du côté du Zéphyr et de la brume printanière, de l'autre côté d'Aet [emitas ] (555). Soulignons encore une fois que, sur l'Arc de Trajan à Bénévent, sans doute ajoutées par ordre d'Hadrien (556), les saisons étaient placées à côté des fleuves, qui

les génies semblent masculins et chaque enfant porte un attribut qui caractérise la saison qu'il représente (des épis jaunes pour l'été), dans une mosaïque datée du premier tiers du $\mathrm{II}^{\mathrm{e}}$ siècle. L'enfant de Mérida qui porte lui aussi un bouquet d'épis dorés n'était peut-être que l'un des putti-at tributs des quatre saisons, le seul qui ait subsisté. La mosaïque de Mérida serait ainsi le deuxième exemple de ce motif iconographique, sans doute antérieur à celui de Volubilis, puisque l'enfant - et nous savons que le motif des saisonsenfants sera appelé à une grande fortune - n'est pas dissociable de la saison à laquelle il donne la main. C'est bien selon Hanfmann (Season Sarcophagus, t. II, p. 160 n. $^{\circ} 290-291$, p. $\left.142, \mathrm{n}^{\circ} 79 \mathrm{a}\right)$ à la fin du $\mathrm{II}^{\mathrm{e}}$ siècle que les puttisaisons font leur apparition dans l'iconographie. Il note qu'ils sont encore très proches des карлоí de la terre. Sans aucun doute, l'enfant de Mérida

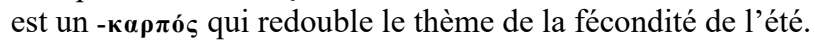

(553) Voir Virgile, Bue., IV, 6-9, 23, 28-29; Géorg., II, 520-524 et Aelius Aristide, Eloge $\S 7$, (voir note 131) et $\S 109$ où l'auteur emploie le

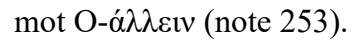

(554) Voir supra, I, p. 55 et notes 162-163.

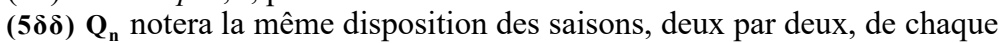
côté d'un personnage central, dans un sarcophage chrétien de Tipasa où le Christ enseignant entre deux colonnes est vu de face; il a à sa droite le printemps et l'été, à sa gauche l'automne et l'hiver. Les saisons ne sont pas des femmes mais des jeunes gens vêtus seulement de la chlamyde (voir L. LESCHI, Etudes d'épigraphie, d'archéologie et d'histoire africaines, Pans, 1957, p. 408 fig. 3).

$(\delta \delta \beta)$ Voir Hanfmann, Season Sarcophagus, t. I, p. 172. 
représentaient les provinces conquises de l'Empire; l'hiver se trouvait auprès du Danube et l'automne auprès de l'Euphrate. L'association des saisons avec les quatre vents, Notus, Eurus Boreas, Zephyrus, habituelle chez les poètes dès le règne d'Auguste $\left.{ }^{\left({ }^{\delta} 7\right.}\right)$, est relativement banale dans l'iconographie impériale ( $\left.{ }^{\delta 88}\right)$. Pourtant le rapprochement de Notus avec l'été et d'Eurus avec l'automne ne semble pas attesté dans les spéculations astrologiques ou néo-pythagoriciennes des $\mathrm{II}^{\mathrm{e}}$ et $\mathrm{III}^{\mathrm{e}}$ siècles. Celles-ci mettaient en relation, si l'on en croit G. M. A. Hanfmann, le printemps avec le vent du Sud, l'été avec le vent d'Est, l'automne avec le vent du Nord et l'hiver avec le vent d'Ouest. Mais G. M. A. Hanfmann s'appuyait sur le témoignage d'Antiochos dont on sait maintenant qu'il a vécu à la fin du II e siècle de notre ère $\left(557 *{ }^{* 59}\right)$. La contradiction n'est donc pas gênante. La mosaïque, nous avons eu l'occasion de le souligner plusieurs fois déjà, n'exprime pas des préoccupations réellement astrologiques $\left({ }^{56}\right)$, mais elle autorise et appelle une lecture cosmologique. Les saisons n'y sont pas disposées en file $\left({ }^{561}\right)$ ou réunies dans un seul groupe de quatre, elles sont associées aux quatre points cardinaux. Les saisons - nous l'avons déjà mentionné - jouent un rôle essentiel à la fois dans les spéculations cosmologiques et dans l'idéologie officielle et témoignent, comme les autres figures, de l'interaction de ces deux domaines sous l'Empire ( ${ }^{562}$ ).

(557) Voir Hanfmann, Season Sarcophagus, t. I, 121-122.

(558) ID., ibid., t. I, p. 188; 227-230; 251 et D. LevI, Hesperia, XIII, p. 296-297.

(559) Voir Hanfmann, Season Sarcophagus, t. I, p. 155-156, d'après Antiochos d'Athènes (F. Bols, C.C.A.G., VII, p. 104 sq). Sur la date d'Antiochos, voir le compte rendu de l'ouvrage de W. et H. G. GundeL, Astrologúmena, Die astrologische Literatur in der Antike und ihre Geschichte, Wiesbaden, 1966 par D. Pingree dans Gnomon, 40, 1968, p. 278. Le schéma reproduit par Hanfmann, I, 155, qui est très répandu, ne serait pas réellement attesté avant le II $\mathrm{e}$ siècle de notre ère.

$\left(5^{\circ}\right)$ Voir Manilius, Astronomica, II, 265-269; 418; 425-426; 429-431.

(561) Voir Hinks, Myth, p. 46 et pl. 4. Le printemps vient en tête, suivi par l'été, l'automne et l'hiver.

(562) Voir supra, I, p. 79 et notes 404-407. 
Constatons que dans la mosaïque de Mérida les saisons qui subsistent sont présentées comme bénéfiques ( $\left.{ }^{563}\right)$, qu'elles sont individualisées et ne sont pas confondues avec les Heures, comme

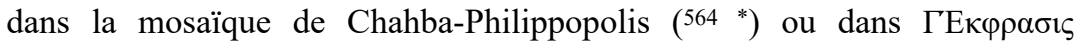

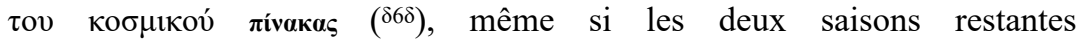
sont de type hellénistique $\left({ }^{566}\right)$. Souvenons nous qu'au $\mathrm{II}^{\mathrm{e}}$ siècle, dans la partie grecque de l'Empire, les saisons ne sont pas seulement perçues comme «les antiques divinités de la fertilité», «les gracieuses Heures, qui ensemble favorisent la croissance des plantes, l'éclosion des fleurs et la maturation des fruits, mais comme le printemps, l'été, l'automne et l'hiver» $\left({ }^{567)}\right)$, saisons individualisées et personnifiées qui sont décrites par Quintus de Smyrne, Philostrate ( ${ }^{568}$ ) et peuvent recevoir à l'occasion une dédicace, comme c'est le cas sur l'Hermès de Byzance où elles sont associées aux vents, aux pluies, à VAgathos Daimon et kVAgathé Tyché\{ $\left.{ }^{569}\right)$.

$\mathrm{Au}$ second siècle, les saisons, comme les vents et les luminaires, sont perçues, avant tout, comme des signes de l'harmonie cosmique dont elles garantissent la permanence $\left({ }^{570}\right)$. Elles sont créées en même temps que le monde $\left({ }^{571}\right)$ et sont liées à l'ordre de l'Univers( $\left.{ }^{572}\right)$;

(563) A la différence de ce que l'on trouve chez VIRGILE dans les Géorgiques où le poète insiste sur la variété des activités selon les saisons (I, 297 et sq.), chez Celse (voir HanfMann, t. I, p. 122 et note 104).

(564) Voir Blanco-Freijeiro, pi. IX.

(5B5) $\mathbf{Y}_{\mathbf{0}} \mathbf{j}_{\mathbf{r}}$ planche IX.

(566) Assez proche du type pompéien, voir Hanfmann, Season Sarcophagus, t. I, p. 134-136.

(567) L. Robert, Hellenica, IX, p. 61.

(5ß乃) Voir Hanfmann, Season Sarcophagus, t. I, p. 148; cf. Philostrate, Imagines, II, 34 et Quintus de SMyrne X, 335.

(569) Voir L. Robert, Hellenica, IX, p. 61-62. L'auteur souligne que dès la fin du Irer siècle, la Ги́ $\pi \alpha ́ v \kappa \alpha \rho \pi o \varsigma$ peut être associée avec l'air et le feu à

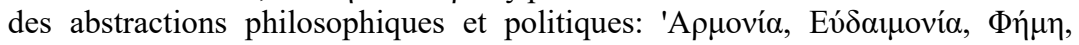
B $\alpha \sigma 1 \lambda \varepsilon i ́ \alpha$.

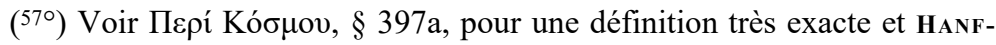
ManN, Season Sarcophagus, t. I, p. 150-151 pour des exemples particuliers. C'est là une conception d'origine stoïcienne essentiellement (voir S.V.F., I, 165; II, 665 et Dion de Pruse, Or. 12, 32), qui est désormais admise par tous (cf. Hanfmann, Season Sarcophagus, t. I, p. 148).

(571) Voir Platon, Timée, 37 d-e.

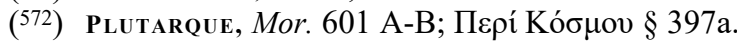


elles sont amenées par le soleil(573), par Zeus $\left({ }^{874}\right)$ ou par la nature (575); elles sont symboles de l'exactitude et de la régularité des cycles cosmiques $\left({ }^{576}\right)$; «elles sont génératrices de toutes choses et provoquent à heures fixées, été et hiver, jour et nuit, pour l'accomplissement des mois et de l'année...»( $\left.{ }^{577}\right)$. A ce titre, elles sont indissociables des «autres phénomènes qui se produisent dans l'atmosphère et reviennent en leur temps grâce à la cause première et originelle» $\left({ }^{578}\right)$. Elles témoignent donc de l'existence d'une Providence universelle $\left({ }^{579}\right)$.

Aussi, comprenons-nous qu'elles aient pu être utilisées par l'idéologie impériale et qu'elles participent, sous l'Empire, au IIe siècle, à la redéfinition d'une nouvelle culture internationale $\left({ }^{50^{\circ}}\right)$. A Rome, l'âge d'or n'est plus perçu comme le temps d'un printemps éternel (581). Il est devenu la Felicitas Temporum (582) que célèbrent les panégyristes ( ${ }^{583}$ ) et que proclament à l'envie les émissions monétaires ${ }^{(584)}$. Cette èie nouvelle de bonheur universel est pré-

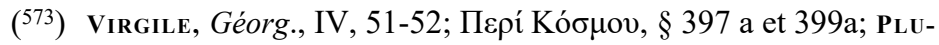
tarque, Mor., 1007D et 601 A-B; Orphica, VIII, 5, 10, 19.

(574) Pausanias I, 40, 4; Philostrate, Vita Apollonii, VI, 19; Aelius Aristide, Or. XLIII, 24 et sur ces distinctions, voir Hanfmann, Season Sarcophagus, t. I, p. 151-152.

(575) Marc Aurèle, Pensées, IV, 23.

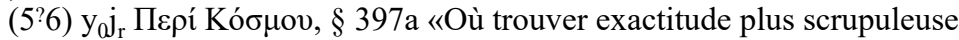
que chez les nobles saisons...» et même Manılıus, Astronomica, II, 428-431.

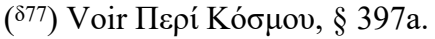

(878) Ibid., § 399a.

(579) Voir Dion de Pruse, Or., 12, 32 et Plutarque, Mor., 601 A-B.

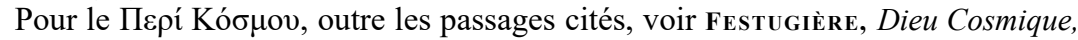
p. 504-506 et Hanfmann, Season Sarcophagus, t. I, p. 158 et 163-174. L'auteur en souligne l'importance dans les émissions monétaires.

$\left(5 \mathrm{~s}^{\circ}\right)$ Voir Hanfmann, Season Sarcophagus, t. I, p. 138; 179.

${ }^{(881)}$ ID., ibid., t. I, p. 121 et t. II, $\mathrm{n}^{\circ} 41$, p. 71. Pour la conception du 1er siècle, voir Virgile, Géorg., Il, 323-342 et Dion de Pruse, Or. 36, 58 pour une même vision de l'Univers au printemps de la création.

(582) Voir sur cette transformation, Hanfmann, t. I,p. 169; 172-173;176.

(583) Aelius Aristide, Eloge, $\S 7$ et $\S 109$.

(5S4) Voi $i_{r}$ Hanfmann, supra, note 582 et Toynbee, Roman Medallions, p. 90-92. Hanfmann souligne (t. I, p. 169) qu'il faut distinguer trois types: le premier, avec les légendes, Felicitas Temporum, Felicia Tempora, Eutyches 
sentée comme un temps où, dans un monde pacifié, sur la Tellus ou Terra Stabilita des monnaies d'Hadrien, d'Antonin et de Commode (585), toutes les saisons apportent, ensemble, en même temps, leurs bienfaits dans l'Empire (586). L'âge d'or n'est plus un temps mythique $\left.{ }^{587}\right)$. Il recouvre à la fois la prospérité économique et le bonheur philosophique ou religieux de vivre selon la grande loi de l'Univers, en étroite sympathie avec tous les phénomènes naturels. Désormais les saisons sont devenues autant symboles d'éternité que de bonheur $\left.{ }^{588}\right)$.

Nous pouvons conclure que, dans la mosaïque de Mérida, les saisons renvoient à différents registres et peuvent faire l'objet de lectures multiples, non contradictoires, à la fois spatiale, cosmologique, religieuse et idéologique, sans pour autant qu'il faille supposer un intervention directe de la cour impériale ni

Kairoi, et Saeculi Felicitas, représente quatre jeunes garçons-saisons qui dansent avec leurs attributs; le second, très exceptionnel, figure Héraclès conduisant un attelage de saisons centaures avec la légende Temporum Felicitan, et le troisième, proche du type Terra Stabilita, mais avec la légende Felicitas Temporum, représente la terre s'appuyant sur un globe; près d'elle le groupe des 4 saisons féminines, enfants, dansent en franchissant le cercle du zodiaque que tient un adolescent (cf. HanfmanN, t. II, $n^{\circ} 318,324-328$ et pl. 127, 128, 131). Voir, pour les reproductions, GNecCHI, Medaglioni romani, III, 19, $\mathrm{n}^{\circ} 91$, pl. 146, $\mathrm{n}^{\circ} 1$; pl. 148, $\mathrm{n}^{\circ} 18 ; 38, \mathrm{n}^{\circ} 204-205$, pl. 152 $\mathrm{n}^{\circ} 5$; II, 41, $\mathrm{n}^{\circ} 28$, pl. 69, $\mathrm{n}^{\circ} 3 ; 44, \mathrm{n}^{\circ} 1$, pl. 72, $\mathrm{n}^{\circ} 1 ; 66, \mathrm{n}^{\circ} 135$, pl. 87, $\mathrm{n}^{\circ} 3-5$.

(588) Sur ce type, voir Toynbee, Roman Medallions, p. 93 et Strong, J.R.S., 1937, p. 120. Pour les reproductions, voir GNecChI, II, pl. 86, $\mathrm{n}^{\circ}$ 8-10; pl. $87, \mathrm{n}^{\circ} 1$; III, pl. $145, \mathrm{n}^{\circ} 12$. Dans cette série les saisons sont féminines.

(586) Voir Hanfmann, 1.1, p. 157-158; pour Rome, voir Aelius Aristide, Eloge, $\S 7$ et la place importante des saisons dans la codification de l'éloge des cités par MÉnandre de Laodicée, dans Spengel, Rhetores Graeci, III p. 344-348, 447-448.

(587) Sur le mythe de l'âge d'or en Grèce ancienne, voir J.-P. Vernant, Mythe et pensée chez les Grecs, Paris, t. 1, 3e éd. p. 13-79, pour Hésiode, et P. Vidal-Naquet, Plato's myth of Statesman, the Ambiguities of the Golden Age and of History, dans J.H S., 98, 1978, p. 132-141 pour une redéfinition du mythe par Platon. Il y a un changement absolu entre la Grèce ancienne et l'Empire romain.

(588) Voir Hanfmann, t. I, p. 173. 
chercher dans ce pavement une influence directe de l'idéologie officielle $\left({ }^{589}\right)$.

Ainsi en va-t-il aussi pour Natura.

\section{D) Natura}

Natura $\left(5^{5}\right)$ occupe, dans la mosaïque de Mérida, une place considérable ( $\left.{ }^{591}\right)$, quoiqu'elle ne soit pas entièrement figurée dans le tableau, puisque le cadre qui borde Yemblema passe au niveau de son genou droit. Natura est assise de trois quarts, le corps légèrement tourné vers la gauche, sur un bloc rocheux situé au niveau du bras \& Euphrates. Une draperie épaisse, vert mousse, assez sombre, dissimule ses membres et le bas de son corps. Elle se tient très raide et solitaire. Le bras droit a disparu dans une lacune, le gauche, puissant, est levé au-dessus de sa tête pour retenir de la main un voile déployé en conque. Par l'emploi de zones concentriques, traitées en divers tons de vert dégradé, où l'on distingue du vert mousse, du vert pâle, du vert canard, du bleu turquoise, du gris bleu et même quelques touches de brun foncé, le mosaïste a su créer l'illusion de la profondeur et mettre le personnage en valeur, comme dans une sorte de niche (592). Grâce à cet artifice, Natura, se détache, comme les personnages cités au registre supérieur, sur un fond bleu vert. Le mosaïste montre par là que Natura, qu'il a placée au registre intermédiaire de la terre dont elle gouverne tous les phénomènes, est aussi une force cosmique. Son buste, très allongé $\left({ }^{593}\right)$, semble vêtu d'une

(589) Voir supra, I, p. 20, 41. Cette interprétation me semble même contraire à l'atmosphère mystique qui se dégage du tableau (voir infra p. 76). Sur l'influence de la cour impériale dans l'iconographie des saisons, voir Hanfmann, Season Sarcophagus, t. I, p. 181.

$\left(5^{\circ}\right)$ Voir Garcîa-Sandoval, p. 14, 20, 26, qui donne seulement une description de la figure et Blanco-Freijeiro, p. 167-170, et Emerita, p. 193. Cf. supra I, p. 39.

(591) Elle occupe en hauteur un peu plus du tiers du tableau $(\operatorname{lm} 73 /$ /4m 70 du sommet du voile aux pieds; $\operatorname{lm} 53$ de la tête aux pieds).

(592) Voir note 104, supra. Remarquons que le voile de la Vénus de Boscéaz joue le même rôle (voir V. Von Gonzenrach, Die romischen Mosaiken der Schweiz, Bâle, 1961, p. 189 et pl. 61.

(593) Voir note 101, supra. 
chemise transparente plutôt que nu; un collier orne son cou, deux bracelets son bras gauche $\left.{ }^{594}\right)$. Ces bijoux, comme tous ceux que portent les figures féminines $\mathrm{du}$ registre inférieur, sont de simples anneaux formés par un rang de tesselles dorées. La chevelure, grossièrement roulée sur le front et les tempes, forme casque et ne prêterait aucun charme à un visage, plutôt lourd, dont les traits épais seraient laids, si le regard tendu vers Caelum ne semblait pensif et comme perdu dans une sorte de contemplation intérieure, quasi mystique, qui projetterait tout l'être vers l'infini.

A. Blanco-Freijeiro a été très sensible à la beauté plastique de cette figure. Il reconnaît en Natura la Physis grecque des Hymnes Orphiques (595) et des Dionysiaques (596) de Nonnos, une déesse cosmogonique, créatrice des hommes et mère de toute chose, qui jouerait, dans la mosaïque de Mérida, le rôle dévolu à Prométhée, dans la mosaïque de Chahba-Philippopolis $\left(^{597}\right)$; mais il veut

(594) Le rang de tesselles dorées qui constitue le collier et les bracelets se superpose dans le cas de Natura aux bords de ce qui semble être une chemise légère.

(595) Blanco-Freijeiro, p. 169, cite le texte de Orphica, X.

(596) Blanco-Freijeiro, p. 168, cite nonnos (Dionysiaques, XLI, 51 et sq.). Le rapprochement ne s'impose pas, quoique Natura soit présentée dans ce poème comme la garante de l'ordre cosmique, l'intendante de l'Univers, la nature primordiale, une force plus puissante que la Terre-Mère, car Nonnos (fin IV $\mathrm{IV}^{\mathrm{e}} \mathrm{e}$ siècle) n'a pas de l'Univers une conception semblable à celle que représente le mosaïste de Mérida. Dans les Dionysiaques, Typhée, qui est l'adversaire de l'harmonie universelle (I, $397 \mathrm{sq}$ ), bouleverse l'Univers en cherchant à ravir à Zeus son pouvoir. La Typhonie dépeint le désordre qui s'empare alors du Cosmos: le cours du temps et des saisons est arrêté, les signes du zodiaque bouleversés, le soleil et la lune menacés, la terre, la mer et le ciel se confondent, les fleuves sont asséchés les bêtes massacrées, les arbres saccagés, les activités humaines interrompues (II, 258-280). Natura n'est dans le poème qu'une allégorie de l'ordre du monde qu'elle restaure sur terre, sur mer et dans le ciel, après la défaite de Typhée (II, 650-659). Sur les conceptions de Nonnos, voir F. Vian, Les Dionysiaques, C.U.F., 1976, Paris, p. 92-100.

${ }^{597}$ ) Le rapprochement (BLANCo-FreiJeiro, p. 169, pi. IX) ne s'impose pas non plus. La mosaïque de Chahba-Philippopolis, à l'exception des vents,

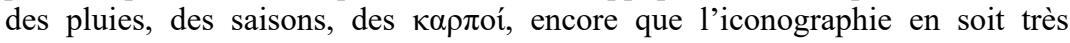
différente, ne représente aucun des personnages qui figurent dans la mosaïque de Mérida. Pour l'interprétation de la mosaïque de Philippopolis, voir A. J. Festugière, La mosaïque de Philippopolis et les sarcophages au Pro- 
aussi voir, en elle, la déesse Vénus, la mère des Romains, à laquelle Hadrien — il le rappelle — a fait élever le temple de Vénus et de Rome. Aussi, sans qu'il y ait aucune allusion précise, perçoit-il comme tout particulièrement sensible, à ce registre, la présence de Rome ( $\left.{ }^{598}\right)$.

Natura est bien une figure essentielle dans la mosaïque de Mérida, mais sans le caractère dynastique que lui attribue A. Blanco-Freijeiro. Par la place qu'elle occupe dans la mosaïque, par la synthèse philosophique et religieuse qu'elle suppose, par révolution qu'elle marque dans la personnification des abstractions depuis l'époque hellénistique, elle est très caractérisque de la nouvelle culture gréco-romaine qui s'élabore dans l'Empire, au II ${ }^{\mathrm{e}}$ siècle de notre ère $\left({ }^{599}\right)$.

Natura n'est pas ici une simple abstraction de la langue poétique ou philosophique, comme ce fut le cas du IVe siècle av. J.-C. jusqu'au milieu du second siècle. Lucrèce avait pu célébrer sa puissance créatrice et tenter d'en expliquer les lois $\left({ }^{60^{\circ}}\right)$, Manilius souligner la régularité des cycles qu'elle gouverne $\left({ }^{601}\right)$, elle ne faisait l'objet d'aucun culte particulier. Si Aristote a commencé son Traité des animaux par des considérations générales

méthée, dans Hermétisme et mystique païenne, Paris, 1967, p. 313-321 et supra, note 41. A Mérida, l'homme n'est pas présent. Voir supra I, p. 18.

(598) Blanco-Freijeiro, p. 170 «Tal vez, por tanto, no hicieran falta más alusiones a Roma para que la presencia de esta se hiciera sentir en el cuadro».

(599) Voir Hanfmann, t. I, p. 138; 159; il souligne, p. 176, la vogue particulière des figures allégoriques et l'importance du phénomène de personnification des abstractions sous le règne d'Antonin le Pieux. Sur ce même phénomène à la fin du II ${ }^{\mathrm{e}}$ siècle dans la partie grecque de l'Empire, voir A. M. Vérilhac, La déesse Physis dans une épigramme de Salamine de Chypre, dans B.C.H., 1972, p. 427-433; particulièrement p. 431.

$\left(6^{\circ}\right)$ Sur la conception de Natura chez Lucrèce, voir K. G. Sallmann, Die Natur bei Lukrez; Natura und der Naturbegriff. Dissert., Cologne, 1961. Particulièrement sur Natura et Physis, p. 117-140 et sur Natura et Vénus, p. 141-150. L'ouvrage a été publié sous le titre: K.G. Sallmann, Studien zum philosophischen Naturbegriff der Romer mit besonderer Berücksichtigung des Lukrez (Archiv. für Begriffsgeschichte, 7), Bonn, 1962; et sur l'évolution du concept de Nature, voir E. R. Curtius, Gõttin Natura, dans Europaïsche Literalur und lateinisches Mittelalter, Bern-Munich, 1973, p. 116-137.

(601) Astronomica, I, 129 et 147-193. 
sur la finalité de la Nature dont les accents sont presque religieux, c'est aux stoïciens, sans doute plus particulièrement à Posidonius (602), qu'est revenu le mérite d'avoir reconnu en Physis une «force cosmique intelligente, douée de sentiment, qui pénètre et vivifie tous les êtres, une véritable Providence qui du dedans les maintient, les ordonne et les conduit à leur fin»(603). C'est eux qui en ont fait la grande loi ordonnatrice de l'Univers et l'ont célébrée comme «l'artiste» dont l'oeuvre parfaite, le Kosmos, ne peut être égalée $\left({ }^{604}{ }^{*}\right)$. Pourtant, ce n'est qu'au II ${ }^{\mathrm{e}}$ siècle de notre ère que Natura devient une figure syncrétique de la pensée religieuse et reçoit avec d'autres abstractions ( $\left.{ }^{608}\right)$ un véritable culte. C'est alors qu'elle est célébrée dans des hymnes ( $\left.{ }^{606}\right)$, qu'on lui adresse des prières $\left({ }^{607}\right)$ et l'invoque dans des dédicaces $\left({ }^{608}\right)$. Elle incarne,

$\left(6^{\circ 2}\right)$ Voi $_{\mathrm{r}} \mathrm{v}_{\text {0N }}$ Arnim, S.V.F., I, no 158 et Festugière, Dieu Cosmique, p. 405-425 où il expose ces conceptions à propos du De natura Deorum de Cicéron.

(603) Festugière, Dieu cosmique, p. 416, attribue, après K. Reinhardt, cet argument vitaliste à Posidonius.

(604) ID., ibid., p. 396-397.

(eos) voip VériLHAC, B.C.H., 1972, p. 431. A côté des anciennes divinités

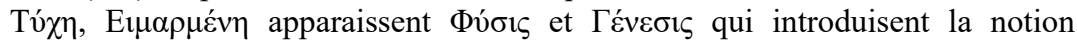
plus précise de nécessité inscrite dans les lois de la nature. Elles sont honorées comme déesses du destin à la fin du $\mathrm{II}^{\mathrm{e}}$ et au $\mathrm{III}^{\mathrm{e}}$ siècles.

(eoe) Hymne orphique qui date du $\mathrm{II}^{\mathrm{e}}$ siècle ( ${ }^{\circ} 10$ édition G. Quandt, Orphica, Berlin, 1955) et Hymne de Mésomédès attribué à l'affranchi d'Hadrien (cf J. U. Powell, Collectanea Alexandrina, Lyr. Alex. Adespota, Oxford 1925 , p. $197, \mathrm{n}^{\circ} 35$, v. $1-2,15$ sq.) :

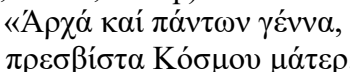

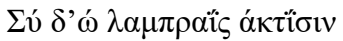

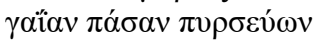

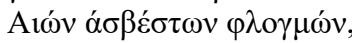

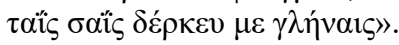

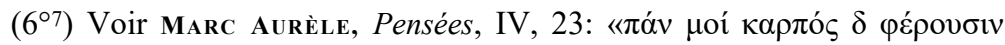

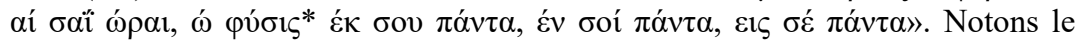

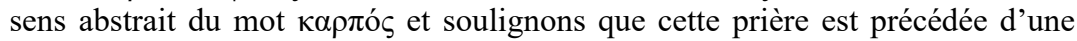

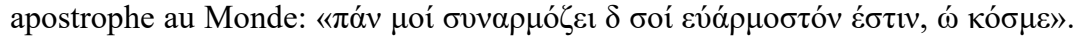

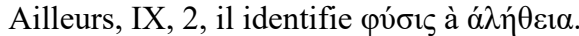

(eos) Voir Vérilhac, B.C.H., 1972, p. 431 et passim. 
à la fois, la nécessité des lois cosmiques ${ }^{609}$ ) et la Providence divine $\left({ }^{610}\right)$, sans cesser d'être honorée comme «mère et créatrice de toute chose» (611).

Dans la mosaïque de Mérida, Natura est l'un des éléments fondamentaux de la symphonie cosmique, une divinité très puissante, certes, mais qui n'appartient pas au Panthéon Olympien. Aussi ne devons-nous pas la confondre avec "Vénus (612), la mère des Romains», ce qui limiterait son importance de force cosmique ou laisserait supposer une influence officielle de l'idéologie impériale dans la conception du pavement que rien, par ailleurs, ne permet de justifier.

Nous pouvons, cependant, supposer que la présence de Natura, à gauche, dans la partie médiane du tableau, à un niveau intermédiaire entre les fleuves et les saisons, implique que Tellus ou Terra ( $\left.{ }^{613}\right)$ figurait, à droite, à peu près au même niveau et de façon symétrique, dans la partie ruinée de la mosaïque, essentiellement le registre terrestre —à côté de [.Hiems] et de [Ver], entre Mons, Nix, et Pontus, à proximité des deux autres fleuves, comme symbole de la terre ferme et du quatrième élément (qui serait sans cela absent du tableau), où se déploie principalement la force génératrice de Natura.

Une rapide étude stylistique nous permet de constater que le traitement du visage de Natura, la forme de ses yeux, la direction de son regard, son immobilité, la tension contenue de toute la figure caractérisent, sans qu'il y ait recherche excessive de pathétique, l'art de la période antonine (614).

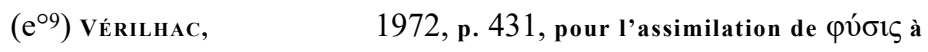
une déesse du destin.

${ }^{(610)}$ Sur ce rôle de providence, voir Festugière, Dieu cosmique, p. 395-399.

(611) Ce sont les expressions qui reviennent dans les Hymnes (cf. Orphica X,

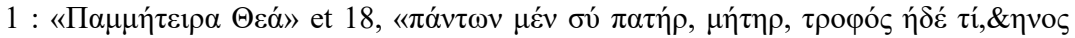
et Hymne de Mésomédes, Y, 1 : cité note 606.

(612) Il est possible cependant qu'à Rome, Vénus soit assimilée à cette force cosmique génératrice de l'Univers, mais dans le contexte de la mosaïque le rapprochement ne s'impose pas.

( $\beta 13$ ) Blanco-Freijeiro, p. 172, suppose aussi l'existence de Tellus à droite, à côté de Pontus, voir supra, $\mathrm{I}$, p. 21 , son schéma.

(6*4) D. Levi, Antioch Pavements, I, p. 524-528; Blanco-FreiJeiro rapproche Natura de la Vénus de Boscéaz (p. 169 pi. X. a). Il y a plusieurs

Conimbriga 19 (1980), 5-127 


\section{E) Aeternitas}

Sur l'axe absidial de la mosaïque, au centre de Yemblema, se trouve placé, en position de frontalité, un personnage très endommagé, qui, s'il était figuré en pied, debout, occuperait en hauteur un peu plus du tiers du tableau (615). Ne subsistent que des parties de la tête et du torse; les bras et les épaules ne sont pas visibles; le corps, coupé par la lacune, un peu au-dessous de la taille, est nu et lisse. On ne distingue ni protomé de lion, ni anneaux de serpent $\left({ }^{616}\right)$. Le visage, dont ne subsiste que le côté gauche, semble imberbe et juvénile. La chevelure, coiffée en boucles courtes, dégage le front et retombe sur la nuque. Une aile se détache dans la chevelure, du côté gauche - le seul conservé , qui est représentée déployée et de face. Elle est sensiblement plus grande que celles des vents et paraît beaucoup plus large $\left({ }^{617}\right)$. Elle ne saurait être un indice suffisant pour attribuer à cette figure, comme l'a fait E. Garcia-Sandoval ${ }^{(618)}$, la légende Eurus qui, placée sous les naseaux des chevaux d'Oriens, serait beaucoup trop éloignée du personnage qu'elle est censée désigner, ce qui ne correspond pas à la pratique du mosaïste, dans l'ensemble du tableau.

La lacune nous interdit toute certitude à ce registre, mais nous pouvons formuler des hypothèses sur l'attribution de la légende incomplète qui figure au-dessus de Portus, sans nous préoccuper

points communs entre les deux mosaïques mais le modelé du corps de Natura, son attitude, son regard n'évoquent nullement la pose gracieuse de Vénus qui se contemple dans son miroir entre deux amours: V. Von Gonzenbach, Rômische Mosaiken, p. 189, pl. 61.

(615) $\operatorname{Im} 57 / 4 \mathrm{~m} 70$ du sommet de la tête à la légende $A E T \ldots .$.

(616) Comme sur le corps de l'Aiôn mithriaque de Mérida, voir supra, I, p. 92 , et note 21 .

(617) L'aile gauche d'Aet [emitas] est beaucoup plus grande que celle des vents; elle mesure $11 \mathrm{~cm} / 6,5 \mathrm{~cm}$ contre $9 \mathrm{~cm} / 4 \mathrm{~cm}$ et $8 \mathrm{~cm} / 3 \mathrm{~cm}$ pour les deux ailes de Boreas et $3 \mathrm{~cm} / 6 \mathrm{~cm}$ et $3 \mathrm{~cm} / 7 \mathrm{~cm}$ pour celles de Notus. Le visagé de Notus mesure $10 \mathrm{~cm}$ contre $18 \mathrm{~cm}$ pour celui de l'adolescent ailé. La disposition des couleurs en est différente. Le dessin de Sandoval pourrait laisser croire que le personnage porte un bonnet: il n'en est rien.

(618) Yoir Garcîa-Sandoval, p. 19. 
encore de sa signification, sans en proposer une leçon. Constatons d'abord que plastiquement cette légende peut s'appliquer à l'adolescent ailé dans le tableau. Elle est placée dans l'axe de son corps, au niveau du socle sur lequel pourrait être juchée la figure, comme c'est le cas pour d'autres personnages dans la mosaïque $\left({ }^{619}\right)$.

L'adolescent lui-même, si l'on étudie les proportions que le mosaïste a données aux autres figures, aurait - mesurant $1 \mathrm{~m} 57$ - une taille proportionnée aux dimensions de son visage et de son torse $\left({ }^{62^{\circ}}\right)$. La représentation partielle semble exclue, puisque le ventre de l'adolescent est en partie visible.

Un autre personnage pourrait, il est vrai, être représenté au premier plan, qui cacherait les membres inférieurs de l'adolescent et auquel s'appliquerait la légende $A E T$... Ce ne pourrait être qu'un génie enfant $\left({ }^{621}\right)$, puisque l'espace attribué à cette nouvelle figure serait infime. Cette hypothèse, qui permettrait de ne pas attribuer à l'adolescent ailé la légende AET[ERNITAS], paraît pourtant peu vraisemblable, car la taille attribuée à l'enfant que désignerait cette légende serait alors très inférieure à celle de toutes les autres allégories situées sur l'axe absidial (Caelum, Portus, Pharus).

Nous avons écarté l'identification du personnage ailé avec Eurus. Par quelle autre légende faudrait-il le désigner? Le nom d'une divinité personnalisée du panthéon traditionnel - qui serait un hapax dans la mosaïque — semble exclue.

Pour un personnage situé comme Morts aux frontières du registre terrestre et $\mathrm{du}$ registre céleste, on pourrait penser à Aer mais ce personnage occupe une place importante dans l'espace de

(619) Voir Pharus, Natura, Pontus.

$\left({ }^{6}{ }^{\circ}\right)$ Il mesurerait $\operatorname{lm} 57$ du sommet du crâne à la légende $A E T$... sa tête mesure $23 \mathrm{~cm}$ (Natura, $25 \mathrm{~cm})$ jusqu'à la naissance du cou, son buste, à la taille, $31 \mathrm{~cm}$ de large.

(621) Je remercie J.-P. Darmon de m'avoir suggéré l'hypothèse que pourrait avoir disparu dans la lacune un génie enfant, comparable au génie zodiacal des mosaïques africaines, un Aiôn/Pais désigné par la légende Aeternitas. On peut citer à l'appui de cette hypothèse le vers d'Héraelite: «Atóv паїs غ̇oti», cf. J. Воцlack, Hèraclite ou la séparation, Paris, 1977, fg. 52. Sur le génie des mosaïques africaines, voir infra p. 64 et note 688 . Sur la notion d'AiônjAeternitas au II siècle, voir infra p. 54-59 et 69-72 sq. et notes correspondantes. 
la mosaïque: il ne peut être un personnage secondaire. Or cela semble être le cas de tous les personnages que le mosaïste a placés au deuxième plan (Chaos, Tranquillitas,Boreas). Plusieurs autres indices - place sur l'axe médian au centre du tableau, position d'exacte frontalité, particulièrement visible dans la disposition du visage et de l'aile qui subsiste, direction du regard qui fixe le spectateur - peuvent nous inciter à penser, au contraire, que ce personnage ailé joue un rôle essentiel dans la composition et qu'il occupe bien, seul, l'espace de la lacune qui s'étend de son bassin à la légende $A E T$...

Mais quelle lecture proposer pour ces trois lettres?

A. Blanco-Freijeiro a lu, à juste titre, dans son premier article, Aet[ernitas] à partir des trois lettres encore visibles dont la lecture est sûre ( $\left.{ }^{622}\right), A, E, T$. Or, il revient aujourd'hui, sans justification, sur cette interprétation dans son deuxième article $\left({ }^{623}\right)$ et semble hésiter entre Aether et Aeternitas ( ${ }^{624}$ ).

La lecture Aether ne peut être retenue, quoique la légende $\mathrm{AI \Theta HP}$ - et le personnage - un adolescent portant des ailes

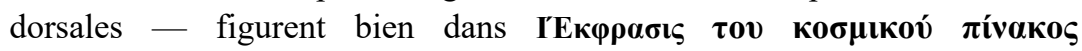
de Jean de Gaza( $\left.{ }^{625}\right)$, pour des raisons évidentes de logique cosmologique interne. Le mot Aether désigne, en latin ${ }^{626}$ ), soit la région supérieure du ciel, soit l'air atmosphérique dans quelques textes poétiques. Nous avons vu que le mosaïste avait choisi de représenter l'Univers selon une disposition étagée dans l'espace $\left({ }^{627}\right)$, assez proche de celle qu'évoque l'auteur du Пврí Kóouov. Si l'éther était représenté dans la mosaïque de Mérida,

(622) $\mathrm{y}_{0} \mathrm{j}_{\mathrm{r}}$ BLANCO-Freijeiro p. 166-167 et pi. VI, b. et note 61 supra.

(623) Blanco-Freijeiro, Emerita, p. 195.

(624) Encore que A. Blanco-Freijeiro précise, p. 195, qu'Aeternitas est ici l'équivalent du grec Aiôn et cite, note 60, Victorinus I, 16: «Tempus generale, quia nec initium nec finem habet, Aeternitas est, quam Graeci Aiona apellant» à l'appui de cette affirmation.

(625) Yoir planche IX. Notons pourtant qu'A. Blanco-Freijeiro ne retient pas Aether dans le tableau des équivalences qu'il a établies entre

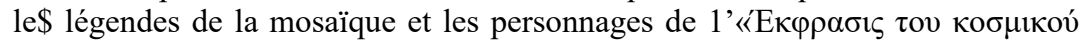

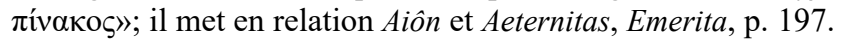

(626) Yoir Thesaurus Linguae Latinae, col. 1149-1152.

(627)Yoir supra; I, p. 60, 98 et note 391. 
il serait situé, comme dans cet ouvrage $\left({ }^{628}\right)$ et dans le poème de Manilius ( ${ }^{629}$ ), au-dessus du monde sublunaire, au plus haut niveau du ciel, au sommet du cintre dans la mosaïque. Mais, nous l'avons constaté $\left({ }^{63^{\circ}}\right)$, le mosaïste de Mérida n'a pas de réelles préoccupations astrologiques; il n'a pas cherché à représenter dans son tableau le ciel des fixes. Si la légende Aether ne figure pas dans le tableau, à la place attendue, au-dessus ou à côté de Caelum, il n'a pas lieu d'identifier comme Aether une figure placée au centre du tableau, sur l'axe absidial de la mosaïque, exactement sous le trône de Caelum, un peu au-dessous du trajet d'Oriens et d'Occasus, à côté des Saisons, au-dessus de Portus.

$\mathrm{Si}$ nous éliminons la lecture Aether, trois autres leçons seulement s'offrent à nous, pour les trois lettres AET... : Aetas, Aeternum, Aeternitas.

La leçon Aetas n'est guère vraisemblable ici, même si le mot a d'abord pu désigner «l'âge comme principe de révolution dans le cours des choses»(631), dans le sens où l'emploie Lucrèce: mutat enim mundi naturam totus aetas (632) et s'il est encore employé dans le sens de temps absolu à l'époque d'Auguste, chez les poètes $\left({ }^{633}\right)$ et dans les Oracles Sibyllins $\left({ }^{634)}\right.$. Aux premiers siècles de l'Empire, le terme Aetas s'emploie surtout au pluriel comme synonyme de Tempus et de Saeculum (635***). Au singulier il se fige

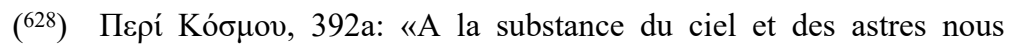
donnons le nom d'éther... Après la nature éthérée et divine... (392b) après cet élément, au-dessous de lui, l'air est répandu... A la suite de l'élément de l'air...».

(629) Manilius, Astronomica, I, 255 sq.

$\left(63^{\circ}\right)$ Voir supra, p. 27.

(631) Voir E. Benveniste Expression indo-européenne de l'Eternité, Bull. Soc. Ling, de Paris, XXXVIII, 1937, p. 103-112, (= Benveniste, Eternité), spécialement p. 105.

(632) LuCRÈCE, V, 828

(688) Virgile, Bue. 9, 51 «omnia fert aetas»; Horace, Odes, 4, 9, 10; StaCe, Silo., I, 2, 187.

(634) Voir note 377 et H. Jeanmaire, La Sibylle et le retour de Vàge d'or, Paris, 1939, p. 110.

(635) Voir Thesaurus Linguae Latinae, col. 1135-1136: Aetates est synonyme de Saecula: cf. Manilius, II, 589 «per... tot aetates hominum, tot tempora et annos». 
dans le sens de durée de vie d'une génération dans des expressions toutes faites $\mathrm{O}^{\circledR 6}$ ), quoique l'on puisse constater une évolution du

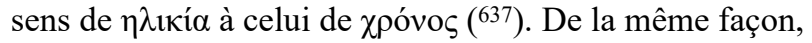

qui désigne un temps limité comme dans l'expression Saeculum Aureum, finit par traduire, semble-t-il, autant qu

la notion grecque $\left.\mathrm{d}^{\prime} \mathrm{Aicb}^{\wedge}{ }^{\circledR 39}\right)$; mais, alors que Saeculum s'est spécialisé dans le sens de continuité des cycles cosmiques $\left({ }^{60^{\circ}}\right)$, les sens d'Aeternitassont multiples et renvoient, semble-t-il, à des domaines différents, spatial, temporel, philosophique, religieux ou politique.

Nous ne connaissons aucune représentation $d$ et personne n'a proposé d'interpréter comme Aetas des figures anonymes, iconographiquement assez proches du personnage central de notre mosaïque ${ }^{(641)}$. Aussi ne retiendrons-nous pas la leçon Aetas qui serait un hapax $\left({ }^{\mathrm{M} 2}\right)$. Si le mosaïste de Ménda utilise des cartons d'origine grecque et traduit assez souvent des termes grecs ( $\left.{ }^{\mathrm{M} 3}\right)$,

(63ß) $\mathbf{v}_{0} \mathbf{i}_{\mathbf{r}}$ Thesaurus Linguae Latinae, dans les expressions : aetate nostra, nostri temporis aetate.

(637) Ibid., col. 1135-1138.

(638) Le mot Aeternitas semble être une traduction cicéronienne à? Aiôn, et apparaît, au 1er siècle av. J.-C., en latm; cf. Ernout-Meillet, Diet. Etym., p. 13.

(639 640) Voir J. Ga GÉ, Le templum Urbis et les origines de l'idée de Renovatio, dans Mélanges F. Cumont (Ann. Inst, de Phil, et d'Hist. Or. et Slav., t. IV), Bruxelles, 1936, p. 177, et M. LE Glay, Dieux Syriens du Janicule, dans M.E.F.R., 60, 1948, p. 138. Sur la confusion entre Aiôn et Saeculum Aureum, voir Hinks, Myth p. 41. Sur le sens de Saeculum = Siècle, dans la langue de l'Église, voir Ernout-Meillet, Diet. Etym., p. 587.

(640) Voir supra, I, p. 89-91; et note 336.

(641) Yoi $_{\mathrm{r}}$ par exemple 1) l'adolescent de la mosaïque de Sentinum (reproduction dans Hanfmann, Season Sarcophagus, t. II, $\mathrm{n}^{\circ} 430$ pl. 108, dans Toynbee, Hadrianic School, pl. 33, dans Levi, Hesperia, p. 288, fig. 14, et Blanco-P'reiJeiro, pl. X,b), pour lequel on a proposé tant d'identifications diverses: Aiôn, Chronos, Annus, Helios (cf. Hanfmann, Season Sarcophagus, t. I, p. 227) et même Mithra (cf. Levi, Hesperia, p. 287-288); 2) le génie ailé du piédestal de la colonne Antonine (cf. Turcan, R.A., p. 306-307) pour lequel on a proposé: Aeternitas, Aion, Ascensus, Zephyrus, Saeculum Aureum, Genius Jovi, Consecratio, le génie du monde.

(642) Le mot ne figure ni dans H. L. Axtell, The Deification of Abstract Ideas in Roman Literature and Inscriptions, Chicago, 1907, (= AxTell, Deification) ni dans Roscher, Lexicon, I, 1, s.v. Aetas.

(643) Comme nous l'avons vu supra, I, p. 21, 38, 62-63 et note 420, pour les vents; I, p. 82 note 300, pour Caelum; I, p. 27 et note 67 pour Navigia. 
il exprime une réalité culturelle romaine, caractéristique d'une époque précise, — qui ne saurait être antérieure à 150-160 ap. J.-C. - pendant laquelle de mot Aetas n'a plus guère cours dans la langue philosophique, religieuse ou politique.

La lecture Aeternum n'est guère plus vraisemblable, car le mot s'emploie, précédé de in, dans des expressions adverbiales mais l'adjectif Aeternus ne semble pas avoir été substantivé ( ${ }^{644}$ ) ni dans la langue philosophique, ni dans le vocabulaire religieux ; il ne fait pas partie des abstractions qui reçoivent un culte sous l'Empire $\left({ }^{645}\right)$.

Reste donc la lecture Aeternitas qui pose elle-même un problème. Le mot est pertinent $d u$ point de vue sémantique et la légende a bien sa place dans un tableau cosmologique, mais les historiens n'ont pas l'habitude d'associer une figure masculine à cette légende $\left({ }^{646}\right)$, sans doute sous l'influence du type monétaire, très largement répandu sous le règne d'Antonin, d'une Aeternitas féminine, voilée, debout ou assise, tenant un sceptre, le globe ou le soleil et la lune... $\left({ }^{647}\right)$.

(844) Voir Thesaurus Linguae Latinae, col. 1142-1144.

(64ס) Voir Axtell, Deification, où il ne figure pas.

(Me) Ainsi on écarte fidentification du génie ailé de la colonne Antonine avec Aeternitas pour la raison «que le sexe du génie est manifestement masculin». Cf. L. Deubner, Die Apotheose des Antoninus Pius, dans Róm. Mitt., 1912, p. 17, et TurCan R.A., p. 307.

${ }^{(647)}$ Sur la représentation d'Aeternitas sur les monnaies, voir, sous les Flaviens, R.M.C., II, p. LXXYI, 265-266, pl. 50, 9. L'éternité est personnifiée par une femme tenant les têtes du soleil radié et de la lune en croissant, ou portant un sceptre et une corne d'abondance et posant le pied sur un globe. Ce type subsiste sous le règne d'Hadrien (cf. Mattingly-Sydenham, R.I.C., II, p. $417 \mathrm{n}^{\circ} 597$ et p. $436 \mathrm{n}^{\circ}$ 744). Sous le règne d'Antonin, le type n'est pas davantage fixé: elle apparaît debout avec un voile et une torche, tenant un globe, devant un autel ,tenant un phénix, un globe, un sceptre... et même les têtes du soleil et de la lune [R.I.C., III, p. 15-16; p. 28, n 18-19; p. $33, \mathrm{n}^{\circ} 64$; p. $40, \mathrm{n}^{\circ} 114$; p. $42, \mathrm{n}^{\circ} 125 ;$ p. $65, \mathrm{n}^{\circ} 320 ;$ p. $\left.69, \mathrm{n}^{\circ} 347 \ldots\right)$. La légende Aeternitas est parfois associée aux images de Junon, Ceres, Fortuna, Providentia, Spes et Faustine l'aînée. Cette légende n'accompagne pas d'ordinaire le génie au cercle zodiacal; on peut, peut-être, excepter le type nouveau qui apparaît sous Antonin le Pieux (R.M.C., IV, 2, p. LXXXIII) d'un génie ailé de l'Eternité conçue comme présent, passé et futur (p. C I). Pour une analyse des types, voir L. Foucher, Annus et Aiôn, dans Caesarodunum, Xbis, Aiôn, le temps chez les Romains, 1976, p. 197-203 (particulièrement p. 199-200). 
R. Turcan (648) s'est élevé contre cette habitude, en soulignant que les légendes Aeternitas, Aeternitati Aug. ou Augg. pouvaient à l'occasion, à l'époque tardive, il est vrai, commenter même sur des monnaies (649) des représentations masculines. Au surplus, VAeternitas monétaire, qui appartient à l'imagerie de la consecratio $\left({ }^{65^{\circ}}\right)$, n'exprime qu'un des sens du mot Aeternitas, celui de «promesse d'immortalité».

Aeternitas, qui dérive à l'origine du mot Aevum a reçu au cours des siècles les diverses acceptions qu'offrait Aı́́v en grec, dans la langue philosophique et religieuse, qu'il s'agisse de traduire Platon, Aristote ou le Corpus Hermeticum (652). Si l'on connaît bien, aujourd'hui, l'évolution sémantique d'Aicov (653) qui

(648) Voir Turcan, RA., 1975, p. 305-318.

(649) La légende Aeternitas accompagne la figure du soleil sur les monnaies de Gordien III, l'effigie de Saturne ou de l'empereur lui-même sur celles de Valérien et de Gallien (cf. Turcan, R.A., p. 307).

$\left({ }^{6 \circ}\right)$ La première mention de la légende figure sur des monnaies d'Emérita Augusta et de Tarraco, accompagnant un temple octastyle, pour célébrer l'apothéose d'Auguste, voir R. Étienne, Le culte impérial dans la Péninsule ibérique d'Auguste à Dioclétien, Paris, 1958, réimpr. 1974, (BEFAr, 191) (== ETIEnne, Culte impérial), p. 331. La première figure d'Aeternitas Augusta en jeune femme voilée commémore la consécration de Yespasien (cf. R.M.C., II, p. LXXYI et n 206, 207 ; p. 265, pl. 50, 9 et 277). Sur l'imagerie et l'idéologie de la Consecratio, voir Turcan, R.A., p. 307-308.

(651) Yoir Thesaurus Linguae Latinae, col. 1139-1141, et sur les rapprochements établis entre Aevum, Aiôn et Mithra, voir R. Dussaud, Syria, 1950, p. 253-260.

(esa) Aeternitas traduit Aı́́v dans YAsclepius latin 10, voir W. Sсотт, Hermética, vol. Ill, III, p. 185-191, avec de nombreux renvois, dans le commentaire, à d'autres textes hermétiques en grec.

(ess) $\mathrm{y}_{\text {oir }}$ A. J. Festugière, Le sens philosophique du mot «AI $\Omega N »$, dans P.P., IV, 1949, p. 172-189. L'auteur précise l'évolution du mot des présocratiques à Plotin en étudiant des textes de Platon, Aristote et Proclus. Il distingue le passage du sens de «durée de la vie individuelle» à celui de «durée éternelle». Il analyse un développement du de Caelo (I, 9, 279a, 22-30)

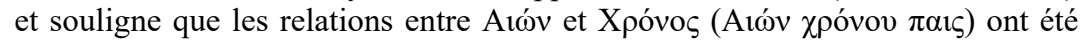
renversées au point que, dès le $\mathrm{IV}^{\mathrm{e}}$ siècle, Platon a pu dire, Timée \%là, 1-8, que le temps est une image de l'éternité de perpétuel recommencement; celle-ci n'est elle-même que l'image mobile, progressant selon la loi des nombres, de l'Eternité de permanence et d'immutabilité qui est celle du modèle intelligible immobile et fixe; Proclus, le commentateur du Timée, aurait

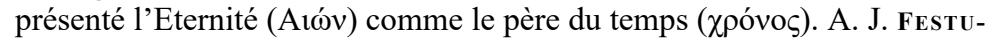


n'a jamais totalement perdu son sens premier (654) de «force vitale», qu'il soit employé pour désigner un concept philosophique abstrait, une hypostase personnifiée ou une divinité, si on n'hésite pas à lui attribuer des types iconographiques variés $\left({ }^{655}\right)$, il n'en est pas de même pour Aeternitas. Ce terme, dont l'évolution sémantique est moins bien connue ${ }^{(656)}$, qui n'est généralement qu'une traduction latine du grec Atóv, se trouve être assez souvent dissocié d'Aion dans les études iconographiques $\left({ }^{657}\right)$, comme s'il était possible

GIÈRE est revenu plus longuement sur les divers sens de Aiôn dans La révélation d'Hermès Trismégiste, t. IV, Le Dieu inconnu et la gnose, Paris, 1954, p. 152-166, pour préciser les sens de $Y$ Aiôn hermétique.

(ß54) Voip Benveniste, Eternité, qui analyse «les formes de la famille du grec Atẃv» dans les autres langues indo-européennes. Il distingue deux thèmes qui auraient donné respectivement Atóv en grec et Juvenis en latin. Il souligne le sens premier de «source de vitalité» et «force de vie» du radical et explique l'évolution du sens premier de «force vitale» capable de maintenir l'homme vivant chez Homère au sens de durée d'une vie humaine (chez Homère encore), puis durée d'une génération, avant que ne se dégage très lentement la notion abstraite d'éternité. Sur le sens de Juvenis, voir l'article de G. Dumézil, Jeunesse, éternité, aube, dans Annales, X, 1938, p. 289-295. Partant de l'article de E. Benveniste, l'auteur étudie la relation établie en latin entre Juventas et Aeternitas et constate que Juventas est donneuse

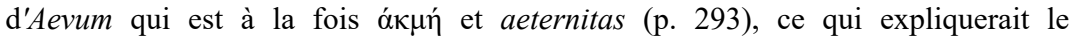
regain de faveur des activités des Juvenes sous l'Empire, selon l'auteur, et l'importance du Princeps Juventutis (peut-être, pourrait-on ajouter, l'importance des enfants dans l'iconographie impériale).

(ess) Voir l'article de D. Levi, Aiôn, dans Hesperia, XIII, 1944, p. 269-314, et L. Foucher, Caesarodunum, X ${ }^{\text {bis, }}$, p. 197-203. Les études récentes sur l'iconographie du temps dans le mithriacisme témoignent d'une grande prudence. Il semble acquis maintenant que le monstre léontocéphale n'est pas Aiôn. Voir R. Pettazzoni, A. C., 18,1949, p. 265-277 ; Lavagne, M.E.F.R.A., 1975, p. 1135-1136; H. Von Gall, The Lion-Headed, the Human-Headed God in the Mithraic Mysteries, dans Acta Iranica, XVII, 1978, p. 511-525.

(ese) Excepté Particle de DumézıL, il n'y a guère d'étude linguistique consacrée à Aeternitas et qui suive l'évolution du mot (voir Thesaurus Linguae Latinae, col. 1139-1141: le mot est employé par Cicéron, Sénèque, Tacite, Apulée et les écrits hermétiques), sinon pour la langue de saint Augustin (voir J. Guitton, La notion de temps et d'Eternité chez Plotin et saint Augustin, Paris 1933; chez Saint Augustin, la distinction entre Tempus et Aeternitas est la suivante (Civ., II, 6) : «discernuntur Aeternitas et Tempus, quod tempus sine aliqua mobili mutabilitate non est, in aeternitate autem nulla mutatio est».

(657) Voir Foucher, Caesarodonum, Xbis, p. 199 et Turcan, R.A., p. 306-307.

Conimbriga, 19 (1980), 5-127 
que des équivalences établies du point de vue de la langue et de la conceptualisation ne se retrouvent pas dans le domaine plastique ou pictural. Assurément les diverses acceptions d'Aeternitas en latin doivent transparaître dans des types iconographiques différents. Nous examinerons, selon ce principe, le champ d'extension d'Aeternitas.

Dès la fin du Ir siècle, Aeternitas est, dans la langue officielle, une vertu qui caractérise l'Empereur ( $\left.{ }^{658}\right)$. Dans la langue philocophique, le mot désigne le concept abstrait d'éternité et se définit shez Cicéron $\left.{ }^{659}\right)$, par rapport à Tempus, comme Aı́́v par rapport à Xpóvos chez Platon ou Aristote $\left({ }^{66^{\circ}}\right)$. Dans la langue religieuse, il présente des sens très nombreux, soit qu'il évoque l'immortalité de l'âme et la promesse d'éternité panthéistique pour les stoïciens et quelques philosophes d'autres écoles (661), soit qu'il traduise, d'ans VAsclepius latin ( $\left.{ }^{662}\right)$, à peu près toutes les acceptions de YAiôn hermétique ( $\left.{ }^{663}\right)$. Ainsi la notion d'Aeternitas ne saurait

(658j Voir Beaujeu, Religion, p. 147-148, et Etienne, Culte impérial, p. 320-334. Nous retiendrons que la légende Aeternitas Aug., qui, n'apparaît pas avant les Flaviens sur les monnaies impériales, se trouve à Mérida dès le règne de Tibère. D'autres vertus du prince sont encore représentées à Mérida: Providentia (gravé sur un autel de la même période) et, à la fin du $\mathrm{II}^{\mathrm{e}}$ siècle, la légende Concordia Augusti qui ne renvoie pas à l'harmonie régnant dans la famille impériale mais se définit comme la vertu que le Prince fait régner sur ses sujets et qui contribue à la Felicitas Temporum.

(659) CiCÉron, De inventione, I, 38: «Tempus est pars quaedam Aeternitatis».

$\left(\beta 6^{\circ}\right) \gamma_{0} \mathrm{j}_{\mathrm{r}}$ supra note 335 et sur la relation entre $\chi \rho o ́ v o \varsigma$ et $\alpha$ lóv chez Platon et Aristote, Festugière, P.P., p. 182-187. L'éternité est alors perçue comme la durée sans limite de la vie du Cosmos qui renouvelle indéfiniment son unité [ibid., p. 187).

${ }^{661)}$ Sur l'idée stoïcienne qu'il n'y a pas d'autre immortalité que celle du Cosmos, de YAiôn, voir R. Hoven, Stö̈cisme et stö̈ciens face au problème de Vau-delà (Bibl. Fac. Philos, et Lettr. Univ. Liège, Fase. CXCVII), Bruxelles, 1971, p. 141 sq.; Marc Aurèle, Pensées, IV, 21; VIII, 18; X, 6-7; XII, 23, 3 et 32; voir aussi D. Levi, Aiôn, Hesperia 13, 1944, p. 269-314 (particulièrement p. 306-312).

(662) JL A s clepi us est une traduction latine du IVe siècle d'un original grec datant du $\mathrm{II}^{\mathrm{e}}$ ou du $\mathrm{III}^{\mathrm{e}}$ siècle (cf. A. J. Festugière, Hermétisme et mystique païenne, Paris 1967, p. 88-90).

(663) Voir A. J. Festugière, Le Dieu inconnu, p. 152-156, pour Aiôn et 166-175, pour Aeternitas. Aeternitas désigne tantôt l'immortalité de l'âme, 
se réduire à l'image de la consécration impériale que peut en donner le type monétaire et nous ne devons pas nous laisser paralyser par des classements trop schématiques (664). Les règnes d'Hadrien et d'Antonin sont des époques d'invention iconographique où les types plastiques ne sont pas fixés $\left({ }^{665}\right)$ : il y a partout, diverse-

tantôt le concept abstrait d'«éternité» qui n'a ni commencement ni fin... qu'on ne peut ni détourner, ni mouvoir, ni détruire, tantôt la vie éternelle, tantôt la source de vie, tantôt l'âme du monde, qui le vivifie de l'extérieur, tantôt la force de vie éternelle de Dieu, tantôt même $Y$ Aiôn, intellect divin, quasi identique à Dieu. Ainsi Aeternitas, comme Aiôn, présente dans le Corpus Hermeticum des sens divers et l'on ne sait trop s'il faut ranger Aeternitas/Aiôn dans la catégorie du temps ou dans celle de l'espace, s'il s'agit d'un concept abstrait ou d'une hypostase plus ou moins personnifiée, douée d'âme et d'activité, dépendante du premier principe qui transmet la force qu'elle en reçoit au terme qui vient après elle, comme dans les listes particulièrement suggestives du C.H. XI, 2 (éd. Nock-Festugière, Paris, G.U.F., 1945, t. I, dont je cite la traduction) : «Dieu fait l'éternité, l'éternité fait le monde, le monde fait le temps, le temps fait le devenir. De Dieu l'essence pour ainsi dire est [le bien, le beau, la béatitude] la sagesse; de l'éternité c'est l'identité; du monde c'est le bon ordre; du temps c'est le changement; du devenir c'est la vie et la mort. Dieu a pour énergie l'intellect et l'âme, l'éternité, la durée et l'immortalité; le monde l'apocatastase et l'apocatastase opposée (cf. note 6, p. 155-156 , les mots désignent proprement le retour d'un astre au point où il se trouvait au moment de la génésis et son passage au point diamétralement opposé) ; le temps, la croissance et la décroissance ; le devenir, la qualité et [la quantité]. Ainsi donc l'Eternité est en Dieu, le Monde est dans l'Eternité, le Temps est dans le Monde, le Devenir est dans le Temps. Et tandis que l'Eternité se tient immobile autour de Dieu, le monde est en mouvement dans l'Eternité; le Temps s'accomplit dans le Monde et le Devenir devient dans le Temps». Et encore, ibid., XI, 3, 4, 5, 6 et 15 et note 8, p. 157. La polysémie d'Aeternitas, sans être aussi complexe, se retrouve dans les pensées de Marc Aurèle et de manière générale caractérise les $\mathrm{II}^{\mathrm{e}}$ et $\mathrm{III}^{\mathrm{e}}$ siècles, voir $\mathrm{A}$. J. Festugière, Hermétisme et mystique, p. 319-321: l'auteur insiste sur le fait que les conceptions cosmologiques des stoïciens ont préparé la voie à l'hermétisme savant et à la gnose philosophique et ont pu se mouler dans la théologie cosmique (ibid., p. 44-50).

${ }^{(664)}$ Tout se passe comme si le mot Aiôn était réservé au domaine religieux et philosophique et le mot Aeternitas à l'univers politique et idéologique, alors que l'un est un mot grec, l'autre un mot latin, et que les documents littéraires, au moins, attestent que dans bien des cas l'un des termes traduit l'autre. Voir D. Levi, Hesperia, p. 257.

(665) Notons l'importance des tâtonnements et la richesse de la création iconographique au $\mathrm{II}^{\mathrm{e}}$ siècle pour représenter des hypostases nouvellement

Conimbriga, 19 (1980), 5-127 
ment exprimés, effort, souci et capacité de redéfinir une culture commune à tout l'Empire $\left({ }^{666}\right)$.

$\mathrm{Si}$ la légende Aeternitas ne figure sur aucune autre mosaïque pour désigner un adolescent à tête ailée, la légende Atóv se lit sur deux mosaïques syriennes du $\mathrm{III}^{\mathrm{e}}$ siècle et sur un Hérôon d'Aphrodisias du Ier siècle av. J.-C.

L'Aiôn d'Aphrodisias orne un fort relief découvert en $1956\left({ }^{667}\right)$, sans doute un herôon consacré à un certain Zoilos par sa cité reconnaissante. C'est un personnage vénérable, barbu, dont la tête est en partie voilée, qui est représenté assis et dont le nom est donné par une inscription dans le champ, «Aıஸ́v». A. Giuliai|o avait ciu pouvoir dater, uniquement d'après le style, ce monument de 130-140 après J.-C. Une étude de L. Robert (668) établit de nombreux rapprochements entre ce monument et des inscriptions concernant un Zoilos d'Aphrodisias, prêtre d'Aphrodite, qui a procuré à sa cité l'autonomie et acquis pour lui-même le droit de cité romaine, qui permettent de dater, avec précision, le document de l'extrême fin du I I rer siècle av. J.-C. $\left({ }^{669}\right)$. A cette époque, en Carie, Aiôn semble symboliser les honneurs éternels attachés à la mémoire de Zoilos, comme sauveur de sa cité en même temps que l'avenir éternel promis à la cité $\left({ }^{67^{\circ}}\right)$. Sur Vherôon de Zoilos, Aiôn voisine en effet avec Demos, Polis, Time, Andreia ( $\left.{ }^{671}\right)$, termes qui renvoient tous à l'univers culturel du gymnase. On

personnifiées, cf. TurCan, R.A., p. 315 et Levi, Hesperia, p. 307, pour l'Eternité et de manière plus générale, cf. Hanfmann, Season Sarcophagus, t. I, p. 159, 176-179, 181 et Toy n B E E, Hadrianic School, p. XXVII sq.

$(\beta \beta \beta)$ voir sur l'élaboration de cette koiné dans le domaine artistique, R. Bianchi-Bandinelli, Naissance, p. 453-460, et pour ce que représente la désignation par un mot latin d'une réalité d'origine grecque ou indigène dans le cas particulier de l'Espagne, voir R. ETIEnNe, Les syncrétismes religieux dans la péninsule ibérique à l'époque impériale, dans Les syncrétismes dans les religions grecque et romaine, colloque G.N.R.S., Paris, 1973, p. 159-160.

(667) Voir A. Giuliano, A.S.A.A., 38-39 (1959-1960), paru en 1962, p. 389-401, Rilievo da Aphrodisias in onore di Zoilos et J. et L. Robert, Rull. Ep., 63, n 249.

$(\beta \beta \beta)$ voir p. RовеRт, Inscriptions d'Aphrodisias, 1ère partie, dans Ant. class., 35, 1966, p. 397-432 (particulièrement p. 427-432).

$\left({ }^{669}\right)$ ID., ibid., p. 427 et 429.

$\left({ }^{670}\right)$ ID., ibid., p. 428.

(671) ID., ibid., p. 428 et 431. 
ne peut donc guère comparer du point de vue iconographique (672) ce vieillard au jeune homme à tête ailée de la mosaïque de Mérida. On ne peut guère les rapprocher, non plus, sur le mode symbolique, car ils s'inscrivent dans des contextes différents: à Aphrodisias, les figures représentées sont toutes des abstractions tirées de la vie politique et civique, à Mérida, Aeternitas voisine avec les saisons, les vents, les luminaires, Polum, Caelum... Le personnage relève donc d'abord d'une lecture cosmologique, voire cosmique.

Dans la mosaïque des Xpóvor d'Antioche, datée du milieu du III ${ }^{e}$ siècle ap. J.-C., à laquelle D. Levi a consacré une très belle et très importante étude $\left({ }^{673}\right)$, la légende Aı́́v accompagne la figure d'un homme âgé à longs cheveux, portant moustache grise et barbe courte, assis à côté d'une roue qu'il fait tourner et qui pourrait être un cercle zodiacal, quoique D. Levi préfère n'y voir que la roue tournante des années $\left({ }^{674}\right)$. Il est placé, comme pour un banquet, à côté, mais un peu à l'écart, de trois autres figures masculines assises sur le même lit, désignées par la légende Xpóvor

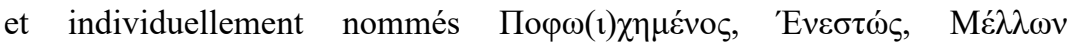
(passé, présent, avenir) ${ }^{(675)}$. Aiôn, dans ce cas, serait, selon le même érudit, le temps absolu, le temps éternel, par opposition aux Xpóvor qui seraient les trois aspects du temps relatif, événementiel, qu'est le temps humain ${ }^{(676)}$. $\mathrm{Ni}$ la figure, trop âgée, ni la valeur uniquement temporelle d'Aiân dans la mosaïque d'Antioche ne nous permettent de rapprocher cette figure de $Y$ Aeternitas de Mérida.

Dans la mosaïque de Chahba-Phihppopolis, qu'E. Will (677) a proposé de dater de 248, Aı́́v est un jeune adulte au torse nu

(672) On ne peut guère le rapprocher non plus du Saeculum de Mérida, même si ce dernier est vénérable et barbu, parce qu'à Mérida Saeculum est inséparable de Caelum et de Polum, voir supra I, p. 81, 84, note 309 et I, p. 93-94, note 362. Pour une représentation iconographique de l'Aiôn d'Aphrodisias, voir Enciclopedia delVarte antica e orientale, s.v. Aiôn, p. 176, fig. 262.

(673) D. Levi, Aiôn dans Hesperia, XIII, 1944, p. 269-314 et fig. 2 et 3.

L'auteur examine, à partir de la mosaïque, les problèmes iconographiques que pose Aiôn et distingue plusieurs Aiônes.

(674) ID., ibid., p. 284.

(675) ID., ibid., p. 273.

(676) ID., ibid., p. 274.

$\left.{ }^{677}\right)$ E. Wilt, Une nouvelle mosaïque de Chahba-Philippopolis, dans Ann. Arch. Syr., Ill, 1953, p. 27-48.

Conimbriga, 19 (1980), 5-127 
auquel le mosaïste aurait prêté, selon J. Charbonneaux ( $\left.{ }^{678}\right)$, le visage de Philippe l'Arabe et son bandeau impérial; il est assis à l'extrême gauche du tableau et tient de la main droite une petite roue qui semble être le cercle zodiacal. Si nous suivons l'interprétation de A. J. Festugière ${ }^{(679)}$, Aı́́v serait dans ce pavement «le temps éternel, spectateur sinon principe de la fécondité de la terre» et «modèle du cycle particulier de chaque vie humaine, dans la mesure où ce cycle lui aussi indéfiniment se renouvelle» $\left({ }^{68^{\circ}}\right)$. A ce titre, il accompagne les figures des saisons, de Gé, des Karpoi, de Triptolème, de Prométhée, de Psyché, d'Hermès, — «le tableau représentant la vie et la mort de l'homme en connexion avec Aiôn, le temps éternel, dans lequel tout naît, croît, parvient à maturité, décline et meurt, pour naître à nouveau et ainsi à l'infini» ( $\left.{ }^{681}\right)$. A. J. Festugière envisage pourtant que la mosaïque de Philippopolis puisse faire l'objet d'une lecture plus optimiste, si l'on accorde plus d'importance au rôle de Gé, des saisons, des Karpoi. Elle serait, alors, un tableau «du monde qui est éternel, heureux et bon».. «la terre, centre du monde, étant elle aussi éternelle, heureuse et bonne puisque, par le jeu des saisons que ramène $Y$ Aiôn, elle produit son ouvrage» $\left({ }^{682}\right)$. L'homme, quoique son cycle individuel soit limité par la naissance et la mort, est éternel dans la continuité des générations, il a un rôle à jouer sur la terre et participe ainsi à la bonté du Monde dont le sage accepte l'ordre immuable ( $\left.{ }^{683}\right)$.

L'interprétation d'A. J. Festugière et celle d'E. Will se complètent sans se contredire. Selon E. Will l'imagerie du tableau

(678) J. Charbonneaux, Aiôn et Philippe l'Arabe, dans M.E.F.R.A., 1960 , p. $253-272$ et 4 planches ( $=$ Charbonneaux, Aiôn $)$. L'auteur lie très étroitement cette mosaïque aux événements contemporains et valorise son importance dans la connaissance de l'idéologie impériale. Sur la ressemblance entre Aiôn et Philippe l'Arabe (ibid.,, p. 264 et 268-269, pi. II, fig. 4 et pi. III, fig. 1 et 2 .

(679) A. J. Festugière, La mosaïque de Philippopolis et les sarcophages au «Prométhée», dans Hermétisme et mystique païenne, Paris, 1967, p. 312-321.

${ }^{(68 \circ)}$ ID., ibid., p. 314.

(681) ID., ibid., p. 318.

(682) ID., ibid., p. 320.

(683) ID., ibid., p. 320.

Conimbriga, 19 (1980), 5-127 
révèle un mélange de philosophie spéculative et pratique, une religiosité d'un genre nouveau dans laquelle les antiques divinités personnelles cèdent le pas aux dynameis personnifiées. Pour A.-J. Festugière, la mosaïque de Philippopolis est témoignage de foi en l'éternité du monde et sans doute aussi promesse d'éternité individuelle, si l'on admet que le rapprochement du cycle de la vie humaine limitée par la mort avec tous les autres cycles de la nature semble garantir la renaissance de l'homme et lui annoncer une éternité cosmique, celle de VAiôn. L'étude de J. Charbonneaux, souligne davantage le lien direct de VAiôn à la personne de l'Empereur: Philippe l'Arabe aurait su profiter de la célébration du millénaire de Rome en 248 pour tenter de consolider sa dynastie, en se faisant représenter sous les traits d'Aiôn et en associant, comme ses prédécesseurs, les légendes d'Aeternitas Augg. et Aeternitas Imperii à celles de Saeculum Novum, Felicitas et Fecunditas temporum dans ses émissions monétaires ( ${ }^{684}$ ).

Nous retiendrons de ces études quAeternitas est évidemment liée à Aiôn dont elle est la traduction» ( ${ }^{685}$ ), que les thèmes de la propagande impériale se servent des abstractions et dynameis nouvellement personnifiées $\left({ }^{686}\right)$ et que la présence d'Aiôn garantit le respect de l'ordre cosmique et met en relation l'éternité de l'Univers et celle d'une dynastie, en même temps qu'elle est promesse d'éternité panthéistique individuelle, lu Aiôn de Philippopolis n'évoque pas pour autant VAeternitas de Mérida: rien dans notre tableau ne rappelle les étapes de la vie humaine qui tiennent tant de place à Philippopolis, et nombre de figures de Mérida (les fleuves, le port, le phare, Oceanus, Mons, Natura, Copiae, Navigia), sont absentes à Philippopolis. Il ne semble pas y avoir, à ce jour, d'autre monument connu sur lequel figure la légende $\operatorname{Aiôn}(G 87)$. Les mosaïques citées plus haut appartiennent à la partie orientale de l'Empire et datent au plus tôt du milieu du IIIe siècle.

(684) Charbonneaux, Aiôn, p. 263-265.

(685) ID., ibid., p. 257.

Í68) ID., ibid., p. 257 et 272.

${ }^{(687)} \mathrm{Si}$ Ton excepte le fragment de vase apulien à figures rouges de Karlsruhe (cf. LEVI, Hesperia, p. 280 et fig. 7) où Aiôn figure à côté d'Orphée et d'Eurydice et dont, vu la date (IV's. av. J.-C.), je ne tiendrai pas compte ici. 
Elles me semblent, par leur style iconographique, postérieures à notre mosaïque.

On désigne encore comme Aiân d'autres figures, que l'on rapproche de celles d'Antioche et de Philippopolis, parce qu'elles sont accompagnées du cercle zodiacal et voisinent, dans quelques cas, avec la Terre, Océan, ou les Saisons: ce sont le génie à la corne d'abondance ou le génie au cercle zodiacal des mosaïques africaines, datant de la fin du III $^{\mathrm{e}}$ ou du $\mathrm{IV}^{\mathrm{e}}$ siècle $\left({ }^{688}\right)$; le génie au sceptre de la patère de Parabiago $\left({ }^{689}\right)$ dont la date discutée

(«se) Voir Levi, Hesperia, p. 287-296, fig. 15; Hanfmann, Season Sarcophagus, t. I, p. 135 et 227, t. II, p. 147 n 129 ; TurCan, R.A., p. 311, fig. 3 et P. Gauckler, Inventaire des mosaïques de la Gaule et de ГAfrique, t. II, $\mathrm{n}^{\circ}$ 41. La représentation de ce petit personnage au zodiaque semble bien attestée sur les mosaïques africaines, voir J. W. SAlomonson, La mosaïque aux chevaux de Гantiquarium de Carthage, p. 62-65: l'auteur rapproche la mosaïque aux saisons et génie zodiacal d'Hippone (pi. XLV/2), de la mosaïque aux chevaux (pl. XLIV/3, et p. 105, tableau 18, fig. 22, qu'il date du début du III ${ }^{\mathrm{e}}$ siècle), de la mosaïque du triclinium de la même maison de Carthage (pl. XLV/5), de la mosaïque d'Ammaedara (pl. XLV/2, datée de l'extrême fin du III ${ }^{e}$ ou début du $I^{e}$ siècle) et de la mosaïque de Thugga sur laquelle le génie qui porte une corne d'abondance mais ne s'inscrit pas dans le cercle zodiacal a été considéré comme la personnification de l'année dont la tradition iconographique remonterait à l'époque hellénistique (ibid., p. 63 note 6). J. W. Salomonson, p. 65, ne croit pas pouvoir donner le «nom d'Aion, aux nuances gréco-philosophiques», au génie du cercle zodiacal et préfère, se refusant à faire un choix, proposer les dénominations d'Annus, Saeculum, Genius Saeculi, Frugifer. On pourrait encore ajouter Ralos Kairos, ou Agathos Daimon - la personnification du moment favorable dont nous savons qu'il avait un autel à Olympie à l'entrée du stade, cf. Pausantas, 5, 14, 9 (éd. M. H.

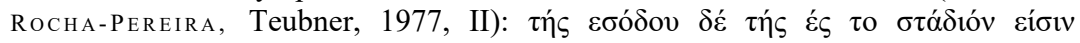

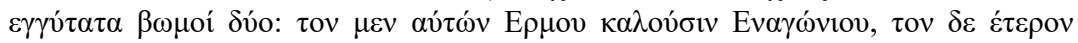
Kaıpov́. Je ne sais pas si l'on peut appliquer à l'Afrique le témoignage des inscriptions grecques d'Asie (cf. sur Ralos Rairos, L. Robert, Hellenica, IX, p. 58, pour son association avec les vents, les pluies et comme synonyme de la belle saison). Voir aussi les travaux en cours de D. PARRISH sur la représentation du temps et des saisons, dans les mosaïques africaines.

(689) $\mathrm{y}_{0} \mathrm{j}_{\mathrm{r}}$ Levi, Hesperia, p. 287-297 et fig. 12 et 13; HANFmann, Season Sarcophagus, t. I, p. 181 sq., 220, 227, 229, 235; t. II p. 82-83, note 241, p. 174, note 449. La patère de Parabiago, aujourd'hui conservée au Palazzo di Brera à Milan, associe au triomphe de Gybèle et d'Attis le soleil précédé de Phosphorus et la Lune précédée d'Hesperus, les allégories de la terre, des saisons, d'Océan et de Thétis et, porté par Atlas, un jeune homme debout dans 
ne saurait être antérieure à la fin du II ${ }^{\mathrm{e}}$ siècle, l'adolescent nu figurant à l'intérieur du cercle zodiacal de la mosaïque de Sentinum qui date du III e siècle $\left({ }^{690}\right)$, le jeune homme de la mosaïque funétaire d'Isola Sacra, datée de l'époque antonine $\left.{ }^{691}\right)$, qui tient le cercle zodiacal à l'intérieur duquel s'avancent les saisons. Ce dernier exemple est proche du type monétaire de $Y$ aureus d'Antonin portant la légende Saeculum aureum ( $\left.{ }^{692}\right)$; les exemples précédents se caractérisent par la présence du même thème zodiacal, figuré par les signes visibles sur le cercle du zodiaque, où R. Turcan $\left({ }^{693}\right)$ reconnaît le Thema Mundi - l'horoscope du monde qui $\mathrm{s}$ est répandu dans l'Empire à partir de l'avènement d'Antonin le Pieux et a connu une grande fortune au cours du IIIe siècle ( $\left.{ }^{694}\right)$.

Il n'y a pas lieu de faire, dans le cadre de cette recherche, une étude systématique de ces documents, puisque nous ne voulons pas étudier l'adolescent ailé de Mérida indépendamment de son contexte. Nous constaterons seulement combien le problème est délicat, combien varient les interprétations (695) et renverrons aux

lç cercle zodiacal qu'il tient de la main droite. D. Levi, rapproche ce personnage du jeune homme qui figure sur une monnaie d'Hadrien (ibid., fig. 19e) avec la légende Saeculum Aureum (cf. Mattingly, B.M.C., III, p. GXXXI sq., p. $278 \mathrm{n}^{\circ} 312$, pl. 52, 10 et TurCAn, R.A., p. 311).

$\left(69^{\circ}\right)$ Voir Levi, Hesperia, p. 287-288, fig. 14; Hanfmann, Season Sarcophagus, t. I, p. 182, 220, 227-228, 235; t. II, p. $173 \mathrm{n}^{\circ} 430$, fig. 108 et TURCAN, R.A., p. 311.

(691) Voir Levi, Hesperia, p. 285, fig. 11, mosaïque que l'auteur rapproche

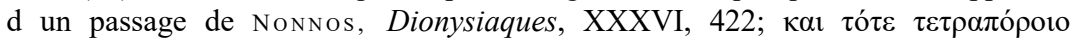

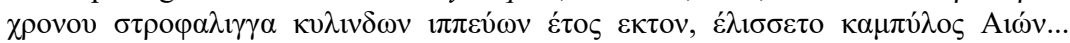
et Hanfmann, Season Sarcophagus, t. I, 181, 230-233; t. II, p. 82, n 237, p. 113 nos 8 et 9 .

(692) Voir Hanfmann, Season Sarcophagus, t. I, p. 232: l'auteur suppose même que cette mosaïque s'inspirerait de la monnaie, et t. II, p. 143, $\mathrm{n}^{\circ} 80$.

(693) Voir Turcan, R.A., p. 308-309. L'auteur souligne que le génie de la colonne Antonine n'expose aux regards que trois signes - Poisson, Bélier, Taureau - qui ne correspondent pas à une saison mais sont, selon Firmicus maternus, ceux qui culminent dans le thème du monde (cf. W. et H. G. Gundel, Astrologumena, p. 230).

(694) Ibid., p. 311-313.

(695) Voir Levi, Hesperia, p. 288 («The god of the zodiac has been variously interpreted as Dionysos, the Solar Apollo, Sol, Annus, Caelus, Phanes and finally as Mithras»); Hanfmann, Season, Sarcophagus, t. I, p. 176-177 
études plus particulièrement centrées sur la figure du génie zodiacal et sur VAiôn(69Q).

Plastiquement, c'est l'adolescent de la mosaïque de Sentinum - le cercle zodiacal excepté — qui se rapproche le plus de Y Aeternitas de Mérida, autant bien entendu que la lacune centrale nous permette d'en juger, et quoique la figure de Tellus, entourée de putti-saisons à Sentinum ( $\left.{ }^{*} 696{ }^{697}\right)$, n'ait pas d'équivalent dans notre tableau (698). Notons la même position du corps, la même nudité, le même visage imberbe et juvénile, la même chevelure courte et luxuriante, la même implantation des ailes sur les tempes, encore que celles-ci soient moins visibles à Sentinum, la même direction du regard, la même impression de force et de sérénité.

(«The figure holding the Zodiac has been variously identified as Sol, $A$ ion, Annus, Cronus, Genius Saeculi, Genius Anni, and Saturn. He must be a personnification of Time; same of the litterary passages suggest Sol, but they are late and need not apply; on coins of Hadrian, the same figure, without the seasons, is inscribed Aureum Saeculum, the Golden Age. All others representations of this youthful god are later and they occur on private monuments which cannot be used indiscriminately to interpret the art of the Roman Court...», et p. 227); Turcan, R.A., à propos du génie de la colonne Antonine, p. 306-307 (:[L'identification] du génie ailé qui emporte au ciel le couple des divi est toujours discutée. On a proposé d'y reconnaître Aeternitas, Aiôn, Ascensus, Zephyrus, Consecratio, Saeculum Aureum); Salomonson, La mosaïque aux chevaux, p. 65.

(696) Voir Levi, Hesperia, passim, Hanfmann, Season Sarcophagus, t. I, p. 182 sq.; Turcan, R.A.; Salomonson, La mosaïque aux chevaux, p. 62-65; Foucher, Caesarodunum, Xbis, p. 197-203; A. Alfoldi, From the Aion Plutonios of the Ptolemies to the Saeculum Frugiferum of the Roman Emperors, dans Greece and the Eastern Mediterranean in Ancient History and Prehistory, Berlin, New-York, 1977, p. 1-30, pi. 275-283 (= Redeunt Saturnia Regna, VI).

${ }^{697}$ ) La représentation de Tellus entourée de saisons-enfants s'inspirerait des types iconographiques diffusés par l'imagerie impériale (cf. HANFManN, ¿eason Sarcophagus, t. I, p. 182, 220, 235) et témoignerait dans la mosaïque de Sentinum de l'ordre et de l'harmonie de l'Univers [ibid., p. 235). Sur le type de Tellus en Gé Karpotrophos avec des putti-saisons, voir ibid., p 220 et Toynbee, Hadrianic School, p. 140-143, fig. 31, 3-4; 33, 3; et

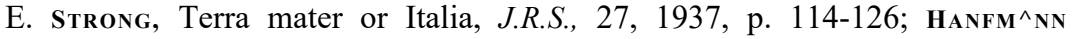
date de l'époque antonine l'introduction des putti-saisons, ibid., t. I, p. 231-B33.

$\left.{ }^{698}\right)$ Tellus pouvait figurer à droite dans la mosaïque de Mérida mais sans les putti-saisons, voir supra p. 49 et note 613. 
Cette similitude pose la question de la personnalité d'Aeternitas dans la mosaïque de Mérida. Essayons donc, avant de parler de syncrétisme, de préciser ce que peut désigner, exactement, dans ce tableau, la légende Aeternitas et à quel registre religieux ou philosophique, voire politique, peuvent renvoyer et cette figure et cette légende.

La figure de Sentinum, dont aucune légende ne donne le nom, a pu être considérée par D. Levi et par G.M.A. Hanfmann comme mithriaque, parce que la mosaïque décorait( $\left.{ }^{699}\right)$, semble-t-il, le sol d'une annexe d'un mithraeum. Elle n'a pas été retenue comme figure mithriaque dans le Corpus de M. J. Vermaseren, et, bien que l'on admette généralement qu'elle s'intégre à un contexte idéologique complexe en rapport avec Mithra $\left({ }^{70}\right)$, elle est encore interprétée très diversement aujourd'hui $\left({ }^{701}\right)$.

La proximité de l'emplacement où ont été découvertes les statues et les inscriptions mithriaques peut expliquer qu'à Mérida, comme à Sassoferrato, on soit tenté de parler de mithriacisme $\left({ }^{702}\right)$. Pouvons-nous, pour autant, reconnaître en Aeternitas un Aiôn mithriaque ou une figure syncrétique à composante mithriaque et rapprocher cet adolescent des statues mithriaques d'Hermès et d'Aiôn trouvées à proximité $\left({ }^{703}\right)$ ?

(699) Voir Levi, Hesperia p. 287-288. L'auteur souligne que la mosaïque de Sentinum (aujourd'hui Sassoferrato) qui se trouve maintenant à la Glyptothèque de Munich décorait le sol d'une pièce dans laquelle a été aussi trouvé un relief de Mithra tauroctone et propose de reconnaître, dans le jeune dieu au zodiaque, Aion, figuré sous les traits de Sol en taureau [ibid., p. 288). HANFMANn, Season Sarcophagus, t. I, p. 182, pense qu'à Sentinum une interprétation mithriaque est légitime: «Here... the god may well be the mithraic Chronus»».

$\left(7^{\circ \circ}\right)$ Voir foucher, Caesarodunum, Xbis, p. 201.

$\left(7^{\circ} \mathrm{i}\right)$ Voir Hanfmann, Season Sarcophagus, t. I, p. 227: «Helios or the year, or Aion, or time personnified is seen on the mosaic from the sanctuary of Mithras at Sentinum». R. TuRCan R.A., p. 311, ne la désigne pas comme une figure mithriaque et L. Íoucher, Caesarodunum, Xbis, p. 201, y reconnaît un génie de l'année au zodiaque, associé à Tellus. Sur le cercle zodiacal comme symbole de l'année, voir HANFMANN, ibid., p. 235, et les références d'écrivains, nombreuses, qu'il cite.

(702) Voir supra, I, p. 7, 8, 11.

(703) Voir supra, I, p. 12, notes 20 et 21. 
De visage, en effet, Aeternitas diffère peu de la figure mithriaque du relief de Modène ( $\left.{ }^{704}\right)$, de la statue de Borcovicus $\left({ }^{705}\right)$, de la statue lysippéenne de Mérida (706). Manquent, pourtant, aux statues mithriaques les ailes dans la chevelure et à $Y$ Aeternitas de la mosaïque soit les flammes du relief de Modène, soit les deux moitiés de l'oeuf originel ou de la sphère des bas-reliefs de Borcovicus et de Modène, soit le serpent et le protomé de lion des statues de Mérida et de Modène. Aeternitas ne présente à Mérida, autant que la lacune nous laisse en juger, aucun attribut des figures mithriaques.

L'aile qui subsiste à droite, dans sa chevelure, peut-elle nous permettre d'identifier le personnage comme un Hermès/Mithra? Quelques documents épigraphiques $\left({ }^{707}\right)$ et quelques monuments figurés $\left({ }^{708}\right)$ attestent l'existence, dès le IIe siècle, de l'équation Mithra=Mercure. R. Turcan $\left({ }^{709}\right)$ a montré que «la position équinoxiale de Mithra entre la lumière et les ténèbres, quand le jour et

(704) Voir Levi, Hesperia, p. 290 et 299 et fig. 16 et Vermaseren, C.I.M.R.M., I, p. 253 sq. $\mathrm{n}^{\circ}$ 695, fig. 197, identifié comme un Aiôn-Phanès.

( $\left.7^{\circ} 5\right)$ Voir Levi, Hesperia, p. 292 et fig. 18; Cumont, T.M.R.M.M., II, $n^{\circ} 273$, p. 395, fig. 315: statue trouvée dans le Mithraeum de Housesteads (autrefois Borcovicus), c'est le torse nu de Mithra entre les deux moitiés d'un oeuf ou d'une sphère, au centre du zodiaque.

$\left(7^{\circ} \beta\right)$ Voir supra I, p. 13 et 92, notes 21,348 et 616.

( $\left.7^{\circ} 7\right)$ Voir Vivienne J. Walters, The cult of Mithras in the Roman Provinces of Gaul, Leyde, 1974, (EPRO) p. 117, $\mathrm{n}^{\circ}$ 46: un autel du II siècle avec la mention Deo/Mercu/rio Mi/thrae... et C.1 .M.R.M., t. I, 780, 1, fig. 213, t. II 1256 et 1267, et T.M.R.M.M., n 529, 150, suppl. 420a.

J708J Voir J. M. G. Toynвe,, Art in Roman Rritain, Londres, 1962, p. 133 et C.I.M.R.M., t. I, 780, 1, fig. 213, particulièrement à Mérida, mais aussi 241,$2 ; 288,8 ; 299,5 ; 477 ; 693,5 ; 716 ; 780 ; 828,2 ; 966$, D,c; t. II, $1048 ; 1089 ; 1090 ; 1128,11 ; 1176 ; 1178 ; 1179 ; 1210 ; 1257 ; 1258 ; 1284 ; 1317$; $1430, \mathrm{C}, 3 ; 1475,7 ; 1755 ; 1815,4 ; 2202,3, \mathrm{c} .$. tous ces monuments témoignent seulement de la présence de Mercure dans les mithraea ou sur des reliefs mithriaques; voir aussi R. TuRCAN, Les religions de VAsie dans la vallée $d u$ Rhône, Leyde, 1972, (EPRO), p. 37 sq. et Cumont, T.M.R.M.M., p. 144-145 et $\mathrm{n}^{\circ} 221 \mathrm{C}, 1 ; 246, \mathrm{G}$ suppl.; 273 ter G, 2. Sur Y Hermès de Mérida, outre l'article ancien de Ch. Picard, Hermès et Mithra, R.A., XLI, 1953, p. 95, voir A. García y Bellido, El culto a Mithras en la Península ibérica, gol. de la Real. Acad, de la Historia, 122, 1948, p. 317-329.

$\left(7^{\circ 9}\right)$ R TURCan, Mithras Platonicus, recherches sur Vhellénisation philosophique de Mithra (e r o), Leyde, 1975 ( - Turcan, Mithras Platonicus). 
la nuit sont à égalité, faisait de lui un dieu médian» $\left({ }^{71^{\circ}}\right)$, facilement assimilable $k$ «Y Hermès-logos» des stoïciens $\left({ }^{711}\right)$, «Zogos-démiurge, logos incarné et répandu à travers le Cosmos, dieu de la raison et de la génération», que connaît Plutarque et que, par l'intermédiaire $\mathrm{du}$ stoïcisme, les platoniciens ont légué aux gnostiques ${ }^{(712)}$. Mais le nom d'Aeternitas n'a jamais été appliqué à un Mercure/Mithra et l'adolescent de la mosaïque ne ressemble guère à l'Hermès du Musée de Mérida. Malgré l'aile qu'il porte dans la chevelure et la position centrale qu'il occupe dans le tableau, le personnage ailé de Mérida ne doit pas être un Mercure/Mithra. Il n'y a aucun dieu personnalisé dans le tableau. Ses ailes $\left({ }^{713}\right)$ ne font de lui ni un vent, ni Hermès, ni Mithra; elles marquent seulement qu'il appartient à la fois au registre céleste et au registre terrestre, disent sa mobilité dans toute l'étendue du Cosmos et témoignent de son caractère coextensif à l'Univers.

Les spécialistes d'iconographie ont tendance à classer les diverses figures que nous avons mentionnées plus haut en deux catégories, selon qu'elles sont ou non pourvues d'ailes.

Est-ce très pertinent? M. J. Vermaseren et R. Turcan( $\left.{ }^{714}\right)$ insistent également sur le caractère polymorphe à'Aiôn. D. Levi notait déjà: «It is true that in this age (sous les Antonins), Aion

$\left(7 \mathrm{i}^{\circ}\right)$ Turcan, Mithras Platonicus, p. 19.

(711) Sur cette équivalence dans la Stoa, voir J. PÉPIn, Mythe et allégorie, Paris, 1958, p. 345 et Turcan, Mithras Platonicus, p. 18-19, (qui cite Plutarque, Mor. 367 d); J. Dillon revient sur le lien établi entre le logos stoïcien, Hermès et Mithra dans The Platonizing of Mithra, dans J.M.S., II, 1, p. 79-85.

(712) A J. Festugière, La révélation d'LIermès trismégiste, t. I, L'astrologie et les sciences occultes, Paris, 1950, p. 71.

(713) Il s'agit bien d'ailes et non de pétase ailé comme dans quelques exemples mithriaques, (C.I.M.R.M., t. I, 693, 5; t. II, 1430, C, 3). Sur d'autres reliefs, Mercure a des ailes dans la chevelure ou aux talons. Sur les ailes comme symbole du temps ou du mouvement, voir HANFMANN, Season Sarcophagus, t. II, note 91, p. 155.

(714) Vermaseren, Mithra, p. 100 et 106-107, et turcan, R. A., p. 314-315.

(715) Levi, Hesperia, p. 307, après A. D. Nock, The genius of Mithraism, J.R.S., 27, 1937, p. 108-113. 
is a fluid conception» ( $\left.{ }^{71 S}\right)$. Evitons donc tout dogmatisme $\left.{ }^{71 \delta}\right)$ et retenons que «l'essence à'Aiônest constituée au $\mathrm{II}^{\mathrm{e}}$ siècle par le concept de vie» $\left({ }^{717}\right)$ : c'est selon les conceptions philosophiques, les cultes, en fonction des circonstances du moment, que la lumière est portée sur tel ou tel aspect de la divinité $\left({ }^{718}\right)$.

Ainsi pourrait peut-être s'expliquer que, ressemblant étrangement au génie au cercle zodiacal de la mosaïque de Sentinum qui est couronné de feuillages, parce qu'il exerce son influence sur la terre féconde, Aeternitas à Mérida soit représenté avec des ailes temporales éployées dans la chevelure, parce qu'il est la force vitale qui parcourt le Cosmos, tandis que le génie ailé de la colonne Antonine présente des ailes dorsales, que nécessite sa fonction actuelle: il emporte dans le séjour des après la cérémonie de consécration, Antonin et Faustine, et s'apparente aux aigles, sculptés de part et d'autre du couple impérial, qui emportent habituellement le divus, lors de l'apothéose $\left({ }^{719}\right)$.

Aeternitas n'est donc pas, pour nous, dans ce tableau, une figure spécifiquement mithriaque, dans la mesure où ne sont placés à ses côtés ni zodiaque, ni serpent, ni protomé de lion. La voûte céleste est bien représentée dans la mosaïque comme dans les antres mithriaques $\left({ }^{72}\right)$ et Polum pourrait à la rigueur s'identi-

(716) Selon les remarques de Vermaseren, Mithra, p. 100: «Le problème de la personnalité d'Aiôn devient absolument inextricable, si l'on n'est pas absolument convaincu, que le mithraïste, à l'instar de ses contemporains, n'avait pas l'habitude de penser selon un dogme établi...».

(717) ID., ibid., p. 107; Turgan, R.A., p. 314 et festugiére, Dieu inconnu, p. 162: «L'Aiôn n'est pas seulement un concept abstrait mais un principe actif, force ou sagesse de Dieu, âme du ciel, principe qui maintient le monde et qui comme toute source de vie peut être dit la 'copie' de Dieu».

(718) Voir Vermaseren, Mithra, p. 100.

(719) Voir Turcan, R.A., p. 307-308 et 315 et F. Cumont, LUX perpetua, Paris, 1949, p. 296.

$\left({ }^{\circ}{ }^{\circ}\right)$ Sur son importance, voir Turcan, Mithras Platonicus, p. 67; Campbell, Mithraic Iconography, p. 49, et 119-121: «Such a conception of religion [qui met en relation] the cyclic motion of time with the motion of wisdom, creator of order and justice in the world, would explain in the Mithraic mysteries, the tendency in a Graeco-Roman environment to make both the cult picture and the Mithreum into an elaborate representation of the Cosmos. 
fier au Titan Atlas qui symboliserait dans le mithriacisme, selon M. J. Vermaseren ( ${ }^{721}$ ), le «fardeau que Mithra doit porter»; mais Aeternitas voisine aussi, dans la mosaïque, avec Portus, Pharus, des fleuves, Copiae, Navigia, toutes légendes qui renvoient à Voikouméné et non à la seule voûte céleste et qui ne se retrouvent pas dans l'iconographie ni la cosmologie mithriaque. Nous avons vu, par ailleurs, que la mention des montagnes, des fleuves, des cités, de l'océan... était un des topoi obligés de la description du monde, dans des textes philosophiques ou religieux marqués par l'influence de la Stoa $\left({ }^{722}\right)$, ce qui semble faire prévaloir une interprétation philosophique du pavement.

Il n'est pas impossible cependant que la représentation qui est faite ici d'Aeternitas puisse se retrouver, ainsi que la cosmologie qu'elle suppose, dans le mithriacisme $\left({ }^{723}\right)$, particulièrement apte à partir du $\mathrm{II}^{\mathrm{e}}$ siècle à s'helléniser et à assimiler des conceptions philosophiques et cosmologiques d'origine diverse ( $\left.{ }^{724}\right)$.

$\mathrm{Si}$ la figure à'Aeternitas ne représente pas, sur ce pavement, un Aiôn mithriaque, elle exprime bien cependant la notion d'Aiôn, et d'un Aiôn indissociable du Cosmos.

A Mérida, en effet, le mosaïste n'a privilégié aucun personnage. Il y a même, pourraît-on dire, dans le tableau une sorte de rivalité pour la prééminence entre le centre et le sommet, entre le haut et le bas, entre les angles et les côtés $\left({ }^{725}\right)$, comme si l'artiste

Revelation and religion would be synonymus in so far as the revelation was complete but completeness would surely require more than one picture or one initiation».

(721) Voir Vermaseren, Mithra, p. 97.

(722) Voir Festugière, Dieu cosmique, p. 227-232, p. 449-459 et p. 555-557 ; 566-567, pour leur mention par Philon.

(723) Sur les relations entre la cosmologie stoïcienne et la cosmologie mithriaque, voir F. Cumont, Les religions orientales, p. 219; sur la projection sur le mithriacisme des conceptions platoniciennes, voir Merкelbach, Die Kosmogonien, p. 219-257 ; et, avec plus de mesure, Turcan, Mithras Platonicus, p. 129-133.

(724) Voir Vermaseren, Mithra, p. 97 et en dernier lieu, le compterendu du colloque de Rome, 23-31 mars 1978, dans J.M.S., II, 2, 1978, p. 241-242.

(725) Voir l'étude de W. HÜBNER, Die olympichen Gotter in Flauberts Tentation de Saint Antoine, Arcadia, 5, 1970, pp. 242-261, pour une analyse de 
avait voulu marquer dans la composition même que toutes les abstractions personnifiées concourraient également à l'ordre, à la beauté et à l'harmonie de l'Univers. Il a accordé autant d'importance à Natura qu'à Aeternitas, aux dieux fleuves qu'à Oceanus, à Oriens et à Occasus qu'à Caelum, aux Vents qu'à Mons, à Portus qu'à Pharus (726). Le mosaïste a construit son tableau

la structure d'une oeuvre d'art. Nous avons dans la mosaïque à la fois une structure étagée et un souci de ne pas accorder plus d'importance aux figures placées au centre qu'à celles qui sont situées à la périphérie. Ce même souci

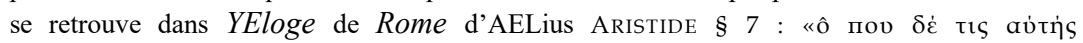

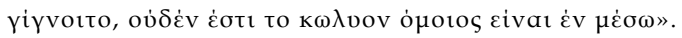

( ${ }^{72 \delta}$ ) Rappelons l'importance de Natura dans le stoïcisme (voir supra, p. 48, et Festugière, Dieu cosmique, p. 280-281, 395-398 et 423-424) ; sur l'énu-

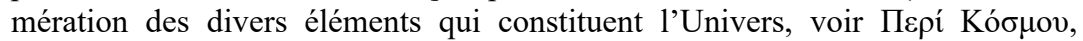
$391 \mathrm{a}$ et 392b, Sénèque, Q.N., I, praef. 9; Maxime de TYr, 23, 6; c'est que pour les stoïciens toutes les parties de l'Univers sont en étroite relation (ID., ibid.,, p. 278, p. 333 sq., p. 418) et que le monde est comparé à une «grande cité» (p. 273-279) avec des citations de Posidonius, Cicéron, Arius Didyme Philon, Sénèque, Plutarque et Dion de Pruse, que je cite, parce qu'il met plus que les autres l'accent sur les différences entre «la cité du monde» et les cités humaines et souligne ce qui les rapproche: principe de communauté et mode de gouvernement, Or. 36, 29-32: «Quant au point de la cité, voici comment il faut l'entendre. Ce n'est pas ouvertement que nos sages ont déclaré que le monde est une cité. Car cela eût été contre la définition qu'ils ont donnée de la cité, savoir, comme je l'ai dit, un ensemble d'êtres humains. En même temps, il n'eût guère été convenable ni croyable, après avoir déclaré proprement que le monde est un être vivant, de dire ensuite qu'il est une cité: car, selon moi, nul n'admettrait aisément que cité et être vivant soient identiques. Toutefois, comme l'Univers a été divisé et distribué en un grand nombre de catégories de plantes et d'êtres vivants mortels ou immortels, en celles aussi de l'air, de la terre, de l'eau et du feu, bien qu'il n'en conservât pas moins son unité naturelle en toutes ces parties et qu'il soit gouverné par une âme une et une puissance unique, on compare tant bien que mal l'actuelle ordonnance du monde à une cité, à cause du grand nombre d'êtres qui naissent et meurent dans le monde, et à cause de l'ordre et de la belle ordonnance du gouvernement divin. Par cette manière de dire, on s'est efforcé brièvement de conjoindre le genre humain au divin et d'embrasser en un seul mot toute la catégorie du raisonnable, parce qu'on ne trouvait que la cité pour être un principe de communauté et de justice solide et infrangible. Que le monde soit donc appelé une cité en ce sens. Elle jouit, par Zeus, de maîtres qui ne sont ni méprisables ni médiocres, elle a vécu un temps infini non pas dans les déchirements et les luttes intérieures que soulèvent tyrannies ou gouvernaments populaires, décarchies ou oligarchies et autres maladies pareilles, mais 
selon les deux axes que les astronomes retenaient dans leurs études du Cosmos: l'axe des pôles et du monde et l'axe absidial marquant le zénith; il a, rappelons-le, disposé les personnages selon des droites parallèles, perpendiculaires à l'axe des pôles, en trois registres, eux-mêmes définis par trois de ces droites.

Nous constaterons que, pour l'essentiel, les figures de Saeculum, Caelum, Polum, Aeternitas, Portus et Pharus s'inscrivent dans les deux triangles définis par ces deux axes. Aeternitas n'est pas isolé et ne jouit pas d'un traitement privilégié (727). Comme les autres figures, il n'est dans la mosaïque qu'une hypostase personnifiée, Aiôn/Aeternitas. Cet Aiôn ne renvoie pas au seul registre temporel $\mathrm{du}$ temps cyclique qu'expriment déjà Saeculum, Oriens, Occasus, les Saisons. Aeternitas n'est pas davantage Aevum/Aiôn, le temps éternel, représenté en vieillard sur la mosaïque d'Antioche. Aeternitas à Mérida est jeune $\left({ }^{728}\right)$, comme le génie de la mosaïque de Sentinum, comme le génie ailé du piédestal de la colonne Antonine. Comme eux, il symbolise plutôt la source de vie et d'éternité du Cosmos, la force vitale qui

au contraire dans le bon ordre, sous la monarchie la plus sage et la plus excellente, régie qu'elle est par un roi qui suit réellement la Loi en toute amitié et concorde: et c'est cela aussi que ce chef et législateur infiniment sage et digne de respect enjoint à tous de faire, mortels et immortels, lui-même prenant la tête et nous donnant, par sa propre manière de gouverner, l'exemple d'une constitution parfaitement heureuse. C'est lui que, instruits par les Muses, les divins poètes célèbrent dans leurs chants quand ils le nomment Père des dieux et des hommes».

(227) Voir supra, p. 50, pour l'importance de sa place au centre du pavement.

(728) Sur l'importance de la jeunesse dans la représentation $<$ TAiôn, outre le sens étymologique du mot (voir supra note 654), voir Hinks, Myth, p. 42. L'auteur souligne que l'Aiôn jeune ou sans âge n'a pas place dans l'iconographie des Olympiens, qu'il ne renvoie pas à une notion temporelle; il propose, quant à lui, une interprétation mithriaque ou orphique, mais son ouvrage est déjà ancien. D. LEVI, dans Hesperia, p. 311, souligne que l'image d'un Aiôn jeune se retrouve aussi dans les spéculations néo-platoniciennes et note la coexistence concomittante de divers types, p. 280, selon la symbolique à laquelle ils renvoient. R. TuRCAN, R.A., p. 314, note, allant plus loin, que l'on a donné à «l'Aiôn gréco-romain, qui personnifie le grand dieu cosmique, l'âme du monde éternelle et coextensive à l'Univers», le type facial d'Alexandre-Hélios (il suit sur ce point L. Vog E L, The Column, p. 34). 
est susceptible d'introduire l'immortalité dans la matière (729) et de vivifier éternellement le Vivant qu'est le Monde, en même temps qu'il garantit la permanence de l'Univers et l'identité des êtres qu'il contient $\left({ }^{73 \circ}\right)$. Mais cette hypostase, éternelle et coextensive à l'Univers, ne peut se concevoir sans le Cosmos, sans Natura, sans la révolution des astres et l'alternance des saisons. C'est une abstraction divinisée, de nom latin, mais dans sa conception assez proche de VAiôn grec qui est invoqué avec Physis par Mésomédès, l'affranchi d'Hadrien, dans un hymnee qui est en même temps une prière (731). Aeternitas n'est pas pour autant un dieu véritable, autonome, distinct du Cosmos, comme cela peut être le cas dans les écrits hermétiques (732); ce n'est qu'une personnification, parmi les autres, à laquelle sa postition de fron-

(729) Voir Corpus Hermeticum, XI, 3: «c'est pourquoi, rien de ce qui est dans le monde ne périra jamais, car l'Eternité est impérissable, ni ne sera détruit parce que le monde est tout enveloppé par l'Eternité... L'Eternité fait du monde un ordre en introduisant l'immortalité et la durée dans la matière» et 4: «Et toutes ces choses subsistent par le moyen de l'Eternité. Et tout ce grand corps dans lequel se trouvent contenus tous les corps, une âme pleine de l'intellect et de Dieu le remplit à l'intérieur et l'enveloppe à l'extérieur, vivifiant le tout, à l'extérieur ce vaste et parfait vivant qu'est le monde, à l'intérieur tous les vivants et en haut le ciel, elle dure sans changer, identique à elle-même, tandis qu'en bas sur la terre, elle produit les variations du devenir» et Festugière, Dieu inconnu, p. 142, 152 sq..

$\left({ }^{73^{\circ}}\right)$ C'est l'idée stoïcienne fondamentale de Sympathie, voir REINhardt, Kosmos und Sympathie, p. 111-112 et Festugière, Dieu Cosmique, p. 418-420. Chez les stoïciens, c'est le logos divin qui est «la force immanente au Cosmos, le souffle ou le feu qui réside en tous les êtres, ici principe de cohésion, là principe de liaison organique et de développement naturel, ailleurs principe de mouvement autonome et de sensibilité, ailleurs enfin principe raisonable en sorte que le monde tout entier soit pénétré d'une même Raison». Ce Logos divin ne se confond plus comme dans l'hymne de CLÉANT He avec Zeus, mais au II' siècle avec l'Aiôn (cf TurCAN, $R A, \mathrm{p} 314$ ).

(731) Voir Collectanea Alexandrina, éd. J. U. Powell, no 35, p. 197,

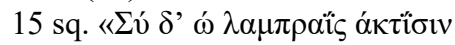

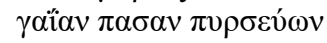

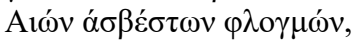

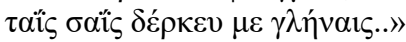

Voir aussi la relation établie entre ques (cf. Festugière, Dieu inconnu, p. 185).

(732) Voir Festugière, Dieu inconnu, p. 159-175. 
talité et sa place centrale dans la composition confèrent une importance majeure.

Ainsi, ce que la mosaïque de Mérida donne à voir n'est pas VAiônlAeternitas, c'est le monde dans sa totalité. Aeternitas n'est qu'une des caractéristiques divinisées du Cosmos. Seul le Cosmos est divin, seul il est immortel. Cette représentation renvoie, comme l'hymne de Mésomédès et les Pensées de Marc Aurèle, à une conception stoïcienne de l'Univers ( $\left.{ }^{733}\right)$, conception dont sont également nourries la théologie mithriaque et la gnose hermétique.

Dans la mosaïque de Mérida - nous l'avons souligné à plusieurs reprises - le monde est représenté comme beau, comme bon, comme prospère, comme ordonné, comme éternel, comme parfait et l'on peut comprendre, à regarder ce tableau, que le sage stoïcien, contemplant le monde, y ait découvert la loi de son créateur et l'ait adorée ( $\left.{ }^{734}\right)$. La mosaïque de Mérida nous aide à admettre,

(733) Voir Festugiè Re, Dieu cosmique, plus particulièrement p. 310-350. Soulignons l'importance de l'hymne à Zeus de CLEANTHE, cité p. 311-313 et dans Powell, p. 227, et notons que le thème de l'ordre du monde et la conception du monde comme temple de Dieu sont devenus un lieu commun au Ier siècle de notre ère (voir MANILIus 1, 20-24: «bina mihi positis lucent alteria flammis, ad duo templas precor duplici circumdatus aestu carminis et rerum: certa cum lege canentem mundus et immenso vatem circumstrepit orbe vixque soluta suis immittit verba figuris» et encore Dion, Or. 12, 33-34; Mor. 477 C; Plutarque, De la tranquillité de Vâme, 20). Cette contemplation du Cosmos est acceptation de sa loi: «Guide-moi, ô Zeus, et toi, ma destinée, vers cette place que vos décrets m'assignent, je suivrai sans murmure» (Powell, p. 229, n $^{\circ} 2$ ) et, excepté chez Aratos, révélation du créateur, ibid., p. 340. Sur le lien entre le Logos stoïcien et le mithriacisme, voir J. Dillon, J.M.S., II, 1, p. 80 et sans nom d'auteur, J.M.S., II, 2, 1978, p. 241-242.

(734) Voir Fes Tu Gière, Dieu cosmique, p. 331-335. L'auteur souligne, que pour les âmes plus méditatives, le consentement à l'Ordre Universel pouvait facilement se tourner en prière et en union à Dieu - tel fut le cas chez Cléanthe, chez Vettius Valens, chez Ptolémée; c'est la contemplation esthétique, que suscite la vue du Cosmos qui fait naître le sentiment religieux. Il en est de même chez Manilius, 4, 96: «Pourquoi Dieu se montre-t-il à nous, dans le Ciel, pourquoi s'offre-t-il, se jette-t-il en quelque sorte au-devant de nous, si ce n'est pour se faire bien connaître?» et chez Dion de Pruse, Or. 12, 28: «Puisque les hommes... sont par nature en plein milieu de Dieu sur la terre», chez Maxime de TyR, 22, 6, quoiqu'on ait parfois mis l'accent sur son rationnalisme (Cra me r, Astrology, p. 197): «Les spectacles qui s'offrent au philo- 
plus facilement que des textes, par sa beauté même ( ${ }^{735}$ ) que le spectacle du monde ait suscité une véritable mystique et que l'adoration du Cosmos ait pu s'intégrer dans la théologie de nombreux cultes $\left.{ }^{736}\right)$. Elle nous oblige à reconnaître que l'éloge de l'Univers n'est pas, comme on a trop facilement tendance à le dire, en parlant de textes littéraires, fadaise rhétorique $\left({ }^{737}\right)$. Ce tableau témoigne de l'adhésion profonde que suscitait la foi dans l'Eternité du monde et nous incite à lire autrement des textes qu'on a l'habitude d'écarter dédaigneusement. Mais la contemplation du philosophe stoïcien, pour mystique qu'elle soit, n'est pas une fuite hors du temps ou $\mathrm{du}$ monde: «le vrai sage cherche à reproduire dans sa conduite et

sophe, à quoi les comparer? A uu songe... dont les images mouvantes nous environnent de tout côté, un songe où le corps n'est nulle part convié à venir, mais où l'âme s'élance sur toute la surface du globe, puis de notre sol au ciel, où elle traverse toute la mer, parcourt toute la terre, franchit dans son vol toute l'étendue de l'air, où elle accompagne le soleil et la lune dans leur voyage circulaire, où elle s'unit au choeur de danse des autres astres et se fait presque la compagne de Zeus pour gouverner et ordonner tout l'ensemble des êtres. O bienheureuse course, ô spectacle merveilleux, ô songes pleins de vérité!»

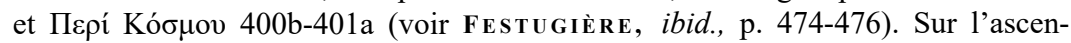
sion de l'âme dans le Cosmos, ibid., p. 444-446 et 452, et le témoignage de Philon, Spec., I, 34-35: «Eh bien donc, celui qui entre dans ce monde qui est vraiment la Grande Cité, quand il a vu montagnes et plaines regorger d'animaux et de plantes, le cours des rivières nées de sources ou de pluies d'hiver, les mers largement épandues, les climats bien tempérés de l'air et les changements des saisons annuelles, puis le soleil et la lune qui président au jour et à la nuit, les circuits et les évolutions des autres astres errants et fixes et du ciel entier, n'est-il pas vraisemblable, n'est-ce pas de toute nécessité qu'on en viendra à la notion du Créateur, du Père, et aussi du Souverain Maître de ces choses? Car aucun produit de l'art ne se fait tout seul; or le monde est l'ouvrage où se voit le plus d'art et de science, en sorte qu'il a été fabriqué par le plus savant et le meilleur des artisans. Voilà comment nous avons acquis la notion de l'existence de Dieu».

(735) Il faudrait pouvoir faire l'étude de la palette du mosaïste et de son art d'utiliser les couleurs aux divers registres.

(78ß) $\mathrm{v}_{0} \mathrm{j}_{\mathrm{r}}$ Levi, Hesperia, p. 307; Festugière, Dieu Cosmique, p. 537. Pour le mithriacisme, voir Merkelbach, Die Kosmogonie, p. 227 et pour le judaïsme, voir les protestations de FLA VIUS Jos È PHE, citées supra, note 404.

( ${ }^{737}$ ) Même lorsque cela peut paraître un lieu commun, voir FESTUGIÈRE, Dieu Cosmique, p. 517 et surtout p. 233, où perce un certain mépris pour Dion de Pruse et Dieu Inconnu p. 265.

Conimbriga, 19 (1980), 5-127 
dans la gestion des affaires de sa cité ou de l'Empire l'ordre divin et éternel de l'Univers dont il veut respecter la loi. Contemplant l'éternité du monde, la promouvant quotidiennement dans sa vie personnelle, il participe déjà de l'ordre cosmique de son vivant et peut espérer atteindre, après sa mort, à l'éternité panthéistique» $(73 * * 738)$. C'est là une attitude mentale toute différente de celle qu'adopte le fidèle de Mithra $\left({ }^{739}\right)$ ou le gnostique païen, même dans l'hermétisme philosophique $\left({ }^{740}\right)$. Si la disposition du fidèle est différente, si nous ne devons pas, malgré les syncrétismes $\left({ }^{741}\right)$, confondre YAiôn mithriaque, YAiôn hermétique, YAiôn de la cosmologie stoïcienne, ces diverses conceptions d'Aiôn renvoient

(73S) Voir Turean, R.A., p. 315.

(739) Selon Gampвetl, Mithraic Iconography, Mithra est non seulement Kosmocrator mais aussi créateur et démiurgue, de là vient que le Mithraeum est conçu comme une réplique du Cosmos (p. 49 et 119) et Turcan Mithras Platonicus, p. 37, commentant Fantre des Nymphes de Porphyre: «Si le monde est un temple, réciproquement tout «temple» de Mithra est une image du monde, non pas seulement comme séjour ténébreux, mais en tant que symbole de l'ordre divin, diakosmèsis, à la fois obscur et charmant à l'égal de l'antre homérique. Le décor peint ou sculpté des Mithraea, la cape étoilée $\mathrm{du}$ Dieu, les zodiaques ornant l'orbe des arcosolia au-dessus du Tauroctone faisaient de ces antres les chapelles d'un culte cosmique». Mais dans le Mithraeum, le fidèle n'est pas appelé à la contemplation, il devient un «soldat du bien» soumis à un cursus très hiérarchisé (voir R. L. Goroon, Mithraism and Roman Society, dans Religion, II, 1972, p. 100 sq.). Mithra participe à l'oeuvre salutaire du créateur, sans se confondre avec lui (cf. Turcan, Mithras Platonicus, p. 88). Sur les rapports de force qui s'établissaient entre le Pater et les fidèles et sur le Mithriacisme comme religion d'obéissance, voir H. LAVAGNE, M.E.F.R.A.. p. 1140-1141.

$\left(74^{\circ}\right)$ Festugière, dans Hermétisme et mystique, p. 75-90, souligne que la différence essentielle entre le sage stoïcien et le gnostique païen consiste en ce que le sage a toujours regard au tout et accepte les difficultés de sa vie personnelle en contemplant l'ordre et l'harmonie du Cosmos; il est volontairement optimiste, au contraire le gnostique a surtout regard sur lui-même.

Le monde lui paraît mauvais mais il cherche à y découvrir Dieu et à s'unir personnellement à lui; il est naturellement pessimiste. Sur les divers aspects de la mystique hellénistique, voir encore ID., Cadre de la mystique hellénistique, dans Mélanges Maurice Goguel, Aux sources de la tradition chrétienne, Paris, 1950, p. 74-85.

${ }^{(741)}$ Ces syncrétismes caractérisent la vie religieuse aux IIe et III ${ }^{\mathrm{e}}$ siècles de notre ère. Voir Turcan, Mithras Platonicus, p. 129, pour «la projection des doctrines grecques sur un mithriacisme déjà fortement occidentalisé». 
toutes cependant à une même représentation mentale de la force vitale de l'Univers. Ainsi la mosaïque de Mérida fait comprendre combien était vive sous l'Empire la foi en l'Eternité, au point que celle-ci a pu sembler, comme le rappelle A. J. Festugière, constituer sous des formes diverses «la seule religion vivante des élites» $\left({ }^{742}\right)$.

\section{F) Le culte de l'Eternité du Monde et le culte de IEternité de Rome}

A. Blanco-Freijeiro ( $\left.{ }^{743}\right)$, à la différence de G. Ch.-Picard( $\left.{ }^{744}\right)$, a insisté sur la valeur idéologique d'Aeternitas dans la mosaïque de Mérida. Toutefois, n'allons pas croire que la présence des deux légendes Saeculum et Aeternitas ( $\left.{ }^{745}\right)$, malgré l'importance de leur diffusion sur les monnaies au $\mathrm{II}^{\mathrm{e}}$ siècle, puisse donner un caractère officiel à ce pavement.

Sans être totalement différente du génie ailé $\mathrm{du}$ piédestal de la colonne antonine ${ }^{(746)}$, Aeternitas n'est pas, à Mérida, une figure d'apothéose ni de consécration, elle n'émane pas de l'imagerie de la cour impériale. $\mathrm{Ni}$ dans sa conception iconographique, ni dans sa signification symbolique, la figure d'Aeternitas ne me

(742) Voir, après Levi, Hesperia, p. 307 et 311, Festugière, Hermétisme et mystique p. 75.

(743) BLANCO-FreIJEIRo, p. 175-178.

(744) G. Ch. Picard, Mosaïque cosmologique, p. 121, refuse l'hypothèse de A. Blanco-Freijeiro, mais souligne lui aussi combien lui paraît fondamentale «l'idée d'Eternité, symbolisée par les figures de Saeculum et d'Aeternitas».

$\left({ }^{745}\right)$ G. Ch. Picard, comme A. Blanco-Freijeiro, se réfère implicitement à la définition des deux termes donnée par J. GAGÉ dans Le Templum Urbis, p. 176-177, «au fond du culte de l'Eternité de Rome tel qu'Hadrien l'instituait, il y a la notion religieuse de l'Aiôn, répandue dans l'Empire sous les formes les plus diverses, seulement philosophiques ou inscrites dans un rituel positif... Les conditions mêmes du vocabulaire faisaient que pour les Romains cette notion représentait nécessairement à la fois l'idée de l'Eternité, c'est à dire du temps infini et celle du renouvellement périodique; Atóv était traduit en latin par ces deux termes Aeternitas ou Saeculum».

( $\left.{ }^{746}\right)$ Même jeunesse atemporelle, même nudité, même coiffure, même regard perdu dans l'infini. 
semble refléter une influence directe de l'idéologie impériale officielle. S'il y a fonctionnement idéologique de l'image et de la légende, cela ne peut s'expliquer qu'autant que le culte du Monde et de l'Éternité de la Loi cosmique a pu s'identifier, de bonne heure, au culte de Rome et à la permanence de son pouvoir $\left({ }^{747}\right)$. Témoigne de ce phénomène la très célèbre inscription d'Eleusis qu'on date de l'époque d'Auguste (748) et qui a été gravée sur la base d'une statue d'Aiôn disparue aujourd'hui. Elle dit: «Pour la domination de Rome et la permanence des mystères, Aiôn qui, par sa nature divine, demeure toujours identiquement le même et qui tout ensemble est le Monde unique, de quelque nature qu'il existe, a existé, existera, qui n'a ni commencement ni milieu ni fin, qui ne participe pas au changement, qui produit la nature divine absolument» $\left({ }^{749}\right)$.

Au-delà des formules stéréotypées, nous retiendrons que VAiôn d'Eleusis est, plus que ne l'est Aeternitas dans la mosaïque de Mérida, une personne divine autonome, qu'il est assimilé au monde, ce qui lui donne un sens spatial que n'a pas Aeternitas à Mérida, mais comme Aeternitas, YAiôn d'Eleusis dépasse la notion de durée infinie, il est une force active immuable, une force de vie qui produit la vie éternelle.

Dans son Eloge de Rome, c'est bien la même force de vie que célèbre Aelius Aristide en demandant que «l'Empire vive et fleuris-

$\left({ }^{747}\right)$ Le stoïcisme a permis cette assimilation; voir Diogène Laerce, $7,88=$ S.V.F., I, 162, p. 43, 1, qui attribue cette opinion à Zénon: «La loi est universelle, c'est la droite Raison qui pénètre en toute chose et qui est identifiée à Zeus, lequel préside au gouvernement de l'Univers. D'où il résulte que, malgré la diversité des lois positives et des religions civiques instituées par ces lois, il n'y a en fait qu'une seule Loi et un seul Dieu, communs à tout l'Univers»; cf. F E S T U G İ̀ Re, Dieu Cosmique, p. 309 et 459.

(748) Voir Syll. ${ }^{3}, 1125$ et F ES T U g İ̀ Re, Dieu Inconnu, p. 180-182. La statue avait été sculptée par un certain Kóïv $\tau$ os По $\mu \pi$ ríios.

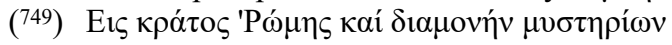

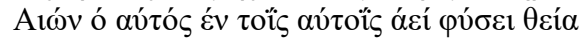

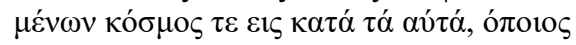

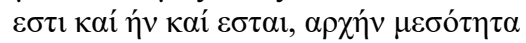

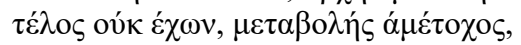

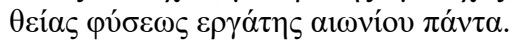


se à jamais» $\left.\left({ }^{750}\right)\right)$. Comme nous l'avions constaté à propos des vents et des saisons, nous pouvons remarquer, une fois encore, $\psi Y$ Aeternitas renvoie dans la mosaïque de Mérida, comme Aiôn à Eleusis, à plusieurs registres: cosmologique, philosophique, religieux et politique. La cosmologie fait sous l'Empire partie intégrante de l'idéologie et cela, sans qu'il y ait intervention directe du pouvoir central.

$\mathrm{Ne}$ faut-il pas distinguer en effet, du point de vue de l'idéologie, ce qui est propagande volontaire des milieux officiels dont témoignent monnaies et monuments officiels et ce qui est idéologie diffuse, fonctionnement des superstructures, ou simple reflet intériorisé des structures du pouvoir en place dans les conceptions philosophiques et religieuses et dont la mosaïque cosmologique de Mérida semble être une très belle illustration?

Il n'est pas besoin de supposer ici une influence de l'iconographie officielle. La représentation d'un monde ordonné et harmonieux suppose l'existence d'une loi universelle et selon Dion de Pruse (751) d'un gouvernement monarchique de l'Univers. Cette loi, qui fut d'abord assimilée à la loi civique, s'est identifiée aux premiers siècles de l'Empire à la loi de Rome et à la volonté du Souverain, tout comme le Corpus imperii qui avait d'abord été étendu à Yoikouméné a pu être défini par Aelius Aristide comme «une seule cité», comparé «au port commun de l'Univers» ( ${ }^{752}$ ) et par analogie implicitement assimilé à «la grande cité» que constituait le Cosmos pour les stoïciens $\left({ }^{753}\right)$. Aussi ne nous étonnons pas de ce que l'Empiie subisse la loi de la sympathie universelle et que l'Empereur puisse apparaître comme le garant de l'ordre

$\left(7^{\circ}\right)$ Voir supra, notes 253, 257.

(751) Dion, Or. 36, 29-32 cité supra, note 726. Cf. Festugière, Dieu Inconnu, p. 279: «La morale stoïcienne est en dépendance immédiate d'une doctrine du monde, c'est à dire d'une explication universelle de l'ordre total des choses. Le logos divin qui pénètre en tous les êtres se manifeste dans l'être humain, comme intellect. Dès lors l'homme est capable de connaître la Raison divine, qui se définit comme la loi de la cité du monde».

(752) Voir supra, notes 137 et 140.

(753) Voir Fest U Giè Re, Dieu Inconnu, p. 272-276 sur la «cité du monde» qui comprend Yoikouméné et les régions de l'éther; nombreures références dans S.V.F., II, 1127; 1131; 528; 1010; 645; 1130; III, 337. 
cosmique, en «Restitutor orbis terraru» ${ }^{754}$ ). Toucher à l'équilibre dont la nature donne l'exemple, c'était toucher à l'ordre du monde et mettre en péril son éternité. Nous pouvons penser que les souverains surent exploiter cette foi dans l'ordre du monde et user de légendes et d'attributs cosmiques dans leur propagande monétaire ( $\left.{ }^{755}\right)$, mais la convergence des légendes et des images n'implique pas nécessairement qu'il faille supposer dans chaque cas, pour la réalisation d'un monument où apparaissent les figures à'Aeternitas ou de Saeculum, une impulsion venue de Rome.

Nous noterons seulement, après J. Gagé (756), que «le culte de l'Eternité de Rome et le culte de l'Eternité de l'Emj)ire se sont développés parallèlement à l'expansion du culte de VAiôm) et nous ajouterons, à celle du culte du Monde.

L'art de Rome consiste à avoir su inscrire son culte dans une conception élaborée par la Stoa qui permette de voir dans l'Empire de Rome la projection sur le plan humain de l'ordre cosmique ( $\left.{ }^{757}\right)$.

(7M) Voir StaCE, Silves, IV, 3, 134-138; pour l'assimilation Dieu = 1 Empereur - La Nature, les 4 discours de Dion, Sur la Royauté. Pour le rôle d'Hadrien, voir Hinks, Myth, p. 76 et Toynbee, Hadrianic School, p. 24 et de façon générale Festugière, Dieu Cosmique, p. 309.

$\left.{ }^{75 S}\right)$ Pour leur importance sous le règne d'Hadrien et d'Antonin, voir supra, notes 647-650.

(75e) GaGÉ, Le Templum Urbis, p. 176.

(757) Voir G. Ch. Piearo, L'Art Romain, p. 85.

Conimbriga, 19 (1980), 5-127

6 


\section{LIVRE III}

\section{LA SIGNIFICATION CULTURELLE DE LA MOSAÏQUE}

\section{CHAPITRE I}

\section{LECTURE D'ENSEMBLE DE LA MOSAÏQUE}

$\mathrm{Au}$ terme de cette étude, nous pouvons regarder avec plus de certitude l'ensemble du tableau. Il subsiste bien évidemment des points qui font encore question $\left({ }^{758}\right)$. Nous avons pu cependant identifier de façon certaine la plupart des personnages représentés sur le pavement ou disparus dans la lacune et nous pouvons proposer de la mosaïque plusieurs approches: lecture cosmologique, lecture philosophique et religieuse, lecture rhétorico-idéologique, qui pouvaient être celles des Anciens, lecture plus moderne par une approche critique de caractère historique qui devrait nous permettre de préciser l'importance culturelle de la découverte de ce pavement à Mérida.

\section{Lecture cosmologique}

La vision de l'Univers qui est proposée dans la mosaïque de Mérida est très ordonnée. On pourrait dire que chaque personnage est à sa juste place et ne peut en changer, comme cela est écrit dans le Corpus Hermeticum ( $\left.{ }^{759}\right)$ : «Si tous les êtres sont en mouvement, les uns dans le ciel, les autres sur la terre, ni ceux qui doivent être à droite ne vont à gauche, ni ceux qui doivent être à gauche ne vont à droite, ni ceux qui doivent être en haut ne vont en bas ni ceux qui doivent être en bas ne vont en haut...» La

(758) Question iconographique: quelle est l'origine et la date du vêtement de l'enfant-attribut de l'été?

${ }^{(759)}$ C.H., XI, 8. 
mosaïque de Mérida est bien étagée dans l'espace et organisée selon trois registres - céleste, terrestre, maritime *- qui découpent trois zones parallèles perpendiculaires à l'axe des pôles et du monde (pi. XII). Les quatre vents Eurus, Notus, Zephyrus, Boreas sont disposés selon les quatre points cardinaux d'une rose des vents très simplifiée. La mosaïque est, par ailleurs, orientée de chaque côté de l'axe absidial selon la trajectoire de gauche à droite des luminaires. A gauche, le soleil, l'Est et le Sud; à droite, la lune, le Nord et l'Ouest. Nous avons montré que, correspondant à Autumnus et Aestas, à Euphrates et Nilus, situés à gauche, devaient f) gurer à droite, dans la lacune, le printemps, Ver et l'hiver, Hiems, un fleuve de l'Ouest - Anas, Tagus, ou peut-être même Eridanus - et un fleuve du Nord — Ister ou Tanais. En position symétrique à celle de Natura, sans doute Tellus et peut-être à proximité une île, un lac, un continent, une acropole. Nous avons reconnu comme le Nil, le fleuve situé à côté de Portus ; comme l'Euphrate, celui qui est placé à côté de Natura. Nous reconnaissons en l'enfant placé au-dessus de Nilus, un putto, fruit de la terre qui redouble le thème de l'été auquel il donne la main. Saeculum exprime, dans la mosaïque, la notion d'Eternité conçue comme le renouvellement périodique des cycles cosmiques. Aeternitas est YAiôn conçu comme la force vitale du Cosmos qui introduit l'éternité et l'identité dans la matière. A côté de Caelum, nous plaçons, non la Nuit, mais Providentia ou Concordia comme allégorie de la grande Loi de l'Univers.

Nous avons remarqué l'absence de plantes, d'animaux, d'êtres humains, comme on en trouvera en grand nombre dans les représentations de la terre peuplée par Dieu des mosaïques de pavements des synagogues et des églises chrétiennes des IVe, $\mathrm{V}^{\mathrm{e}}$ et $\mathrm{VI}^{\mathrm{e}} \operatorname{siècles}\left({ }^{760}\right)$. Mais assurément, c'est bien l'Univers qui était représenté à Mérida avec le ciel et Voikouméné, et c'est bien Yoikouméné tout entière

$\left(7 \beta^{\circ}\right)$ Voir A. Grabar, Cahiers Arch., 12, p. 117-126 sur l'importance des rinceaux habités dans les mosaïques des synagogues et des églises primitives comme héritage hellénistique et p. 141-148 sur la représentation de la terre et du firmament dans les mosaïques de pavement des synagogues dès le III e siècle et des églises à partir du $\mathrm{IV}^{\mathrm{e}}$, dans les provinces orientales de l'Empire. Voir G. Cvetrovic Tomasevic, Une mosä̈que du Ve siècle, de Héracléa Lynkestis, p. 367-368. 
qui était figurée et non une région privilégiée de l'Orient destinée à apaiser la nostalgie d'un Syrien exilé $\left({ }^{761}\right)$. L'Oronte n'a pas sa place ici.

Ainsi reconstituée la mosaïque offre une vision de l'Univers tout à fait comparable à celle des textes littéraires qui font l'éloge $\mathrm{du}$ Cosmos (762). Elle est donc susceptible, à un premieî niveau, d'une lecture cosmologique qui nous permet de proposer, pour Y emblema, le schéma suivant:

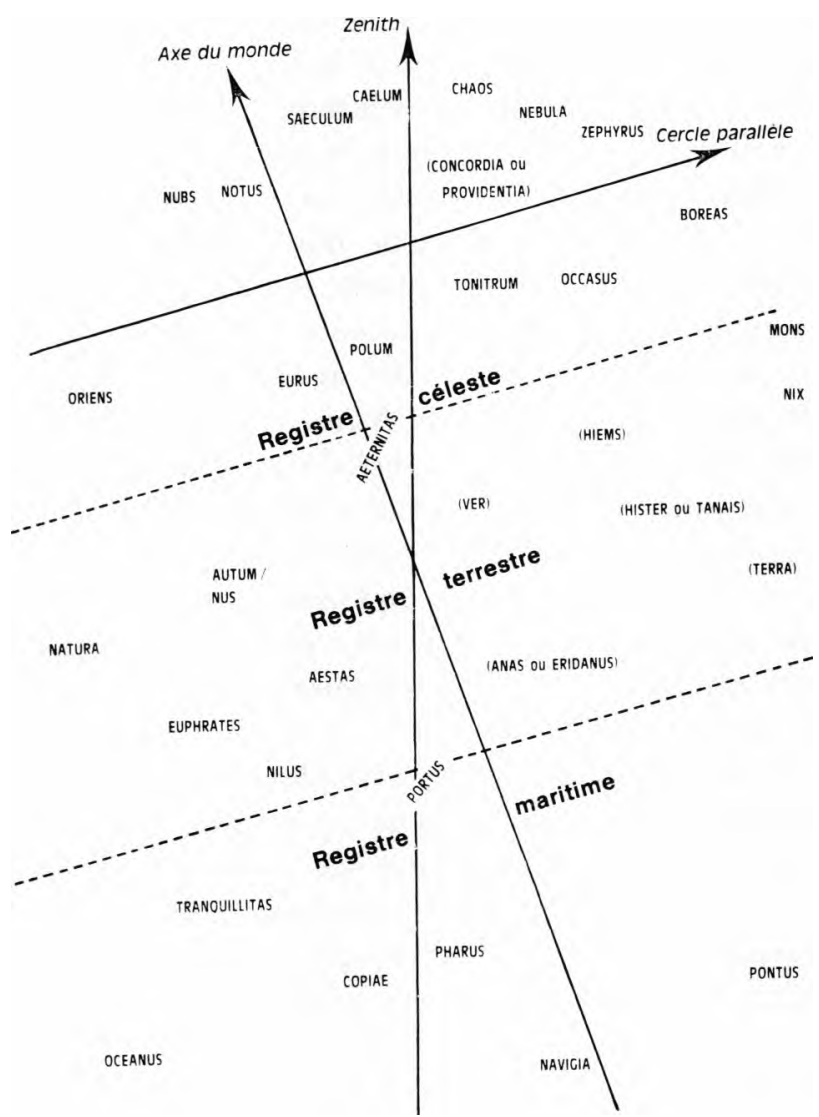

(761) Yoir supra I,p. 11 et G. Cн. PICARD, Mosaïque Cosmologique, p. 124, même si le thème de la représentation du Cosmos est assurément hellénistique et oriental; voir infra, p. 96.

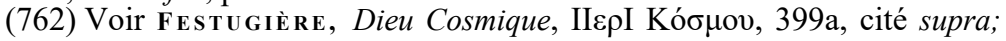
Philon, de praem., 7, 41-42: «D’autres, par leur science, ont bien été capables 


\section{Lecture philosophique et religieuse}

Mais la mosaïque de Mérida fait plus qu'enseigner des notions justes sur la structure du ciel et du Cosmos, sur l'extension de $V$ oikouméné. Elle n'est pas une représentation à caractère didactique comme une sphère armillaire ou une carte de géographie.

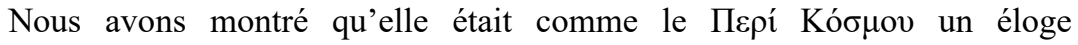
du Monde. Comme ce texte et les autres ouvrages du même genre, la mosaïque de Mérida a une fonction protreptique d'initiation à l'ordre et à la perfection du Cosmos.

Elle parle, en effet, à la fois à l'oeil et à la raison. Du regard, celui qui la contemple, parcourt l'océan, les mers, les fleuves, les montagnes, les ports, découvre l'oeuvre des saisons dans la nature et passe en un rien de temps de la terre au ciel et jusqu'aux extrémités de l'Univers; il embrasse d'un seuJ coup d'oeil l'Est et l'Ouest, le Nord et le Sud et, parvenu là, ayant levé les yeux vers l'éther il contemple le soleil et la lune... le lever et le coucher des astres $\left({ }^{763}\right) \ldots$ Mais ce spectacle n'est pas seulement un plaisir

de se représenter le Créateur et le Chef de PUnivers, mais selon le proverbe, ils ont suivi la route de bas en haut. Car, étant entrés dans ce monde comme dans une cité bien organisée, ils ont vu la terre florissant dans ses montagnes et ses plaines, remplie de plantes, d'arbres et de fruits ainsi que d'animaux de toute espèce; répandus sur la terre, les flots de la mer, des lacs ou des fleuves, tant de ceux qui jaillissent d'une source que de ceux que grossissent les pluies d'hiver; l'heureux tempérament de l'air et des vents; la succession harmonieuse des saisons annuelles; et, au-dessus de tout cela, le soleil, la lune, les planètes et les astres fixes, le ciel entier avec son armée d'étoiles bien disposées rang par rang, ce ciel qui accomplit sa révolution comme un vrai

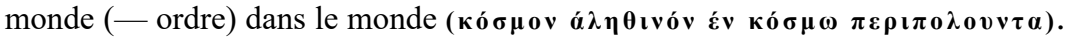
Dès lors, frappés d'admiration et de stupeur, ils en sont venus à l'idée, en conséquence de ce spectacle, que de si grandes merveilles et un ordre si extraordinaire n'ont pu être l'effet du hasard, mais qu'ils sont dus à un Artiste fabricateur du monde, qui est nécessairement une Providence: car c'est une loi de nature que le Créateur prenne soin de l'objet qu'il a créé», (ibid.,, p. 231) et SÉNÈ QUE, Quest, nat. I, praef., 9, (ibid., p. 454).

(763) Cette énumération est à la fois description exacte de la mosaïque et exemple littéraire type: voir Festugière, Dieu Cosmique, p. 230-232 et p. 556-557. 
pour les yeux, il est aussi, comme l'a souligné plusieurs fois admirablement $\mathrm{Phi}^{\wedge}$ on $\left.{ }^{764}\right)$, une découverte pour l'intelligence: «Une fois que notre oeil a montré ce spectacle à notre intellect, celui-ci, après avoir saisi, grâce à la vue, ce phénomène qu'il ne pouvait voir de lui-même, ne s'arrête point aux objets sensibles. Non, comme il aime à s'instruire, et qu'il est épris de beauté, dans la joie que lui donne le spectacle, il conçoit le raisonnement vraisemblable que ces choses ne se sont pas produites d'elles-mêmes par des mouvements irrationnels mais qu'elles sont dues à la pensée d'un Dieu qu'il est permis de nommer Père et Créateur» (765). Dion de Pruse $\wedge^{\wedge}$ 'explicitait pas aussi clairement la relation entre la vue et l'intellect mais le spectacle du Cosmos était bien pour lui ( $\left.{ }^{766}\right)$ comme pour Plutarque $\left({ }^{767}\right)$ «une véritable initiation», dans le «grand temple qui est le monde», «une fête» où se révélait «le chef suprême qui préside à l'ensemble et qui guide le ciel tout entier et le monde, tel un habile pilote dirigeant un navire parfaitement appareillé et paré de tous ses agrès»».

De fait, si la mosaïque parle au regard, par le nombre et la beauté de ses figures, elle signifie aussi par ses images. Nous retiendrons que Dieu est, selon Dion de Pruse, le pilote qui dirige le Navire; «Dieu ressemble encore», s'il est permis de reprendre la

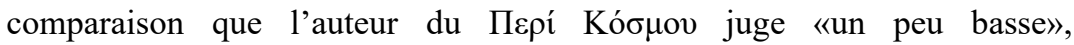
«à ce qu'on appelle la clef de voûte dans les cintres, laquelle située au milieu du cintre, au point de jonction des deux parties, conserve en équilibre et en bon ordre toute l'architecture du cintre et lui assure la stabilité» ( $\left.{ }^{768}\right)$. On ajouterait volontiers, qu'il est, sur Je

( ${ }^{764}$ ) Le thème de la supériorité du sens de la vue pour mener à la philosophie vient du Timée $47 \mathrm{a}-\mathrm{c}$, mais il a été aussi utilisé par Cicéron, De nat. Deor., II, 37, 95 et admirablement exploité par PніLоN, Abr. 156-164, Spec. Ill, 134 et 185-191, De praem. 7, 41-42, Leg. Meg. Ill, 32 et 97-99.

(7ß5) Рнilon, Spec., Ill, 188-189.

(766) voir Supra, I, p. 75-78 et Or. 12, 32-34, à la différence de ce qu'il représente pour Marc AuRÈLe, Pensées, VI, 36 où le voyage à travers le monde est une occasion de mépris pour la petitesse de l'Asie, de l'Europe, du mont Athos...

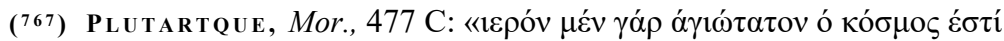

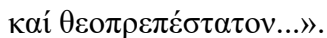

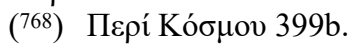


mode métaphorique, «le phare de salut», comme plus tard le Christ sur la mosaïque de Qars el Lebia $\left({ }^{769}\right)$, qu'il est le port $\left({ }^{770}\right)$.

Au-delà de la découverte intellectuelle de l'existence du Dieu invisible et de l'acceptation de la grande Loi de sympathie qui régit l'Univers, la mosaïque de Mérida, par sa composition étagée, par la circulation à tous les registres des regards et des mouvements, par l'égale importance accordée au centre et à la périphérie, par la richesse des couleurs, suscite une émotion esthétique que l'on éprouve, aujourd'hui encore, malgré l'importance de la lacune. Elle pouvait faire naître un enthousiasme religieux et, transportant l'âme dans une sorte d'anabasis cosmique ( ${ }^{771)}$, lui permettre d'accéder à la plénitude d'un bonheur quasi-mystique ( ${ }^{772}$ ), qu'évoquent assez bien Maxime de Tyr, Ptolémée, Vettius Valens ( ${ }^{773) .}$

(7ק») Yoi $\mathbf{i}_{\mathrm{r}}$ supra, $1_{5}$ p. 65-66 et M. Guarduccı, Gasr Elbia, p. 669 et 673 , pi. VI, fig. 1 et 2 .

$\left(77^{\circ}\right)$ Yoi $_{\mathrm{r}}$ Sextus Empiricus cité par Festugière, Dieu Cosmique, p. 230, dans une comparaison: «De même que si un homme qui a l'expérience des bateaux, dès qu'il a vu de loin un bateau ... comprend qu'il y a quelqu'un qui dirige la marche du bateau et le mène au port désigné; de même aussi quand les hommes qui les premiers levèrent les yeux vers le ciel eurent contemplé le soleil accomplissant sa course de son lever à son coucher ainsi que la belle ordonnance... ils se mirent à rechercher l'artisan de cet ordre splendide, conjecturant que cet ordre n'était point dû au hasard mais qu'il dépendait d'un être supérieur et immortel, qui est Dieu».

(771) Sur l'ascension de l'âme dans le Cosmos, voir Festugière, Dieu Cosmique, p. 444-445 et 452-457.

(772) Sur la nature de ce mysticisme, voiries distinctions que fait FESTuGIÊEE dans Dieu cosmique, p. 331, et dans les Mélanges Goguel, p. 75-78. L'auteur souligne que «pour la contemplation panthéistique des stoïciens» qui relève d'un mysticisme intellectuel, assez abstrait, «la vision de Dieu est une fin en soi», p. 82 .

(773) Voir Festugière, Dieu Cosmique, p. 331; Dieu Inconnu, p. 265, où celui-ci cite l'épigramme célèbre de Ptolémée: «Je le sais, je suis mortel et ne vis qu'un jour. Mais quand j'aspire à rejoindre les astres dans leurs courses pressées d'un sens à l'autre du ciel, mes pieds ne touchent plus la terre mais, auprès de Zeus lui-même, je me nourris du breuvage des dieux» et Maхıмe DE Tyr $(22,6)$, sur le voyage de l'âme dans le Cosmos qui se conclut par ces mots: «ô bienheureuse course, ô spectacle merveilleux, ô songes pleins de vérité» et $(17,5)$ : «Quand elle voit le monde, l'âme prononce que tout est l'oeuvre de Dieu et elle est transportée d'amour pour l'artisan». 
Dès lors, on comprend que la contemplation puisse s'achever en hymne à l'Eternité de l'Univers, en prière qui ne s'adresse plus au Zeus hellénistique de l'Hymne de Cléanthe $\left.{ }^{774}\right)$, mais au Dieu unique et invisible qui, pour les stoïciens de l'Empire, n'était qu'une seule et même personne sous des noms divers ( ${ }^{775}$ ) et dont le Monde était le seul temple. Peut-être pourrions-nous ajouter que dans le Cosmos, vivifié par VAiôn, il ne semble pas y avoir de place pour la mort $\left({ }^{776}\right)$.

\section{Lecture rhétorico-idéologique}

Si la mosaïque de Mérida invite à la contemplation et au recueillement, elle n'en porte pas moins la marque de l'idéologie de l'Empire. Il y a loin, dira-t-on, de la mystique à l'idéologie, moins qu'il n'y paraît.

Bien évidemment, la mosaïque cosmologique - nous l'avons souligné à plusieurs reprises — n'exprime pas directement l'idéologie impériale. Le mosaïste ne répond ici à aucune commande officielle, il n'a pas même été influencé dans les types iconographiques qu'il a retenus par les choix de la cour impériale. G. M. A. Hanfmann a pu montrer que cela était le cas au contraire pour la patère de Parabiago et certaines mosaïques funéraires d'Itaiie $\left({ }^{777}\right)$.

(774) Voir supra, note 733 et la traduction de Festugière, ibid., p. 311-313.

(775) C'est là un lieu commun de la théologie stoïcienne, voir FestuGIÈre, Dieu Inconnu, p. 137 : «Ce Dieu unique porte ainsi une multitude de noms, car il en reçoit autant qu'il y a d'effets nouveaux dont il se montre la cause», et Dieu Cosmique, p. 516-517.

(776) L'idée est exprimée dans le Corpus Hermeticum, VIII, 1 et XI, 20 , p. $142,148,151$ et p. 162 note 49: «Tous les changements cosmiques obéissent à un ordre ; la rotation des astres, en les ramenant à leur point de départ, renouvelle les saisons; le soleil se couche pour un nouveau lever; il n'y a nulle part de mort absolue, mais un simple changement de forme». Voir aussi FestuGIÈ RE, Hermétisme et mystique, p. 318.

${ }^{(777)}$ Voir Hanfmann, Season Sarcophagus, t. I, p. 182 et t. II note 232, p. 82. L'auteur distingue trois phases d'évolution: les types iconographiques apparaissent d'abord dans la propagande impériale au début du II ${ }^{\mathrm{e}}$ siècle, puis se rencontrent dans l'art funéraire à Rome et en Italie, avant de se répandre dans l'ensemble de l'Empire après 180. La combinaison Tellus et les saisons caractériserait l'art impérial et ne serait pas attestée ailleurs avant le III siècle (voir aussi ibid., t. II, p. 143 note 81, p. 150, nos 151, 152). 
Ce tableau du Cosmos nous renseigne pourtant admirablement sur les représentations mentales des habitants de l'Empire: il montre comment, peut-être à son insu, le spectateur de la mosaïque cosmologique, à Mérida, pouvait unir dans une même contemplation le Cosmos et l'Empire, et comment le culte de l'Eternité de Rome a pu s'inscrire dans celui de l'Eternité du Monde.

Nous avons pu établir de nombreux rapprochements entre Y Eloge de Rome d'Aelius Aristide et la mosaïque de Mérida (778): nous n'y reviendrons pas. Rappelons seulement que le mosaïste, représentant au registre terrestre et maritime la terre habitée, a limité Yoikouméné aux frontières de l'Empire: l'Euphrate et non l'Indus ou le Gange représente l'Orient. Il a placé au centre du tableau Rome, le «Portus», vers lequel affluent toutes les richesses

- Copiae - de l'Univers et tout ce que produisent les Saisons, et les diverses contrées du Monde. Nombre de figures représentées sur la mosaïque — phare, navire, fleuves, soleil, lune, saisons sont employées fréquemment comme emblèmes monétaires $\left({ }^{779}\right)$, sous le règne des Antonins. Les légendes retenues par le mosaïste

- Aeternitas, Tranquillitas, Saeculum, sans doute Providentia sont en même temps diffusées par la propagande impériale. Elles renvoient toutes à la mystique de l'âge d'or qui caractérise le $\mathrm{II}^{\mathrm{e}}$ siècle. Quelques exemples particuliers nous permettront de préciser notre pensée:

Tranquillitas est ici, du point de vue iconographique, l'équivalent d'une Néréide compagne d'Océan; par sa légende elle évoque à la fois la galéné grecque qui caractérise le flot paisible et la figure monétaire qui proclame la paix des mers sur une monnaie d'Antonin le Pieux datée de 149/150 $\left({ }^{78^{\circ}}\right)$.

Saeculum - nous l'avons montré - exprime dans la mosaïque, $\mathrm{du}$ point de vue cosmologique, la notion de temps éternel conçu comme le renouvellement des cycles cosmiques et créé en même temps que le ciel, après la mise en ordre du chaos. Sur les monnaies, cette légende proclame la permanence de l'Age d'Or que chaque prince réinstaure en même temps qu'il proclame l'éternité de son

(77ß) Voir supra, I, p. 46-52 et notes 120-154.

(779 j Voir supra, notes 78, 94, 95, 207, 208 et 209. $\left({ }^{78^{\circ}}\right)$ Voir supra, note 75, et B.M.C., IV, n $^{\circ} 251$, p. 38, pi. 6, 13. 
pouvoir et la Felicitas Temporum, córame si la régularité des cycles de chaque règne pouvait correspondre à la régularité des cycles cosmiques ${ }^{781}$ ).

Tonitrum est un phénomène atmosphérique placé à côté de Caelum, mais la figure renvoie aussi, par le trait de foudre qu'elle brandit au foudre du Zeus de l'Hymne de Cléanthe et au moins de manière implicite à la foudre ailée qui est un emblème monétaire d'Antonin le Pieux et accompagne la légende Providentia ( ${ }^{782}$ ).

Caelum au sommet du cintre n'est pas seulement le ciel cosmique; il occupe la situation du Dieu invisible ordonnateur de

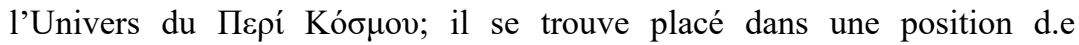
domination comparable à celle du Zeus de Nicée sur le bronze d'Hadrien (783), qui annonce elle-même le thème iconographique de l'Empereur trônant en majesté, si répandu au siècle suivant ( ${ }^{784}$ ). Or, depuis la fin du I ${ }^{\text {er }}$ siècle, on n'hésite pas à comparer le souverain au Dieu suprême. Pline va même jusqu'à féliciter Trajan d'avoir su «se montrer plus clément que le ciel» en «mettant en relation, par des échanges de convois de blé, l'Orient et l'Occident» et en répandant sur l'Egypte «les bienfaits de la Fécondité de la terre $\left({ }^{785}\right) »$.

Placé sous le trône de Caelum, le Titan vaincu Polum, dit par avance l'inutilité de la révolte contre l'ordre de l'Univers, contre l'ordre romain.

Ainsi dans la mosaïque de Mérida, c'est essentiellement, dans le domaine des images et du vocabulaire qu'implicitement l'Empire peut être assimilé au Cosmos et la Virtus Augusti confondue avec la Providence divine (786). Mais seul le Cosmos est représenté

(781) Sur ce mécanisme, voir supra, note 116, Hanf mann, Season Sarcophagus, t. I, p. 165-173; J. Gu EY, A propos du Feríale Dur anum, col. 1, lignes 14-16, 28 janv. 198, ou le siècle des Antonins, R.E.A., 50,1948, p. 60-70 et J. Ga GÉ. Recherches sur les jeux séculaires, Paris, 1934, p. 111 sq.

(782) Voir Beaujeu, Religion, p. 325-326 et R.M.C., IV, 215, 1342, pl. 32-4. Sur l'assimilation d'Antonin à Zeus ou au plus grand et plus manifeste de tous les dieux en Orient, voir I.G.R.R., III, 704.

(783) Voir E. Babelon, Th. Reinach, Recueil des monnaies d'Asie Mineure, t. I, p. $407 \mathrm{n}^{\circ}$ 68, le bronze d'Hadrien de Nicée et supra, note 214.

(784) $\mathrm{y}_{0} \mathrm{i}_{\mathrm{r}}$ note 301.

(785) Panégyrique, 32.

(786) Voir supra, note 160 et I, p. 99-100; cf. Hanfmann, Season Sarcophagus, t. I, p. 16 et sq., note 138. 
sur le pavement où ne se rencontre aucune allusion directe au souverain. Le mosaïste n'a pas prêté aux fleuves le visage de Septime Sévère $\left({ }^{787}\right)$, ni donné à Saeculum l'apparence juvénile du génie monétaire au cercle zodiacal, qu'accompagne la légende Saeculum aureum sur une monnaie d'Hadrien $\left({ }^{788}\right)$. La mosaïque cosmologique de Mérida n'illustre pas directement l'idéologie impériale. Elle nous renseigne seulement sur le fonctionnement des superstructures de pouvoir; elle nous révèle le rôle important joué en ce domaine par la philosophie stoïcienne $\left({ }^{789}\right)$ et témoigne de l'importance des clichés rhétoriques, fussent-ils traduits en images, comme lieu d'intériorisation de l'idéologie officielle.

La mosaïque cosmologique n'a pas à ce jour d'équivalent iconographique dans le monde romain. Elle est un hapax. Aussi oublie-t-on facilement que ce tableau exprime, par l'image, ce qui est topos rhétorique pour Ménandre de Laodicée $\left({ }^{79}\right)$ et dont A. J. Festugière ( ${ }^{791}$ ) a montré qu'il était devenu à la fin du Ier et au $\mathrm{II}^{\mathrm{e}}$ siècle un lieu commun de la pensée philosophique et religieuse. Notre étude a permis de replacer la mosaïque cosmologique de Mérida dans son contexte culturel. Il nous reste à essayer de préciser l'importance de la découverte d'un tel pavement à Mérida et la place qu'il occupe dans la redéfinition d'une nouvelle culture panhelléno-romaine.

(7S7) Nous avons refusé l'hypothèse de A. BLANco-Freijeiro, selon laquelle la tête qu'il attribue au Nil (p. 173, pi. VI, C) et qui appartient de fait réellement à l'Euphrate, puisse être un portrait de Septime Sévère, voir supra, note 77 .

(7SS) Voir supra, note 354. C'est sous le règne d'Hadrien qu'il apparaît pour la première fois. Il se présente sous l'aspect d'un jeune homme à demi drapé, tenant le Globe sur lequel est posé le phénix, emblème d'éternité. Mattingly a marqué l'intérêt de ce type, qui exprime l'idée de la Felicitas temporum. Sur la représentation d'Hadrien ou de Trajan assis en majesté au centre du cercle zodiacal, voir GNecChI, Medaglioni romani, III, p. 21, $\mathrm{n}^{\circ} 105$, pl. 147, 3 et 4 et Toyn B E E, Roman Medallions, p. 92.

(789) Voir Festugière, Dieu Cosmique, p. 441 et B.M.C., III, p. LXXIX, et $81,82,87,95$. H. Mattingly note que «la doctrine stoïcienne avait rendu familière aux Romains l'idée de l'éternité mais que la conception orientale, notamment égyptienne, d'Aiôn se reflète dans l'idée romaine».

$\left(7^{\circ}\right)$ Voir supra, I, p. 44, note 113 et p. 20 note 465; cf. MÉNANDre de

LAODICÉE, dans SPENGEL III, p. 347.

í791) Voir Festugière, Dieu Inconnu, p. 265 et supra, p. 76 note 737.

Conimbriga, 19 (1980), 5-127 


\section{CHAPITRE II}

\section{SIGNIFICATION HISTORIQUE DE L'EXISTENCE DE CE PAVEMENT A MÉRIDA}

Nous n'avons guère parlé de la Péninsule ibérique jusqu'ici: presque toutes nos références sont grecques ou appartiennent à la partie orientale de l'Empire, que ce soit dans le domaine littéraire, épigraphique, cosmologique ou même iconographique. Pourtant la mosaïque cosmologique a été découverte à Mérida, autrefois Emerita Augusta, colonie fondée, si l'on en croit Dion Cassius (792), par Auguste en 25 av. J.-C., devenue capitale de la Lusitanie entre 16 et 13 av. J.-C., et qui est très rapidement devenue une cité prospère, comme en témoignent ses monuments et ses vastes maisons ornées de mosaïques $\left({ }^{793}\right)$.

Nous devons donc nous demander maintenant qui a pu réaliser ce pavement, pour qui il a été conçu, à quel local il était destiné et ce que son existence nous permet de deviner de la vie culturelle de cette cité de Lusitanie dont nous savons qu'elle a abrité, aux environs de 150-160, des fidèles de Mithra, très actifs et très hellénisés $\left({ }^{794}\right)$.

\section{a) Le mosaïste.}

Nous n'avons pas systématiquement procédé à une recherche des modèles iconographiques, mais notre étude nous a permis de

(792) Selon le témoignage de Dion Cassius, 53, 25, 2. Voir sur ce sujet J. Alvares Sáenz de Buruaga, La fundación de Mérida, dans Augusta Emerita, p. 19-30.

(793) Sur la Mérida romaine, voir dans Augusta Emerita, ouvrage consacré à la célébration du Bimillénaire de Mérida, les articles de A. Balıl Illana, sur l'Architecture domestique, p. 75-91, de Tн. Hauschild sur les problèmes des constructions romaines, p. 107-110, de L. ABaD Casal, sur les fresques des habitations romaines, p. 163-182.

(794) Voir supra, notes 20-21; 348, 616 et infra p. 97-102. 
relever un certain nombre d'indices qui sembleraient confirmer l'intuition de G. Ch. Picard selon laquelle «le mosaïste de Mérida» aurait «reçu sa formation dans l'un des grands centres de la Méditerranée orientale» ( $\left.{ }^{79 S}\right)$ et non «en Afrique» comme le pensait A. Blanco-Freijeiro ( $\left.{ }^{796}\right)$.

La mosaïque a bien été exécutée à Mérida $\left.{ }^{797}\right)$, comme c'était l'habitude dans l'Empire pour les mosaïques à grand champ; des tesselles de même couleur, dans les divers tons de bleu si caractéristiques de $Y$ emblema, se retrouvent d'ailleurs dans les mosaïques de pavement de la Casa del Anfiteatro (798). Les thèmes retenus sont cependant totalement différents: ici le , là les poissons, Vénus et Eros, une scène de vendanges, des décors géométriques $\left({ }^{799}\right)$.

Or, le tableau de notre mosaïque est plus que les autres pavements marqué par l'hellénisme, comme en témoignent les observations suivantes:

Les personnages, comme généralement sur les mosaïques d'Antioche $\left({ }^{8} 0^{\circ}\right)$, sont tous des personnifications d'abstractions, d'éléments ou de forces naturelles.

(795) Voir supra, I, p. 11.

(796) Voir supra, note 10.

(797) C'est la règle pour les mosaïques antiques, si l'on excepte quelques médaillons de petites dimensions, voir Рн. Bruneau, Perspectives sur un domaine encore mal exploré de l'ait antique: à propos des actes du Colloque international sur la mosaïque gréco-romaine, dans R.E.G., 1966, n 376-378, p. 704-726 (particulièrement p. 715-719).

(798) Comme je l'ai moi-même constaté. Sur la casa del Anfiteatro voir A. Balil Illana, Sobre la arquitectura domestica en Emerita, dans Emerita Augusta, p. 75-91 (particulièrement p. 85-91) et sur les mosaïques qui la décorent, Blanco-Freiseiro, ibid., p. 188-191. Il faudrait pouvoir étudier la nature des matériaux, la qualité de l'exécution, les techniques de pose et préciser davantage ce qui rapproche la mosaïque cosmologique des autres mosaïques de Mérida, et ce qui l'en distingue. Souhaitons que ce travail puisse se réaliser un jour.

(799) Voir Blanco-FreIJEIRo, ibid., pl. LXXX, b - LXXXVI.

$\left({ }^{8} 0^{\circ}\right)$ Voir, outre D. Levi, Antioch, passim, G. Downey, Personnifications of Abstract Ideas in the Antioch Mosaics, dans Transactions of the Amer. Philol. Assoc., LXIX, 1938, p. 349-363 et ID., Representations of Abstract Ideas in the Antioch Mosaics, dans Journ. of the History of Ideas, I, 1940, p. 112-113. Le phénomène s'accentue aux III et $\mathrm{IV}^{\mathrm{e}}$ siècles. 
Les figures sont, pour la plupart, accompagnées de légendes, comme on en rencontre très tôt dans la partie grecque de l'Empire ( $\left.{ }^{801}\right)$ et plus tardivement en Occident.

Les légendes, écrites en latin., présentent quelques anomalies dans les formes - Nubs qui est rarissime, Polum, Caelum, Tonitrum qui sont rares, Pharus qui est une graphie plus grecque que latine, le neutre pluriel Navigia, utilisé comme un féminin singulier ${ }^{802}$ ) - et cela peut laisser supposer que le mosaïste traduit en latin des termes grecs.

Les noms des quatre vents retenus sont la transposition des noms grecs des vents désignés d'après les quatre points cardinaux et non leur nom latin ( $\left.{ }^{803}\right)$.

Pour les quelques exemples que nous avons examinés, l'iconographie des personnages fait surgir des questions analogues. La couronne tourelée est un attribut très couramment utilisé en Orient, plus rarement en Occident ${ }^{(804)}$. L'importance et le traitement des figures maritimes et fluviales - Pharus, Navigia, Copiae, le personnage à l'ancre, la figure féminine dans le giron de Nilus — et leurs attributs - proue, aplustre, vergue, rames, corne d'abondance — renvoient à des modèles de l'Orient hellénistique $\left({ }^{805}\right)$, quoique ces images ne nous permettent pas de reconstituer la forme réelle de tel ou tel monument $\left.{ }^{806}\right)$. La représen-

(801) Voir M. RostovtzefF, R.E.A., 42, p. 508-514.

(802) $\mathrm{y}_{\text {oir suprai }} i_{9 v} 18$ notes 44j 64) 67) 30 $\left.\mathrm{O}, 388\right) 396 \mathrm{j} 418>$

(803) Voir supra, notes 415 et 416.

(S04) Voir supra, I, p. 61-62.

(805) Voir supra, notes 64, 67-71, 73.

(806) Dans la mosaïque de Mérida, la figure de Pharus ne nous renseigne pas plus sur l'aspect de la statue qui pouvait se trouver au sommet du phare d'Alexandrie que Navigia et Copiae sur la forme des navires et des barques. Cette remarque me semble infirmer les observations de D. GiongEtTI à propos de la mosaïque de Quars El Lebia (cf. supra, note 211). Celui-ci [Atti. Acc. Lincei, 1977), s'appuyant sur l'étude de l'Epigramme de Poseidippos par F. Снамoux (dans Hommages à Cl. Préaux, Bruxelles, 1975, p. 184-222), sur les monnaies d'Alexandrie (cf. G. Tabarroni, La rappresentazione del Faro suile monete di Alessandria, dans Num. e Antich.. Class., 5,1976, p. 191-203) et sur la mosaïque de Qars El Lebia, affirme que le phare d'Alexandrie n'aurait pas été surmonté d'une statue d'homme à l'époque hellénistique, qu'une statue masculine, proche du Poseidon qui figure sur les monnaies de Domitien de 91/92 et sur toutes les émissions alexandrines jusqu'à la fin du 
tation des dieux fleuves, bien attestée sur les mosaïques d'Antioche $\left.{ }^{(807}\right)$, la disposition hellénistique des vents, comparable à celle de la Tasse Farnèse $\left.{ }^{808}\right)$, le choix grec de saisons féminines $\left({ }^{809}\right)$, peuvent suggérer des comparaisons avec l'art alexandrin, mais, en aucun cas, il n'y a seulement copie.

Sans doute, on peut supposer avec G. Ch. Picard que le mosaïste de Mérida est un «Grec» ou «un Oriental hellénisé venu d'une des grandes cités orientales de l'Empire» $\left({ }^{81^{\circ}}\right)$. Je ne me prononcerai pas sur sa technique, ni sur les relations qui ont pu exister entre les ateliers d'Orient et d'Occident (811). Mais la culture grecque dont fait preuve l'artiste n'implique pas automatiquement une origine hellénique. Celui-ci ne fait pas oeuvre personnelle, il exécute une commande. $\mathrm{La}$ culture que révèle le pavement n'est donc pas imputable au seul mosaïste, elle exprime le choix du destinataire. D'ailleurs, cette «culture grecque» n'est-elle pas devenue, dès le $\mathrm{I}^{\mathrm{e}} \mathrm{s}$ siècle de notre ère, le bien commun de la majeure partie des élites. Le fait est que, si le mosaïste s'inspire de modèles iconographiques grecs, voire alexandrins, il a utilisé ses cartons dans une optique nouvelle pour élaborer une composition originale qui n'est plus spécifiquement hellénistique ${ }^{(812)}$ et dont le syncrétisme culturel correspond bien aux nouvelles structures mentales des habitants de l'Empire, par le sentiment qu'il exprime de l'unité du macrocosme et du Corpus Imperii (813).

règne de Marc Aurèle aurait été ajoutée à la fin du Ier siècle. A la fin du II ${ }^{e}$ ou au début du IIIe siècle, on aurait remplacé ce Poseidon par Hélios qui aurait été restauré par Anastase I, à la fin du Ve siècle. L'adolescent nu de Mérida n'évoque ni Poseidon, ni Hélios. Il représente de manière allégorique le port d'Alexandrie et dit de manière symbolique, sans doute aussi, que la Providence divine est source de salut pour les hommes comme le phare pour les navires. Voir supra, I, p. 65-66.

$\left(s^{\circ} 7\right)$ Voir SUpraj notes 77, 81, 88, 91.

$\left.{ }^{808}\right)$ Voir supra, notes 82 et 103 et pi. VIII.

${ }^{(809)}$ Voir supra, p. 36-39 et notes 535 et 566.

$\left({ }^{(81}\right)$ Voir supra, I, p. 11.

${ }^{(811)}$ Sur la transmission des thèmes iconographiques, voir PH. BRUNEAU, R.E.G., 1966, p. 711-713.

(si2) Voir, pour un phénomène analogue, l'analyse de Cн. Picard, La patère d'Aquileia et PEleusinisme à Rome, au début de l'époque impériale, dans Ant. Class., 20, 1951, p. 351-381 (et particulièrement p. 364-374).

(sia) $\mathrm{y}_{0} \mathrm{j}_{\mathrm{r}}$ supra, I, p. 78-79 et notes $263,289-290$ et 730. 


\section{b) Le destinataire}

Le destinataire est assurément un homme cultivé, pénétré d'un hellénisme philosophique de bon aloi — presque toutes nos références sont grecques -, très intéressé par les spéculations cosmologiques - non par l'astrologie —, sensible à l'harmonie de l'Univers, et vivant en accord avec l'idéologie diffuse de son temps. Rien de tout cela ne trace le portrait d'un homme qui aurait vécu, comme le suppose G. Ch. Picard (814), en exil à Mérida, ou se serait réfugié, en esprit, dans sa langue et dans sa culture d'origine. Le latin est la langue qu'il parle dans la ville où il vit et il tient à ce que le pavement soit lisible pour d'autres que lui, peut-être pour des amis moins hellénisés. Devons-nous supposer qu'il ait été Syrien?

La colonie syrienne était importante à Mérida $\left({ }^{815}\right)$ et les Syriens semblent avoir plus que d'autres aimé représenter Je Cosmos, comme l'attestent les mosaïques de pavement des synagogues et des églises paléochrétiennes d'Orient ${ }^{(816)}$, aux $\mathrm{III}^{\mathrm{e}}$ et IVe siècles. Plus que les autres aussi, ils ont célébré le culte de l'Eternité.

Le propriétaire de la Casa del Mitreo a donc pu avoir des origines syriennes mais il est à Mérida bien intégré dans l’Empire.

(su) Voir supra, I, p. 11.

${ }^{(815)}$ Sur l'importance des Syriens à Emerita Augusta et à Italica qui sont des ports importants sur le Guadiana et le Guadalquivir, voir E. ALBertini, Les étrangers résidant en Espagne à l'époque romaine, dans Mélanges Cagnat, Paris, 1912, p. 297-318; J. M. BLÁzquez, Relaciones entre Hispania y los Semitas (Sirios, Fenicios, Chipriotos, Cartagineses y Judios) en la Antigüedad, dans Beitràge zur alten Geschichte und deren Nachleben, Festschrift für F. Altheim zum 6/10/1968, Berlín, 1969, I, p. $42-75$ et spécialement p. 70-71 et R. ETIENNE, Les syncrétismes religieux dans la péninsule ibérique à l'époque impériale, dans les Syncrétismes, p. 161.

(816) Voir A. Grabar, Cahiers Archéologiques, 12, p. 149-152. M. BLANChaRd-Lemée note cependant (Promenades à travers formes et thèmes, Gaule, Germanie, Bretagne - mosaïques, décors de sols —dans Doss. Arch., n' ${ }^{\circ}$ 15, 1976, p. 43-55) que s'exprime un goût marqué pour les scènes mythologiques classiques, les scènes cosmologiques et les sujets littéraires, dans les parties occidentales de l'Empire et comme le refus des références aux cultes locaux. 
C'est Yoikouméné romaine qu'il a fait représenter et non telle ou telle région privilégiée de Syrie; il ne limite pas son intérêt à l'Oronte. Sa patrie, c'est l'Univers. Pourtant il n'éprouve aucun mépris pour la petitesse de la terre habitée $\left({ }^{817}\right)$. Bien au contraire, le spectacle d'une intense activité portuaire et des échanges fructueux entre l'Orient et l'Occident lui est source de contentement. C'était, sans aucun doute, un homme pour lequel avaient compté les choses de la mer et le commerce par voie maritime. Nous connaissons l'importance du port d'Augusta Emerita sur le Guadiana $\left({ }^{818}\right)$ - Il y a dans la mosaïque des richesses transformées Copiae - et transportées sur la mer - Navigia —, non des plantes ou des animaux, tout au plus un putto-karpos, attribut de l'été. C'est l'image de l'Empire comme port qui est privilégiée et non celle de la Gé-Karpotrophos. Ce citoyen de Mérida est heureux de vivre en son temps dans la perfection d'un âge d'or qui est pour lui source de prospérité économique.

Il est d'un naturel religieux, voire mystique; il aime se perdre dans la contemplation du Cosmos, pour y découvrir l'existence du maître de l'Univers, peut-être pour accéder à l'éternité de YAiôn $\left(^{819}\right)$ mais son mysticisme est raisonnable, philosophique, proche de celui de Dion de Pruse, teinté de stoïcisme et d'acceptation de l'ordre des choses $\left({ }^{82^{\circ}}\right)$.

L'importance de la Domus où a été retrouvé le pavement $\left({ }^{821}\right)$, la culture dont témoigne la composition, la foi philosophique qu'elle révèle et le plaisir de vivre qu'elle suppose nous confirment que le destinataire de cette mosaïque appartenait à la classe des notables de Mérida, «classe riche, instruite, délivrée des préoccupations matérielles, d'un niveau spirituel et culturel très élevé»,

(817) A la différence de Marc Aurèle, voir supra note 766.

${ }^{818)}$ Voir A. Balıl, Economía de la Hispania Romana, dans Estudios de Economia antigua de la península ibérica, 1958, p. 289-369, (particulièrement p. 293-5) et J. Alvarez Sáenz, La Fundación, dans Emerita Augusta, p. 24-25.

(819) Voir supra, notes 734, 736, 738.

$\left({ }^{82}\right)$ Voir supra, p. 76-81 et notes 733-734, 740 et 747.

(821) Voir L. Abad Casal, Pintura, dans Emerita Augusta, p. 164-174

et García-Sandoval, p. 17.

Conimbriga, 19 (1980), 5-127 
qui fournissait les cadres du régime municipal et impérial $\left({ }^{822}\right)$. Sans doute même pouvons-nous dire qu'il se rattachait au même milieu socio-professionnel des grands commis de l'Etat que les dignitaires du mithriacisme ( ${ }^{823}$ ) pour lesquels la loi de l'Univers et la loi morale pouvaient très facilement se confondre avec la loi de Rome ${ }^{(824)}$. A la différence des masses, soumises à la hiérarchie, et seulement sensibles au symbolisme astral du triomphe sur la mort $\left.{ }^{825}\right)$, cet homme aspirait au dépassement mystique. Sa foi s'exprimait-elle dans la solitude d'un cabinet ou s'inscrivait-elle dans des pratiques collectives? La nature du local où a été retrouvée la mosaïque peut-elle nous renseigner sur ce point?

\section{c) La nature du local}

Nous savons que le décor ornemental d'une mosaïque correspond souvent à la nature du local dans lequel elle a été posée $\left({ }^{826}\right)$, sans qu'il $y$ ait pourtant recherche systématique du caractère fonctionnel de la décoration, ni toujours parfaite adéquation $\left({ }^{827}\right)$.

A Mérida, L. Abad Casal a pu montrer que le pavement de la pièce où se trouve la mosaïque cosmologique avait été posé en deux étapes et que Vemblema avait été rajouté sur un décor géométrique plus ancien $\left.{ }^{828}\right)$. La pièce pourrait donc avoir reçu une destination

(822) Voir r etienne, G. Fabre, P. Le roux, A. Tranoy, Les dimensions sociales de la romanisation dans la Péninsule ibérique, des origines à ïa fin de l'Empire, dans le VIe Congrès International des Etudes Classiques: Assimilation et résistance à la culture gréco-romaine dans le monde ancien, Paris, 1976, p. 95-107 (particulièrement, p. 104).

(828) Voir H. Lavagne, Pour une problématique nouvelle des recherches sur la religion de Mithra, Le II ${ }^{\mathrm{e}}$ Congrès International d'Etudes Mithriaques, dans M.E.F.R.A., 2, 1975, p. 1131-1142 (particulièrement p. 1141).

(824) $\mathrm{y}_{0} \mathrm{i}_{\mathrm{r}}$ supra, notes 247, 371-378, et I, p. 95-96. Sur l'importance de cette loi morale dans le mithriacisme, voir G. DumÉzıL, dans J.M.S., 1976, II, 1.

(825) Y $_{0}$ ir R. Etienne, G. Fabre, P. Le Roux, A. Tranoy, p. 105.

(826) G. Becatti (La mosaïque Gréco-romaine, I, p. 15-28) note que le mosaïste romain, à la différence du mosaïste grec, conçoit la décoration en étroite relation avec l'architecture et la destination des pièces. Voir aussi G. Lassus, La mosaïque Gréco-romaine, II, p. 332-333 et G. Сh. Picard, R.E.L., 1965, p. 508-522.

(827) Voir $\mathbf{p}_{\mathrm{H}}$. Bruneau, R.E.G., 1966, p. 714-715.

(828) Voir supra, note 19. 
précise. La mosaïque a été conçue comme un vaste tableau orienté, de plein champ, et doit être obligatoirement regardée avec un peu de recul depuis le registre inférieur. Tous ces indices excluent l'hypothèse d'une salle à manger mais ils ne nous renseignent pas autrement sur la destination de la pièce, sur son usage privé ou public. Nous n'avons guère d'éléments pour trancher. La pièce donne sur un atrium tétrastyle; elle n'est pas très vaste, mais de belles proportions. Nous avons découvert que le propriétaire de la Casa del Mitreo était vraisemblablement un notable stoïcien de tempérament mystique. Pareille mosaïque pouvait donc tapisser le sol d'une pièce réservée à la méditation individuelle. Nous ne croyons guère cependant que ce tableau ait été réalisé pour satisfaire le seul plaisir esthétique, philosophique et religieux d'un homme seul ${ }^{(829)}$. C'est plus vraisemblablement le sol d'une pièce ouverte à des amis, sinon au public, que décorait cette mosaïque. Ce n'était sans doute pas une salle d'apparat - car la pièce est petite chez un représentant officiel du pouvoir. Il a existé de nombreux collèges dans les cités antiques: la religion y était pratique collective. La mosaïque cosmologique de Mérida a donc pu orner le sol d'une salle de réunion, destinée à un cénacle philosophique d'inspiration stoïcienne, et, sinon à des fidèles du culte du monde $\left({ }^{83^{\circ}}\right)$, du moins à des hommes qui vénéraient la grande Loi d'harmonie du Cosmos et non un dieu en particulier. Nous ne nous étonnerons pas qu'un tel cénacle ait pu exister à Mérida.

\section{d) Le milieu éméritain et ibérique}

Nous pouvons expliquer la présence d'un pavement cosmologique à Mérida par l'existence très ancienne en cette ville d'une communauté syrienne et d'un temple à $Y$ Aeternitas Augusta, à l'effigie duquel avaient été frappées des monnaies dès le règne de Tibère ${ }^{(831)}$. A Mérida les hommes qui célébraient le culte de

(829) Sur le rôle des goûts du propriétaire dans le choix du tableau, et la dimension de Yemblema, voir PH. Bruneau, R.E.G. p. 714 et R. ThOuvenot, La mosaïque Gréco-romaine, I, p. 272.

$\left({ }^{9}{ }^{\circ}\right)$ Voir supra, I, p. 85-86 et notes 313-325.

(S3i) $\mathbf{y}_{0} \mathbf{i}_{\mathbf{r}}$ R. ETIENNe, Culte impérial, p. 320-324. 
Mithra et ceux qui vénéraient VAeternitas cosmique, en adorant la Providence divine du maître suprême de l'Univers, se retrouvaient au temple de Y Aeternitas Augusta pour célébrer le culte impérial.

Rappelons la faveur dont jouissait celui-ci dans la Péninsule ibérique $\left({ }^{832}\right)$ et notons la place toute particulière des provinces espagnoles dans l'élaboration de la mystique impériale ( $\left.{ }^{833}\right)$. Dans la Péninsule ibérique, la symbolique cosmologique ( $\left.{ }^{834}\right)$ est bien mieux attestée que dans le reste de l'Occident. C'est en Espagne que, selon $Y$ Histoire Auguste ${ }^{835}$ ), Septime Sévère aurait fait le rêve de découvrir du haut d'une colline l'harmonie concertante $\mathrm{du}$ monde romain. Nous ne pouvons penser qu'il avait vu la mosaïque cosmologique de Mérida, mais ici, plus qu'ailleurs en Occident, les hommes étaient prêts à confondre l'éternité du Monde et l'éternité de l'Empire. C'est dans la Péninsule encore que le même empereur a dédié un autel au Soleil et à la Lune pour l'Eternité de l'Empire et pour le salut de la famille impériale $\left({ }^{836}\right)$. Ces dernières réflexions nous invitent à poser plus nettement la question de la date de réalisation du pavement.

\section{e) Date du référent culturel et date de réalisation de la mosaïque}

Les rapprochements que nous avons pu établir du point de vue littéraire - oeuvre de Dion de Pruse, Plutarque, Aelius

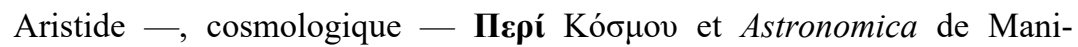
lius —, numismatique — monnaies d'Hadrien et d'Antonin presque

(832) R. Etienne insiste sur la réussite exceptionnelle du culte impérial dans la péninsule ibérique par la convergence qui existait entre le culte du chef indigène à l'époque préromaine et le culte de l'empereur (cf. Culte impérial, p. 81-115; Les syncrétismes, p. 157-159).

(S83) Yoi ${ }_{\mathrm{r}}$ R Etienne, Culte impérial, p. 359 sq. ; Les syncrétismes, p. $159-160$.

((834) Sur l'importance du symbolisme astral et le rôle du culte de Lux Divina, voir I D., Les Syncrétismes, p. 162.

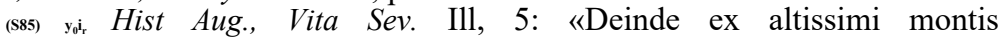
vertice, orbem terrarum Romamque despexit concinentibus provinciis lyra voce vel tibia» et sur le rôle de Septime Sévère dans la Péninsule ibérique, voir R. Etienne, Culte impérial, p. 497-512.

(836) Voir R. Etienne, Culte impérial, p. 512 qui cite l'inscription C.I.L., II, 259. 
exclusivement —-, idéologique — sentiment de l'unité de l'Empire et redéfinition d'un âge d'or qui soit abolition du temps et projection immédiate dans l'éternité de la félicité et de la prospérité du régime politique présent -, iconographique - goût pour la personnification des forces cosmiques, création d'abstractions nouvelles encore qu'en ce domaine la plupart des documents rapprochés d'Aeternitas datent du III ${ }^{\mathrm{e}}$ siècle, artistique même - mélange de classicisme académique et de mollesse, pathétique dans l'expression des visages, virtuosité de la composition et délicatesse du modelé, atmosphère pénétrée et édifiante - nous renvoient tous ou presque à l'époque automne, plus exactement aux règnes d'Hadrien, d'Antonin le Pieux, voire de Marc Aurèle. C'est précisément le temps où la vie culturelle et religieuse et la création artistique semblent avoir été actives à Mérida. Aussi pourrait-on être tenté de proposer une date assez haute pour la réalisation de ce pavement, plus proche du règne d'Antonin que de celui de Septime Sévère. D'autres indices, il est vrai, évoquent une exécution plus tardive. La présence des légendes donnant le nom des personnages, la composition à grand champ et la polychromie ne sont attestées qu'assez tardivement en Occident ${ }^{837}$ ) et nous savons bien que le style et les thèmes iconographiques de l'époque automne perdurent sous les Sévères, au III e et même au IVe siècle ( $\left.{ }^{838}\right)$.

Nous distinguerons donc entre la date de réalisation de la mosaïque et la date du référent culturel que suppose la composition de Vemblema.

La date d'exécution ne saurait être antérieure au règne d'Hadrien. Notre étude ne nous permet pas de fixer un terminus ante quem. Formulons le souhait que d'autres critères, plus techniques, de nouvelles découvertes archéologiques ( $\left.{ }^{839}\right)$ permettent

(S37) Pour la Péninsule ibérique, voir A. BALIL, La mosaïque Grécoromaine, I, p. 29-39. Celui-ci constate que la mosaïque figurée, polychrome, n'apparaît qu'à la fin du $\mathrm{II}^{\mathrm{e}}$ siècle et tend alors à couvir une plus grande surface du sol des maisons.

(S3S) Voir PII. Bruneau, R.E.G., 1966, p. 720-721 et G. Becatti, Scavi di Ostia, IV, p. 379.

$\left({ }^{839}\right) \quad$ Sur les difficiles critères stylistiques, iconographiques, techniques, archéologiques, qui, en l'absence de datation absolue, permettent de dater les mosaïques, voir PH. BRUNeAu, ibid., p. 719-724. 
d'apporter quelques précisions en ce domaine et aident à situer la mosaïque cosmologique dans le Corpus des mosaïques de Mérida.

Les références culturelles du tableau sont au contraire parfaitement datables. Elles ne sauraient être, nous l'avons montré, antérieures au règne d'Hadrien et reflètent la sensibilité religieuse et les superstructures idéologiques du temps que l'on a l'habitude d'appeler l'âge d'or des Antonins, la deuxième moitié du IIe siècle.

Mais quelle que soit la date de réalisation de ce pavement, il est un admirable document sur l'importance des phénomènes syncrétiques dans l'Empire et sur le rôle de la Péninsule ibérique dans la redéfinition d'une nouvelle culture panhellépo romaine.

\section{f) La mosaïque cosmologique comme exemple de création syncrétique}

La mosaïque cosmologique rappelle, s'il était besoin, le rôle important joué par la culture grecque des habitants de l'Orient hellénisé $\left({ }^{840}\right)$, devenus citoyens de l'Empire, par les traditions iconographiques alexandrines dans la vie culturelle des cités d'Occident. L'«Orient», ce n'est pas seulement «les religions orientales», quel que soit leur nombre en Lusitanie $\left({ }^{841}\right)$. Nous avons pu être tentée, après A. Blanco-Freijeiro et G. Ch. Picard, d'interpréter la mosaïque cosmologique dans une optique mithriaque, de reconnaître en Aeternitas une figure d'Hermès/Logos/ /Mithra/Mésitès ( ${ }^{842}$ ). Nous avons dû y renoncer. La mosaïque cosmologique reflète les enseignements de la cosmologie et de la philosophie stoïciennes. Elle est révélation de l'harmonie de l'Univers.

( $\left.{ }^{840}\right)$ Rappelons, après L. RoBERT, que les habitants des cités des provinces de la Méditerranée orientale ne sont pas des orientaux. Ils sont imprégnés de culture grecque et se considèrent eux-mêmes comme les descendants des Grecs d'autrefois.

(841) Sur l'importance des religions orientales en Lusitanie, voir R. ETIEnne, Les Syncrétismes, p. 161 et A. García y Bellido, Religions orientales, p. 26-33, pour Mérida. Celui-ci explique les phénomènes de transposition entre les divinités indigènes et les divinités orientales par un phénomène de superposition et d'assimilation [ibid., p. 67-70).

$\left.{ }^{842}\right)$ Voir supra, p. 68-69 et notes 709, 710, 711, 712. 
Il y avait dans le Mithraeum de Mérida des statues de Vénus, Mercure, Océan, Neptune, d'un monstre léontocéphale, d'un Aiôn adolescent, de Sarapis... ( $\left.{ }^{843}\right)$. Les rapports des écoles philosophiques et des autres religions a ${ }^{\mathrm{r} e c}$ le mithriacisme sont des sujets controversés, encore mal élucidés. Nous savons que «le mithriacisme a pu prendre des «visages religieux» très différents selon les commu-

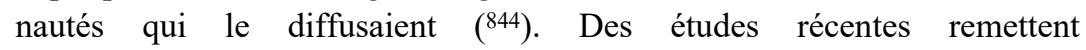
en cause, de tout côté, ce qui semblait acquis du temps de F. Cumont, mais il nous paraîtrait aventureux à l'excès de supposer que l'on ait pu être à Mérida à la fois stoïcien et fidèle de Mithra. Par contre, il est très vraisemblable que le stoïcisme dont la présence est sensible dans la Casa del Mitreo et les croyances des fidèles de Mithra, qui se retrouvaient au sanctuaire voisin, ont été nourris des mêmes spéculations cosmologiques, élaborées dans un même milieu culturel hellénisé qui parlait néanmoins le latin.

A en juger par les nombreuses statues mithriaques de facture grecque, il y eut à Mérida projection sur le mithriacisme des figures $\mathrm{du}$ Panthéon traditionnel ${ }^{\wedge 45}$ ) et des modèles iconographiques grecs, comme il y eut dans la mosaïque cosmologique volonté de transformer en dynameis personnifiées de caractère cosmique $\left({ }^{846}\right)$ les anciennes divinités olympiennes, selon les principes de correspondance élaborés par la Stoa $\left({ }^{847}\right)$ : Caelum a remplacé Zeus; Saeculum, Chronos; Chaos, Kronos; Providentia, Héra; Aeternitas, Hermès; Oceanus, Poseidon; Natura, Vénus. Dans les deux cas,

(843) Voir supra, I, p. 13, note 21 et pour Sarapis, A. García y Bellido, Religions orientales, p. 137-138.

(844) Voir A. D. Nock, J.H.S., XLV, 1925, p. 89 sq.; H. Lavagne, M.E.F.R.A., 1975, 2, p. 1138, et les Actes du $2^{e}$ congrès international des études mithriaques (Téhéran, Irer-8 sept. 1975), Téhéran, Liège, Leyde, 1978.

(845) Voir supra, note 21 et Tu RCAN, Mithras Platonicus, p. 129.

(846) Sur le goût de l'époque hadrienne et antonine pour les personnifications de nature cosmique et chronologique, voir Hanfmann, Season Sarcophagus, t. I, p. 181 et E. Will, Ann. Arch. Syr., 1953, p. 27-48.

${ }^{(847)}$ Voir supra, I, p. 97-98 et notes 342, 390. Sur ces équivalences, voir aussi J. PÉPIN, Mythe et allégorie, Paris, 1958, p. 320, 328-335, 339, 342, 345-346, 382. J. O. BRENdel souligne dans Symbolism of the Sphere: a Contribution to the History of earlier Greek Philosophy, Leyde, 1977, p. 40, que c'est un mode de penser stoïcien de représenter Dieu sous diverses formes: «God is Aiôn, Kosmos, Chronos, Genesis». 
il $\mathrm{y}$ a souci et effort des élites locales pour adapter leur culture d'origine à leur situation de citoyens de Гoikouméné romaine. Aussi ne chercherons-nous pas quels ont pu être les modèles du mosaïste: «fresque murale de la fin du II ${ }^{\mathrm{e}}$ siècle après J.-C.» ou tableau hellénistique représentant les divinités supérieures réglant du haut du ciel la marche de $\Gamma$ Univers» $\left({ }^{848}\right)$. Pourquoi cette quête des origines ? Il y a tradition hellénistique - elle est incontestable - il y a aussi, très manifestes, souci et capacité de redéfinir une nouvelle culture syncrétique panhelléno-romaine $\left({ }^{849}\right)$ où se mêlent conceptions philosophiques, aspirations mystiques et idéologie politique. Dans l'Empire, en Orient comme en Occident, l'héritage hellénistique s'est adapté à des structures idéologiques et mentales nouvelles.

Avec R. Bianchi-Bandmelli $\left({ }^{85^{\circ}}\right)$, nous dirons que «l'art ne se transmet jamais par 'infection' passive, mais seulement par fécondation cherchée et réalisée dans une conjonction idéale». Tel fut le cas à Mérida, pour la mosaïque cosmologique*.

\section{MARIE-HENRIETTE QUET}

Septembre 1978

(848) Voir supra, I, p. 9 et G. Ch. PICARd, Mosaïque Cosmologique, p. 121.

(849) Voir A. D. Noск, A.J.A., III, 1946, p. 163-169.

$\left(\mathbf{8 5}^{\circ}\right)$ Voir R Bianchi-Bandinelli, Naissance et dissociation de la koinè hellénistico-romaine, dans Le Rayonnement des civilisations grecque et romaine dans les cultures périphériques, Paris 1965, p. 448.

* Ma gratitude va à la Fondation Hardt de Vandoeuvres: c'est dans le calme de cette paisible retraite genevoise que j'ai achevé de rédiger cette étude. 


\section{BIBLIOGRAPHIE}

\section{OUVRAGES DE CONSULTATION}

Année Philologique (U), publiée sous la direction de J. Marouzeau, 1914-1924, et J. Ernst, depuis 1924. (Tome XLVII, 1976, dernier paru en 1978).

Bulletin de VAssociation pour l'étude de la mosaïque antique (annuel depuis 1969) $=$ AIEMA.

Bulletin de ГAIEMA, 2 Juin 1970: p. 136-143, Méthode de classement pour un répertoire de la mosaïque antique.

Bulletin de VAIEMA, $\mathbf{n}^{\circ}$ 4, 1973: Blanchard-Lemée ÍM.), Christophe (J.), Darmon (J.-P.), Layagne (H ), Prudhomme (R.), Stern (H.), Répertoire graphique du décor géométrique dans la mosaïque antique.

Daremberg (C.), Saglio (E.) et Pottier (E.):

Dictionnaire des Antiquités grecques et romaines (9 vol.), Paris, 1877-1919.

Das Lexicon der alten Welt, Zurich - Stuttgart, 1965 (3.523 col.).

Ernout (A.), Meillet (A.):

Dictionnaire étymologique de la langue latine, Paris, 1959-1967.

Leclerce (Dom H.), Cabrol (Dom F.).

Dictionnaire d'antiquité chrétienne et de liturgie, 1924.

Pauly (A.), Wissowa (G.) et de nombreux collaborateurs: Beal-Encyclopadie der Klassischen Altertums Wissenschaft, Stuttgart, 1893-1922, avec suppléments en cours de publication, + Index to the Suppl, par J. MurPhy, Chicago, 1976. $=$ B. E.

ROBERT (J.) et (L.) :

Bulletin épigraphique, annuel dans la B.E.G., depuis 1938.

ROSCHER (W. H.):

Ausführliches Lexicon der gr. und rom. Mythologie (6 vol.), Leipzig, 1884-1937, avec suppl. (2 vol). (= ROSCHER)

Thesaurus Linguae Latinae en cours de publication chez Teubner, Leipzig, $1900 \ldots=$ Thesaurus.

WALDE (A.), HoFMANN (J. B.):

Lateinisches etymologis ches W orterbuch, 3ème éd., Heidelberg, 1938-1954.

Conimbriga, 19 (1980), 5-127 


\section{LES SOURCES}

\section{A) Littéraires}

Aelius Aristide: Eic 'Pó $\mu \eta v$, consulté dans:

1) L'édition Dindorf, Opera Omnia, 3 vol., Coll. Teubner, Leipzig, 1928.

2) F. W. LENZ et C. A. BEHR, 3 vol., Leyde, 1976.

Aelius Aristide: Éloge de Rome = Éloge.

Édition, traduction et commentaire de J.-H. Oliver, The Ruling Power, a Study of the Roman Empire in the Second Century after Christ through the "Roman Oration» of Aelius Aristides, Trans, of the Am. Philos. Soc., N. S., vol. 43, part. 4, Philadelphie, 1953.

AUSONE:

Oeuvres, éd. PEI PE R, coll. Teubner, Leipzig, 1886.

Aristote:

Du Ciel [De Caelo), éd. trad. P. Moraux, C.U.F., Paris, 1965.

ARISTOTE :

Météorologiques, éd. trad., H. D. LEE, Londres Cambridge, Mass., 1952 (Loeb class. Lib.).

\section{CICÉRON :}

De Finibus bonorum et malorum, éd. trad., H. Rаскнам, Cambridge, Mass. 1951 (Loeb class. Lib.).

\section{CICÉRON :}

Des termes extrêmes des biens et des maux, éd. trad. J. Martha, 2 vol., C.U.F., Paris 1928-1930.

\section{Cíćron :}

Les Paradoxes des Stoïciens, éd. trad. J. Molager, C.U.F., Paris, 1971.

\section{CICÉRON :}

Tusculanes, éd. trad. J. Hu м в E R т, C.U.F., Paris, 1931.

CICÉRON :

De Natura Deorum:

1) Éd. trad. H. Rаскнам, Londres, Cambridge, Mass., 1956 (Loeb class. Lib.).

2) Éd. trad. O. Pla s B E R g, coll. Teubner, Leipzig, 1933.

\section{CICÉRON :}

De Divinatione, De Fato, Timaeus, éd. R. Gıмmıı, coll. Teubner, Leipzig, 1975.

Claudien :

1) Oeuvres complètes, éd. trad. M. Platnauer, Londres, Cambridge, Mass., 1956 (Loeb class. Lib.).

2) Carmina, éd. J. Косн, coll. Teubner, Leipzig, 1893. 
Collectanea Alexandrina, éd. J. U. Powelu, Oxford, 1925.

Corpus Hermeticum:

1) Hermès Trismégiste, éd. trad. A. D. Nock, A. J. Festuguère, 4 vol., C.U.F., Paris, 1945. (= C.H.).

2) Hermética, éd. W. Sсотт, 3 vol., Oxford, 1926.

DENYS D'HALICARNASSE :

1) Antiquités romaines, éd. trad. E. Cary, E. Spelman, 7 vol., Londres, Cambridge, Mass., 1947-1960 (Loeb class. Lib.).

2) Antiquitates Romanae, éd. С. Јасову, 4 vol., coll. Teubner, Leipzig, 1885-1905.

\section{DIOGÈNE LAERCE:}

Vie des philosophes, 1) éd. trad. R. D. Нгскs, Londres, Cambridge, Mass., 2 vol., 1958-1959 (Loeb class. Lib.).

2) éd. H. S. Lon G, 2 vol., 1964 (coll. Scrip. Class, bibi. Oxon.).

Dion de Pruse:

Orationes, éd. G. DE Budé, 2 vol., coll. Teubner, Leipzig, 1916-1919.

Dio Chrysostom, Orationes, éd. trad. J. W. Cohoon, H. Lamar Cros в Y, 5 vol., Londres, Cambridge, Mass., 1949-1956 (Loeb Class. Lib.). (=Or.).

Dion Cassius:

Histoire Romaine, éd. trad, par E. Cary, H. B. Foster, 9 vol., Londres, Cambridge, Mass., 1954-1961 (Loeb class. Lib.).

Cassii Dionis Cocceiani historiarum romanarum, quae supersunt édit.

U. P. Boissevain, 3 vol., Weidmann, 1895-1931, réédit. Berlin, 1955.

EPIPHANE :

S. Epiphanius Constantiae Ancoratus und Panarion, éd. K. Holl, 2 vol., Leipzig, 1915-1922.

Flavius Josè Phe, Oeuvres:

1) éd. trad. H. St. J. Thackeray, R. Marcus, A. Wikgren, L. H. Feldman, 9 vol., Londres, Cambridge, Mass., 1956-1965, (Loeb class. Lib.).

2) éd. S. A. Na BER, 7 vol., Leipzig, 1888-1896.

Fragments Orphiques: (= Orphica).

1) Orphicorum Fragmenta, éd. O. Ke RN, Berlin, 1922.

2) Orphica, éd. G. QuAnd T, Berlin, 1955.

HERACLITE D'ÉPHÈSE:

1) Heraclitus, the Cosmic fragments. A critical study with introduction, text and translation par G. S. Kı к к, Cambridge, 1954.

2) Heraclitus Ephesius, Eradito, éd. trad, commentaire par R. MonDOLFO et L. TaRAn, Florence, 1972.

Conimbriga, 19 (1980), 5-127 
Héraclite ou la Séparation,

Choix de textes, avec traduction française, édit. J. Bollack, Paris, 1972.

HERACLITE :

Allégories d'Homère, éd. trad. F. Buffière, C.U.F., Paris, 1962.

HÉRODIEN :

1) éd. trad. C. R. Whittaker, Londres, Cambridge, Mass., 2 vol., 1969-1970 (Loeb class. Lib.).

2) Hérodien, éd. I. BeKKero, Leipzig, 1855.

\section{HÉSIODE :}

Théogonie, éd. trad. P. Mazon, C.U.F., Paris, 1928.

Histoire Auguste:

(spécialement, Vita Hadriani, Vita Commodi Antonini, Vita Pii), dans

1) The Scriptores Historiae Augustae, éd. trad. D. Magie, 3 vol., Londres, Cambridge, Mass., 1953-1954 (Loeb class. Lib.). = S.H.A. .

2) Scriptores Historiae Augustae, éd. E. Нонц, 2 vol., coli. Teubner, Leipzig, 1965. = S.H.A..

HORACE :

Odes etépodes, éd. trad. F. Villeneuve, C.U.F., Paris, 1927, rééd. 1959.

ISOCRATE :

Discours, éd. trad. G. Mathieu, E. Brémond, 4 vol., C.U.F., Paris, 1928-1938.

JEAN DE GAZA:

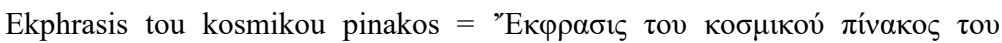

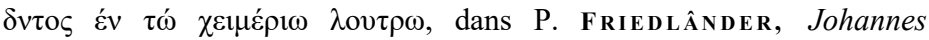
von Gaza und Paulus Silentiarius, Kunstheschreihung Justinianischer Zeit, Berlin, Leipzig, 1912, pp. 132-224.

LUCAIN :

La guerre civile (La Pharsale), éd. trad. A. Bourgery, 2 vol., C.U.F., Paris, 1926.

Manilius: Astronomica:

1) éd. Van Wageningen, coll. Teubner, 1914-1921.

2) A. E. Housman, éd. trad, commentaire, 5 vol., 1903-1932, 2ème éd. 1937.

3) éd. trad. G. P. Goold, Londres, Cambridge, Mass., 1977 (Loeb class. Lib.), avec 2 cartes.

Marc Aurète:

Pensées, éd. trad. A. J. Teannoy, C.U.F., Paris, 1925.

Conimbriga, 19 (1980), 5-127 
MAXIME DE TYR:

éd. Н. Нов в I , coll. Teubner, Leipzig, 1910.

MÉNANDRE DE LAODIGÉE, danS L. SPENGEL:

Rhetores Graeci, vol. Ill, pp. 331-446, coll. Teubner, 3 vol., Leipzig, 1853-1856.

NonNos de PANOPOLIS:

Les Dionysiaques, éd. trad. F. Vian, G.U.F., 2 vol., Paris, 1976.

OVIDE :

L'art d'aimer, éd. trad. H. BornecQue, C.U.F., Paris, 1924.

OVIDE :

Pontiques, éd. trad. J. And ré, G.U.F., Paris, 1977.

Panégyriques Latins:

éd. trad. E. Galle tier, 3 vol., G.U.F., Paris, 1949.

PAUSANIAS:

Description de la Grèce, éd. M. H. Rocha Pereira, 1. I-IV, coll. Teubner, Leipzig, 1973.

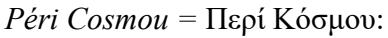

Traité pseudo-aristotélicien «du Monde», traduction A. J. FESTUGière, dans La Révélation d'Hermès Trismégiste, II, Le Dieu Cosmique, Paris, 1949, pp. 461-518.

PHiLOSTRATE :

1) Imagines, éd. trad. A. FaIrBanks, Londres, Cambridge, Mass., 1960 (Loeb class. Lib.).

2) Opera, éd. C. L. KAYs E R, 2 vol., coll. Teubner, Leipzig, 1870.

PHILON D'Alexandrie: Oeuvres:

1) éd. trad. F. H. Colson, R. Marcus, G.-H. Whitaker, 12 vol., Londres, Cambridge, Mass., 1949-1962 (Loeb class. Lib.).

2) Oeuvres éditées par R. Arnaldez, J. Poullloux, Cl. Mondésert, Paris, éd. du Cerf.,

vol. 1) De opificio mundi, R. Arnaldez, 1961.

vol. 2) Legum allegoriae, Cl. Mondésert, 1962.

vol. 15) Quis rerum divinarum heres sit, M. Harl, Paris, 1966.

vol. 16) De Fuga et inventione, E. Starobinski-Safran, 1970.

vol. 19) De Somniis, I-II, P. Savinel, 1962.

vol. 20) De Abrahamo, G. Gorez, 1966.

vol. 22) De vita Mosis I-II, R. Arnaldez, Cl. Mondésert, J. Pouilloux, P. Savinel, 1967.

vol 24) De Specialibus Legibus, I-II, S. Daniel, 1975.

vol 25) De Specialibus Legibus, III-IV, A. Mosès, 1970.

vol. 27) De Praemiis, A. Beckaert, 1961. 
vol. 30) De aeternitate mundi, A. Arnaldez et J. Pouilloux, Paris, 1969.

vol. 33) Quaestiones in Genesim et in Exodum:

fragmenta graeca,

F. Petit, 1978.

vol. 35) De Providentia, I-II, M. Hadas-Lebel, 1973.

Platon:

Timée, dans Oeuvres Complètes, t. X, éd. trad. A. Rivaud, G.U.F., Paris, 1925.

Pline l'AnCien:

Histoire naturelle, livre II, éd. trad. J. Be Au JE U, C.U.F., Paris, 1950.

Plutarque :

1) De Fortuna Romanorum, éd. G. N. Bernardakis, Moralia, vol. II, coll. Teubner, Leipzig, 1889.

2) Moralia, éd. trad. F. C. ваввitt, W. C. Helmbold, P. H. de LaCy, B. Tinarson, E. L. Minar, F. H. SANdBaCh, H. N. Fowler, H. Cherniss, 17 vol., Londres, Cambridge, Mass., 1949-1976, (Loeb class. Lib.) (= Mor.).

Pomponius Mela:

Chronographia, éd. F Rick, coli. Teubner, Leipzig, 1880.

PORPHYRE :

jVantre des Nymphes, éd. trad. Tra в u c co, Paris, 1918.

PROPERCE :

1) Elégies, éd. trad. D. Pagane Lli, C.U.F., Paris, 1929.

2) Elégies, éd. trad. H. E. Butrer , Londres, Cambridge, Mass., (Loeb class. Lib.), 1912, réimp. 1958.

Ptolémée (Claude):

Apotelesmatica (Tetrabiblos) dans Handbuch der Astronomie, 2 vol., éd. K. Manitius, coll. Teubner, Leipzig, 1912.

QUintus de SMYRNe:

1) La chute de Troie, éd. trad. A. S. W Ay, Londres, Cambridge, Mass., 1955 (Loeb class. Lib.).

2) La suite d'Homère, éd. trad. F. Vı an, 3 vol., C.U.F., Paris, 1963-1969.

SÉNÈQUE :

Questions naturelles, éd. trad. P. Olt ra ma RE, 2 vol., C.U.F., Paris, 1929.

STACE:

Silves, éd. trad. H. Frère et J. Is A AC, 2 vol., C.U.F., Paris, 1944.

STове́E:

Eclogarum Physicarum Liber, I, éd. K. Meineke, coll. Teubner, Leipzig, 1860.

Stoicorum Veterum Fragmenta:

édit. H. Von ARnim, 1903-1924, coll. Teubner, réimp. anast. 1968, Stuttgart (= S.V.F.).

Conimbriga, 19 (1980), 5-127 
STRABON:

Géographie, I, livre 1, éd. trad. G. Aujac et F. Lasserre, vol. 1, G.U.F., Paris, 1969; I, livre 2, éd. trad. G. Aujac, + carte, G.U.F., Paris, 1969; livres 3 et 4, éd. trad. F. Lasserre, vol. 2, C.U.F., Paris, 1966.

TACITE :

Annales éd. trad. P. Wuilleumie R, C.U.F., Paris, 1974.

Tite-Live :

Histoire romaine, éd. H. J. Müller, coll. Teubner, 6 vol., Berlin, Leipzig, 1880-1924.

VARRON :

De Lingua latina, éd. O. MüLLER, Leipzig, 1833.

VIRGILE :

Enéide, éd. trad. H. Goe Lze r, G.U.F., Paris, 1939.

VIRGILE :

Bucoliques, éd. trad. E. De SAInt-Denis, G.U.F., Paris, 1942.

VIRGILE :

Géorgiques, éd. trad. E. DE S AIn T-DEnis, G.U.F., Paris, 1942.

B) Épigraphiques

CAgnat (R.). - Inscriptiones graecae ad res romanas pertinentes, 3 vol. (I, III, IV), Paris, 1911-1927 (= I.G.R.R.).

Dittenberger (W.). - Sylloge inscriptionum graecarum, 3ème éd., 4 vol., Leipzig, 1915-1924 (= Sylloge).

Corpus Inscriptionum Latinarum [= C.I.L.).

Inscriptiones Graecae (= I.G.).

C) $N$ umismatiques

Babelon (E.), Waddington (W. H.), Reinach (Th.).). - Recueil général des monnaies grecques d'Asie mineure, 4 vol., Paris, 1904-1912.

Dat T A R I (G.). - Numi Augg. Alexandrini, Le Caire, 1901, t. 1 (= Dat ta Ri).

Gnecch (F.). - 1 Medaglioni romani, t. I, II, III, Milan, 1912,réimp. Bologne, 1968, (= Medaglioni romani).

Mattingly (H.) et Sydenham (E. A.). - The Roman Imperial Coinage $=$ R.I.C., t. II, III, IV, Londres, 1923-1930.

Mattingly (H.), - - Coins of the Roman Empire in the British Museum = B.M.C. 4 vol., t. III-IV, Londres, 1923-1940.

MaZzini (Ing. G.). - Monete imperiali Romane, II, 1957. 
D) Archéologiques

Adriani (A.).- - Repertorio d'arte delVEgitto Greco-romano, série A., vol. II, Palerme, 1961.

Becatti (G.). - Scavi di Ostia, Mosaici e pavimenti marmorei, vol. IY $(1,2)$, Rome, 1961 (= Scavi di Ostia).

BLAKE (M. E.). - Roman Mosaics of the Second Century in Italy, dans MAAR, vol. 13, Rome, 1936.

Blanco-freijeiro (A.). - Mosaicos romanos de Mérida, corpus de Mosaicos Romanos de España, Fase. I, Madrid, 1978.

B rown (Blanche R.). - Ptolemaic Paintings and Mosaics and the Alexandrian Style, Cambridge, Mass., 1957.

Cumont (F.). - Textes et monuments figurés relatifs aux mystères de Mithra, 2 vol., Bruxelles, 1896-1899 (== T.M.R.M.M.).

Darmon (J.-P.) et Lavagne (H.).-Le recueil général des mosaïques de la Gaule, Lyonnaise, II, 3, suppi. X à Gallia, Paris, 1977.

Enciclopedia delVArte Antica, Classica e Orientale (dir. R. BIANchi-BANDINELLI), Rome, 1958-1963.

F U RT WÂn GLE R (A.). - Die Antike Gemmen, Leipzig, 1900.

GaUCKLeR (P.). - Inventaire des mosä̈ques de la Gaule et de ГAfrique, t. 2, Paris, 1910.

Germain (S.).-Les mosaïques de Timgad étude descriptive et analytique, Paris, 1969.

Gonzenbach Von (V.).—Die Romischen Mosaiken der Schweiz, Bâle, 1961.

Gullini (G.). - I Mosaici di Palestrina, Rome, 1956.

Helbig (W.).-Führer durch die offentlichen Sammlungen, Klassischer Alterthümer in Rom, (traduet. fr. Toutain, Guide des Musées d'archéologie classique de Rome), Leipzig, 1893, t. 1 (= Guide).

Lavios a (C.). - Scultura tardo etrusca di Voherra, Florence, 1964.

Le vi (D.). - Antioch Mosaic Pavements, Princeton, 1947, 2 vol. (=Antioch).

Pachtère (F. G. DE). - Inventaire des mosä̈ques de la Gaule et de VAfrique, t. 3, Paris, 1911.

Ragghianti (C. L.). - Pittori di Pompei, Milan, 1963 (= Pittori).

Stern (H.) et Blanchard-Lemèe (M.). - Recueil des mosä̈ques de la Gaule Lyonnaise, t. II, 2, suppi. X à Gallia, Paris, 1957.

VERMASEREN (M. J.). - Corpus inscriptionum et monumentorum religionis Mithriacae, 2 vol., Leyde, 1956 (= C.I.M.R.M.). 


\section{OUVRAGES PARTICULIERS}

Abad CaSAl (E.). - Pintura Romana en Mérida, dans Augusta Emerita, pp. 163-184.

Abaecherli-Boyce (A.). - The Harbour of Pompeiopolis, a Study in Roman Imperial Ports and dated coins, dans $A J A$, III ser., 62, 1958, pp. 66-78 et pl. 14-15.

Adriani (A.). - SulVArte Alexandrino, Naples, 1972.

Albertini (E.). - Les étrangers résidant en Espagne à l'époque romaine, dans Mélanges R. Cagnat, Paris, 1912, pp. 297-318.

Alfold I (A.). - Insignien und Tracht der Romischen Kaiser, dans Mitteilungen des Deutschen Archàologischen Institut, Romische Abteilung, 50, 1935, p. 1-171.

'. Die monarchische Repràsentation im romischen Kaisereich, Darmstadt, 1970.

---Redeunt Saturnia regna II, «An Iconographical pattern, Heralding the return of the Golden Age in or around 139 B. C.», dans Chiron, 3, 1973, pp. 131-142.

--Redeunt Saturnia regna IV, «Apollo und die Sibylle in der Epoche der Bürgerkriege», dans Chiron, 5, 1975, pp. 165-192.

--Redeunt Saturnia regna VI, «From the Aion Plutonios of the Ptolemies to the Saeculum Frugiferum of the Roman Emperors», dans Greece and the Eastern Mediterranean in Ancient History and Prehistory, Berlin, New-York, 1977, p. 1-30, pl. 275-283.

Almagro-Basch (M.). - Guia de Mérida, 4ème édition, 1969.

Alvares Sáenz de Buruaga (J.). - La fundación de Mérida, dans Augusta Emerita, pp. 19-30.

And Reae (B.).-Uart de Tancienne Rome, Paris, 1973.

Augusta Emerita, Actas del simposio internacional commemorativo del Bimilenário de Mérida, 16-20 de Noviembre de 1975, Madrid 1976.

( = Augusta Emerita).

Au JAC (G.). - Strahon et la science de son temps, Paris, 1966 (= Strabon).

'-La géographie dans le monde antique, Paris, 1975 (= La géographie),

Aurigemma (S.).-_Villa Adriana, Rome, 1962.

Axtell (H. L.). - The Deification of Abstract Ideas in Roman Literature and Inscriptions, Chicago, 1907.

BA B E LON (J.). - Le voile d'Europè, dans $R A$, 20, 1943, pp. 125-140.

Conimbriga, 19 (1980), 5-127 
Balil (A.). - Les écoles de mosaïque dans le Conventus Tarraconensis, dans La mosaïque gréco-romaine, I, pp. 29-40.

Economía de la Hispania Romana, dans Estudios de Economía antigua de la península ibérica, 1968, pp. 289-369.

Balil Illana (A.). - Sobre la arquitectura domestica en Ementa, dans Emerita Augusta, pp. 75-91.

Balty (J.).--Mosaïque de Gé et des Saisons à Apamée, dans Syria, 50, 1973, pp. 336-340.

BeAujeu (J.). - La religion romaine à Vapogée de VEmpire, 1, Paris, 1955 (= La religion romaine)

BeCATt I (G.). - Alcune caratteristiche del mosaico bianco-nero in Italia, dans La Mosaïque gréco-romaine I, pp. 15-28.

Alcune caratteristiche del mosaico policromo in Italia dans $L a$ Mosaïque gréco-romaine, II, p. 173-192.

BECK (R.). - Cautes, cautopates - some astronomical considerations, dans JMS, 1977, II, 1, pp. 117-123.

The seat of Mithras at the Equinoxes, dans JMS, 1976, I, 1, pp. 95-98.

Interpreting the Ponza Zodiac, dans JMS, 1976, I, 1, pp. 1-19.

Becker (F.). - Histoire de Vastronomie, 2ème éd. compl., texte français de F. Cusset, Paris, 1955.

Benvéniste (E.). - Expression indo-européenne de l'Éternité, dans Bull, de la Société de linguistique de Paris, 38, 1937, pp. 103-112.

BérANGER (J.). - Recherches sur Vaspecl idéologique du principal, Lausanne, 1953 (= Recherches).

BÉRANGER (J.). - La notion de principat sous Trajan et Hadrien, dans Les Empereurs romains d'Espagne, pp. 27-44.

Bernand (A.).-Alexandrie la Grande, Paris, 1966.

Bianehi-Bandinelu (R.). -Naissance et dissociation de la koiné hellénistico-romaine, dans Le rayonnement des civilisations grecque et romaine sur les cultures périphériques (VIIIème Congrès Int. d Arch, class., Paris, 1963), Paris, 1965, t. 2, pp. 443-463.

Rome, le centre du pouvoir, Paris, 1969.

Bikermann (E.). - Le culte des Souverains dans l'Empire romain, dans Entretiens de la Fondation Hardt, XIX, 1973, pp. 3-25.

Blancharo-lemé (M.). - Promenades à travers formes et thèmes - Gaule, Germanie, Bretagne - mosaïques, décors des sols, dans Doss. Arch., $\mathrm{n}^{\circ} 15,1976$, pp. 43-45.

Conimbriga, 19 (1980), 5-127 
Blanco-Freijeiro (A.). - El mosaico de Mérida con la alegoría del Saeculum Aureum, dans Estudios sobre el mundo helenístico (Anales de la Universidad Hispalense, serie Filosofía y Letras, $\mathrm{n}^{\circ}$ 8), Séville, 1971, pp. 151-178, 6 fig., XII planches de photos en noir et blanc (= BLANCo-FREIJEIRO).

-Los mosaicos romanos de Mérida, dans Augusta Emerita, pp. 183-198 $(=$ Emerita $)$.

Blázquez (J. M.). - Relaciones entre Hispania y los Semitas (Sirios, Fenicios, Chipriotes, Cartagineses y Judios) en la Antigüedad, dans Beitràge zur alten Geschichte und deren Nachleben, Festschrift für F. Altheim zum 6.10.1968, Berlin, 1969, I, pp. 42-75.

Bleicken (J.). - Der Preis des Aelius Aristides auf das rõmische Weltreich, dans Nachrichten der Akademie der Wissenschaften in Gottingen, 1, 7, 1966, pp. 225-277.

Bollack (J.).-—Héraclite ou la séparation, Paris, 1977.

Bonneau (D.). - La crue du Nil, divinité égyptienne, à travers mille ans d'histoire, Paris, 1964 (= La Crue).

----Le fisc et le Nil, Paris, 1971.

Bouché-Lecherce (A.). - Histoire de la divination, 4 vol., Paris, 1879-1882. I, Introduction, divination hellénique (Méthodes).

-------- L'astrologie grecque, Paris, 1899, réimp. Bruxelles, 1963 (= Astrologie).

Boulanger (A.). - Aelius Aristide et la sophistique dans la province d'Asie au 2e siècle de notre ère, Paris, 1923.

Bow a (C. M.).-Melimno's Hymn to Rome, dans JRS, XLVII, 1957, pp. 21-28.

Bowersock (G. W.). - Greek Intellectuals and the Imperial Cult in the second century A. D., dans Entretiens de la Fondation Hardt, XIX, 1972, «Le culte des Souverains dans l'Empire romain», pp. 197-206.

BOYANCÉ (P.)-_Études sur le songe de Scipion, Limoges, 1936.

Brisson (L.).-Le même et l'autre dans la structure ontologique du «Timée» de Platon, Paris, 1974 (=Le même).

Bruneau ( $\mathrm{Ph}$.). - Perspectives sur un domaine encore mal exploré de l'art antique: à propos des actes du colloque international sur la mosaïque gréco-romaine, dans $R E G, 79$ 1966, pp. 704-726.

_Existe-t-il des statues d'Isis Pélagia?, dans RCH, 98, 1974, pp. 333-341.

Cам P B E Ll (L. A.). - Mithraic Iconography and Ideology, Leyde, 1968.

Casson (L.). - Ships and Seamenship in the Ancient World, Princeton, 1971.

Chamoux (F.). - L'épigramme de Poseidippos, dans Hommages à Claire Préaux, Bruxelles 1975, pp. 184-222. 
Charbonneaux (J.). - La signification et la date de la Tasse Farnèse, dans Monuments Piot, t. 50, Paris, 1958, pp. 85-103.

Aiôn et Philippe l'Arabe, dans MEFRA, 72, 1960, pp. 253-272.

Chiarlo (C. R.). - Un sarcófago, I venti ed Aion, dans SCO, 26, 1977, pp. 69-78.

Clay (Curtis L.). - Nilus and Four Seasons on a new as of Septimius Severus, dans Num. Chron., 10, 1970, pp. 71-87.

Collinet-Guérin (M.). - Histoire du Nimbe, Paris, 1961.

Colloque de Rome du 23 au 31 mars 1978, dans JMS, II, 2, 1978, pp. 241-242 (compte-rendu anonyme).

Colloque international pour l'étude de la mosaïque antique:

La mosaïque gréco-romaine, I (Paris 29 août — 3 septembre 1963), Paris, C.N.R.S, 1965.

La mosaïque gréco-romaine, II (Vienne, 30 août 4 septembre 1971), Paris, C.N.R.S., 1975.

Colloque international du C.N.R.S., Madrid, 1964: Les empereurs romains d'Espagne, Paris, 1965 (= Les Empereurs).

Colloque de Strasbourg,C.N.R.S., 1971: Les syncrétismes dans les religions grecque et romaine, Paris, 1973 (= Les syncrétismes).

Ville Congrès international d'archéologie classique, Paris, 1963: Le rayonnement des civilisations grecque et romaine sur les cultures périphériques, 2 vol., Paris, 1965.

Ville Congrès international d'archéologie chrétienne, Barcelone 5-11 oct. 1969, publié dans Studi di Antichita Cristiana, 30, 1972.

Vie Congrès international des études classiques, Madrid, 1973: Assimilation et résistance à la culture gréco-romaine dans le monde ancien, Paris, 1976.

Ile Congrès international des études mithriaques 1-8 sept. 1975, Téhéran = Acta Iranica, XVII, Téhéran, Liège, Leyde, 1978.

Cramer (F. H.).- - Astrology in Roman Law and Politics, Philadelphie, 1954 $(=$ Astrology).

Cumont (F.). - L'éternité des empereurs romains, dans Rev. Hist, et litt. relig., I, 1896, p. 435-452.

Jupiter summus exsuperantissimus, dans Archiv. für Relig., IX, 1906, pp. 323-326.

La théologie solaire du paganisme romain, Bruxelles, 1908 (Mémoires présentés par divers savants à l'Académie des Inscriptions et Belles Lettres, t. XII, 2ème partie).

_Les religions orientales dans le paganisme romain, Paris, 1929.

Recherches sur le symbolisme funéraire des Romains, Paris, 1942.

-Lux perpetua, Paris, 1949.

Conimbriga, 19 (1980), 5-127 
Cumont (F.) et Bidez (F.). - Les mages hellénisés, Zoroastre, Ostanès et Hystaspe d'après la tradition grecque, 2 vol., Paris, 1938.

Curtius (E. R.), Gottin Natura, dans Europàische Literatur und Lateinisches Mittelalter, Berne-Munich, 1973, pp. 116-137.

Cvetrovi6-Tomasevic (G.). - Une mosaïque du Vème siècle de Héracléa Lynkestis et la question de la formation du style de l'art médiéval, dans le 8ème Congrès International d'Archéologie Chrétienne, Barcelone 5-11 oct., 1969, publ. dans Studi di Antichità Cristiana, 30, 1972, CCXXXV-CCLII.

Darmon (J.-P.). - Sur deux mosaïques de l'Yonne, dans La mosaïque grécoromaine, II, Paris, 1975, pp. 307-316.

Pelatte (L.).-Les traités de la Royauté d'Ecphante, Diogène et Sthénidas, Liège, 1942.

DeN Boer (W.). - Religion and Literature in Hadrian's Policy, dans Mnemosyne, 8, 1955, pp. 123-144.

Déonna (W.). - Histoire d'un emblème, la couronne murale des villes et pays personnifiés, dans Genava, 18, 1940, pp. 116-236.

------Eternité, dans Hommages à J. Bidez et à F. Cumont», Bruxelles 1948, pp. 71-76.

-Les crucifix de la vallée de Saas (Valais): Sol et Luna, Histoire d'un thème iconographique, dans RHR, 132, 1946, pp. 5-47.

DESIDER I (P.). - Dione di Prusa, une intelletuale greco nelVimpero romano, Florence, 1978.

Deubner (L.). - Die Apotheose des Antoninus Pius, dans Rom. Mitt., 27, 1912, pp. 1-20.

Dillon (J.). - The Platonizing of Mithra, dans JMS, 1977, II, 1, pp. 79-85.

Dion (R.). - Aspects politiques de la géographie antique, Paris, 1977 (= Aspects politiques).

D'Ors (A.). - L'oeuvre d'Hadrien et l'histoire du droit romain, dans Les Empereurs romains d'Espagne, pp. 147-158.

Downey (G.). - Personnifications of Abstract Ideas in the Antioch Mosaics dans Trans, of the Amer. Philol. Assoc., LXIX, 1938, pp. 349-363.

Representations of Abstract Ideas in the Antioch Mosaics, dans Journal of the History of Ideas, I, 1940, pp. 112-113.

Drexler (W.) dans Roscher s. v. Horai, col. 2728-2739 et s. v. Fortuna, col. 1522 .

Du MÉzıl (G.). - Jeunesse, éternité, aube, dans Annales, X, 1938, pp. 289-295.

Dunand (F.). - Le culte d'Isis dans le bassin Oriental de la Méditerranée, III (Etudes préliminaires aux religions orientales dans l'Empire romain, t. XXVI), Leyde, 1973.

Conimbriga, 19 (1980), 5-127 
Duss a d d $(\mathrm{R} \cdot)^{*}$ —* Dieu mithriaque léontocéphale, dans Syria, 27, 1950, pp. 253-260.

Etienne (R.). - Une mosaïque de Volubilis, dans MEFRA, 62, 1950, pp. 93-118 .

---- Le culte impérial dans la péninsule ibérique d'Auguste a Dioclétien (BEFAR, 191), Paris, 1958, réimpr., 1974 (=Le Culte impérial).

------La oie quotidienne à Pompéi, Paris, 1966, 2ème éd., 1977.

------Les syncrétismes religieux dans la péninsule ibérique à 1 époque impériale, dans Les syncrétismes dans les religions grecque et romaine (Colloque C.N.R.S.), Paris, 1973.

Etienne (R.), Fabre (G.), Le roux (P.), tranoy (A.). - Les dimensions sociales de la romanisation dans la péninsule ibérique des origines à la fin de l'Empire, dans le Vlème Congrès International des Etudes Classiques: Assimilation et résistance à la culture gréco-romaine dans le monde ancien, Paris, 1976, pp. 95-107.

Fabre (G.) voir etienne (R.), fabre (G.), le roux (P.), tranoy (A.).

Festugière (A.-J.). - La révélation d'Hermès Trismégiste, t. II, Le Dieu cosmique, Paris, 1949 (= Dieu cosmique).

Le sens philosophique du mot 'AI $\Omega$ N*, dans Parola del Passato, IV, 1949, pp. 172-189.

Cadre de la mystique hellénistique, dans Mélanges Maurice Goguel, «Aux sources de la tradition chrétienne», Paris, 1950, pp. 75-85.

----- La révélation d'Hermès Trismégiste, t. I, L'astrologie et les sciences occultes, Paris, 1950.

— La révélation d'Hermès Trismégiste, t. IV, Le Dieu inconnu et la gnose, Paris, 1954 (= Dieu inconnu).

------La mosaïque de Philippopolis et les sarcophages au Prométhée dans Hermétisme et mystique païenne, Paris, 1967, pp. 312-321.

----- Hermétisme et mystique païenne, Paris, 1967.

Fine Licht (K. De) - The Rotonda in Rome, a study of Hadrian s Pantheon (Jutland Arch. Soc.), 1968.

Flacelière (R.).- Plutarque, De Fortuna Romanorum, dans Mélanges J. Carcopino, Paris, 1966, pp. 367-375.

Foucher (L.). - Navires et barques, dans Institut National d Archéologie et Arts, Musée Alaoui, notes et documents, XV, 1957, pp. 5-43.

L'art de la mosaïque et les poètes latins, dans Latomus, 23, 1964, pp. 247257. 
_ Les mosaïques nilotiques africaines, dans La Mosaïque gréco-romaine, I (Colloque Mosaïque, Paris, 29/8-3/9,1963, Paris, C.N.R.S., 1965), pp. 137-146 (= M. N.).

------Notes sur l'iconographie du Dieu Océan, dans Caesarodunum 10, 1975, pp. 48-52.

— Annus et Aiôn dans Caesarodunum, Xbis, Aiôn, le temps chez les Romains» 1976, pp. 197-203.

Francois (L.). - Essai sur Dion Chrysostome, philosophe et moraliste cynique et stö̈cien, Paris, 1921.

FriedLÀnder (P.). - Johannes von Gaza und Paulus Silentiarius, Kunstbeschreibung Justinianischer Zeit, Berlin-Leipzig, 1912.

G A GÉ (J.). - Recherches sur les jeux séculaires, Paris, 1934.

------Le Templum Urbis et l'idée de Renovatio, dans Mélanges F. Cumont, Bruxelles, 1936, 1, pp. 151 sq.

------Sur quelques particularités de la 'censure ${ }^{5}$ du roi Servius Tullius, dans R.H.D., 35, 1958, pp. 461-490.

García y Bellido (A.). - El Culto a Mithras en la Península ibérica, dans Bol. de la Real. Acad, de la Hist., 122, 1948, pp. 317-329.

--------Les religions orientales dans V Espagne romaine, Leyde, 1967 (= Religions orientales).

García-Sandoval (E.). - El mosaico cosmogónico de Mérida, dans BSEAA, XXXIY-XXXV, pp. 9-29 (= GARCÍA-SANDOVAL).

-El mosaico cosmogónico de Mérida, dans Le Xlème Congreso Arqueológico Nacional Mérida, 1968, Cáceres-Saragosse, 1969, pp. 743-768.

Gatz (B.). - Weltalter Goldene Zeit und Sinnverwandte Vorstellungen, Diss. Tubingen, 1967.

Giorgetti (D.). - - II faro di Alessandria fra simbologia e realtà: Dall'Epigramma di Posidippo ai Mosaici di Gasr Elbia, dans Atti della Accademia Nazionale dei Lincei, 374, 1977, pp. 245-262.

Gissinge R (F.). - s.v. Oikumene orbis, col. 2165-2167, dans RE, 17(2), 1937.

Giuliano (A.). - Rilievo da Aphrodisias in onore di Zoilos», dans $A$ SA $A$, 37-38 (1960), pp. 389-401.

Goldschmidt (V.). - Le système stö̈cien et Vidée de Temps, Paris, 1969, 3e éd. 1977.

Gonzenbach (V. Von). - Die Romischen Mosaiken der Schweiz, dans La Mosaïque gréco-romaine, I, pp. 245-254.

—_ Fliegende Gotter, dans Schweizer Münzblatter, 8, 1958, pp. 110-113.

Goodchild (R. G.), Helios on the Phares dans Antiquaries Journal, 41, 1961, pp. $218-223$. 
Gordon (R.-L.). - Mithraism and Roman Society, dans Religion, II, 1972, pp. 100 sq.

GorgeS (J.-G.). - - Les villas hispano-romaines, inventaire et problématique archéologique (Publications du Centre Pierre Paris, 4), Paris, 1979.

Grabar (A.). - Recherches sur les sources juives de l'art paléochrétien, dans Cah. Arch., 12, 1962, pp. 115-152.

Gros (P.). - Trois temples de la Fortune des 1er et Ilème siècles de notre ère, remarques sur l'origine des sanctuaires romains à abside, dans MEFR, 79, 1967, pp. 503-566.

----- Aurea templa; Recherches sur Varchitecture religieuse de Rome à Vépoque d'Auguste (BEFAR, 231), Paris, 1978.

GUARDUCCI (M.). - La religione di Adriano, dans les Empereurs romains d'Espagne, pp. 209-219.

------La piu antica catechèsi figurata: il grande mosaico della basilica di Gasr Elbia in Cirenaica, dans Memorie della Accad. Naz. dei Lincei, class, se. mor. stor. filol., ser. VIII, vol. 18, fase. 7, 1975, pp. 659-686, et $6 \mathrm{pl}$.

GuEY (J.). - A propos du Feríale Duranum col. 1, lignes 14-16, 28 janv. 198> ou le siècle des Antonins, dans REA, 50, 1948, pp. 60-70.

GuIDI (G.). -La villa del Nilo, dans Africa italiana, V, 1933, pp. 1-56.

GUNDEL (W.). - dans R.E., XI, 1921, s.v. Kometen, col. 1143-1193.

GUNDEL (W. et H. G.).-Astrologúmena, die astrologische Literatur $m$ der Antike und ihre Geschichte, Wiesbaden, 1966 (=Astrologúmena).

Halsberghe (G. H.). - The Cult of Sol Invictus, (Etudes préliminaires aux religions orientales dans l'Empire romain, t. XXVIII), Leyde, 1972.

Hanfmann (G.M.A.). - Season Sarcophagus in Dumbarton Oaks, t. I et II, Cambridge, Mass., 1951 (= Season Sarcophagus).

hauschild (Th.). - Problemas de constructiones romanas en Mérida, dans Emerita Augusta, pp. 107-110.

Heidel (W. A.). - The Frame of the Ancient Greek Maps, New York, 1957 (一 The Frame).

Henri-Martin (Th.). -Etudes sur le Timée de Platon, Paris, 1841 (=Etudes).

Hin ks (R.). - Myth and Allegory in Ancient Art, Londres, 1939 (= Myth).

Hoven (R·). — * Stö̈cisme et stö̈ciens face au problème de l'au-delà, Bibl. Fac. Philos, et Lettres, Univ. Liège, fase. CXCVII, Bruxelles, 1971 ( = Stoïcisme).

Hübner (W.). - Die olympichen Gotter in Flauberts Tentation de saint Antoine, dans Arcadia, 5, 1970, pp. 242-261.

Jean ma ire (H.).—La Sibylle et le retour de l'âge d'or, Paris, 1939.

J о в S T (W.) - Romische Mosaiken aus Ephesos /, Die Hanghàuser des Embolos, (Forschungen in Ephesos, VIII, 2), Vienne, 1977. 
Kâhler (H). - Die Augustus-S tatue von Prima Porta, Cologne, 1959 (= Die Augustus-Statue).

KEUNe (J.B.). - dans RosChER, s. Y. Turrigera, col. 1300.

KLINGNeR (F.). - Rom ais Idee (Rômische Geisteswelt), Leipzig, 1943, 3ème éd. Munich, 1965.

Lafaye (G.). - Histoire du culte des divinités d'Alexandrie en dehors de VÉgypte, Paris, 1884.

Lassus (J.) —Vénus marine, dans La mosaïque gréco-romaine I, pp. 175-192 (Colloque C.N.R.S., Paris, 29/8 - 3/9, 1963), Paris, 1965.

------La mosaïque romaine, organisation des surfaces, dans La mosaïque gréco-romaine, II, Paris, 1975, pp. 327-328 (2ème Colloque International pour l'étude de la mosaïque antique, Vienne, 30/8-4/9, 1971).

Lavagne (H.). - Pour une problématique nouvelle des recherches sur la religion de Mithra, Le Ilème Congrès International d'études mithriaques, dans MEFRA, 87, 1975, pp. 1131-1142.

LE Gall (J.).-Le Tibre, fleuve de Rome dans ГAntiquité, Paris, 1952.

----- Recherches sur le culte du Tibre, Paris, 1959 (= Recherches).

LE Glay (M.). - Dieux Syriens du Janicule, dans MEFRA, 60,1948, p. 129-151.

Le Roux (P.) voir etienne (R.), fabre (G.), Le Roux (P.), Tranoy (A.).

Leschi (L.).-Etudes d'épigraphie, d'archéologie et $d$ histoire africaines, Paris, 1957.

Lévêque (P.) et Vidal-Naquet (P.). - Epaminondas Pythagoricien ou le problème tactique de la droite et de la gauche, dans Historia, 9, 1960, pp. 294-308.

Lévêque (P.) et Vidal-Naquet (P.). - Clisthène ГAthénien, Paris, 1964, 2ème éd., 1973.

LEVI (D.).-Aiôn, dans Hesperia 13, 1944, pp. 269-314.

----- Antioch Mosaic Pavements, t. I et II, Princeton, 1947 (=Antioch).

Lloyd (G.). - Right and Left in Greek Philosophy, dans R. Neednam, Right and Left, Chicago, 1973, pp. 167-186.

L'Orange (H. P.). - Studies on the Iconography of Cosmic Kingship in the Ancient World, Oslo, 1953.

Magie (D.). - Roman Rule in Asia Minor, Princeton, 1960.

Malissard (A.). - L'expression du temps sur la colonne trajane, dans Caesarodunum, 1Obis, 1976, pp. 152-182.

Matz (F.). - Der Gott auf dem Elefanten Wagen, dans Abhandl. der Akad. der Wiss. und der Lit. in Mainz, 1952, n 10, pp. 725-728. 
MAYER (M.)-Die Giganten und Titanen in der antiken Sage und Kunst, Berlin, 1887.

Mazzarino (S.). - Il pensiero storico classico, t. I. Bari, 1966.

Mélanges F. Altheim: Beitráge zur Alten Geschichte und deren Nachleben, Festschrift für Franz Altheim zum 6-10-1968, Berlin, 1969.

Mélanges R. Cagnat: Recueil de mémoires concernant Pépigraphie et les antiquités romaines, Paris, 1912.

Mélanges J. Carcopino: Hommages à la mémoire de Jérôme Carcopino (coll. d'études anciennes...), Paris, 1977.

Mélanges F. Cumont: Annuaire de l'Institut de Philologie et d'Histoire Orientales et Slaves, T. IV, Bruxelles, 1936.

Mélanges R. Dion, Paris, 1974.

Mélanges Maurice Goguel: Aux sources de la tradition chrétienne, Paris, 1950.

Mélanges Ch. Picard: Mélanges d'Archéologie et d'Histoire offerts à Charles Picard à l'occasion de son 65ème anniversaire, 2 vol., Paris 1948.

Mélanges M. Renard: Hommages à Marcel Renard, 3 vol., Bruxelles, 1969 (Coll. Latomus, $\mathrm{n}^{\circ}$ 103).

Mellor (R ) - The Worship of the goddess Roma in the Greek World, Gottingen' 1975.

Merkelbach (R.). - Die Kosmogonie der Mithras Mysterien, dans Eranos. Jahrhuch, 1966, pp. 219-257.

------Eine astrale Deutung der Tazza Farnese, dans Les Syncrétismes dan ${ }^{s}$

les religions grecque et romaine (Colloque de Strasbourg, 1971), Paris, 1973, pp. 67-78.

Moreau (J ). - L'âme du monde de Platon aux stoïciens, Paris, 1939.

Nicolet (Cl.).--Rome et la conquête du monde méditerranéen, t. II, Paris, 1978.

Nielsen (K.). - Les noms grecs et latins des vents, dans Classica et Mediaevalia, VII, 1945, pp. 1-113.

Nock (A. D.). - Studies in the Graeco-Roman Beliefs of the Empire, dans J.H.S., XLV, 1925, pp. 84-101.

-A vision of Mandoulis Aiôn, dans H.Th.R., 27, 1934, pp. 53-104

-The Genius of Mithraism, dans J.R.S., 27, 1937, pp. 108-113.

Sarcophagi and Symbolism, dans A.J.A., III, 1946, pp. 140-170.

Norden (E.). - Ein Panegyricus auf Augustus in Vergils Aeneis, dans R.M., 54,1899 , pp. 466-482. 
Oliver (J. H.). - The Ruling Power, a Study of the Roman Empire in the Second Century after Christ through the Roman Oration of Aelius Aristides (Transactions of the American Philosophical Society, n. s., vol. 43, part. 4), Philadelphie, 1953 (= Ruling Power).

Orgeval (B. d'). - L'empereur Hadrien, oeuvre législative et administrative, Paris, 1950.

Panofsky (E.). - Studies in Iconology, Oxford, 1938, (Essais d'iconologie, Paris, 1967).

Voeuvre d'art et ses significations: essais sur les arts visuels, Paris, 1969.

Paullian (A.). - Le thème littéraire de l'Océan, dans Caesarodunum, 10, 1975, pp. 53-58.

Pavis D'Escurac (H.). - La préfecture de l'Annone, service administratif impérial d'Auguste à Constantin, (B E F A R, 226), Rome, 1976.

PÉ PIN (J.). - Mythe et allégorie, Paris, 1958.

----- Théologie cosmique et théologie chrétienne, Paris, 1964 (= PE PIN).

Pettazzoni (R.). - La figura monstruosa del Tempo nella religione mitriaca, dans $A C, 18,1949$, pp. 265-277 (= The monstruous Figure of Time in Mithriacism, Essays on the History of Religions, Leyde, 1954, 2ème éd. 1967, pp. 180-192).

Pflaum (H. G.). - Tendances politiques et administratives au Ilème siècle de notre ère, dans R.E.L., 42, 1964, pp. 116-118.

PICARD (Ch.).- -La patère d'Aquileia et l'Éleusinisme à Rome au début de l'époque impériale, dans Ant. Class., 20, 1951, pp. 351-381.

------Sur quelques représentations nouvelles du phare d'Alexandrie et sur l'origine alexandrine des paysages portuaires, dans R.C.H., 76, 1952, pp. 61-95.

------Hermès et Mithra, dans R.A., 41, 1953, pp. 95-96.

------Pouzzoles et le paysage portuaire, dans Latomus, 18, 1959, pp. 23-51.

---- Sur l'original de la Némésis-Tyché de Vienne (Isère), dans Rev. Arch, $d u$ Centre, $\mathrm{n}^{\circ} 10,1964$, p. 101-123.

PiCARd (G. Сн.). - Dionysos victorieux sur une mosaïque d'Acholla, dans Mélanges Ch. Picard, II, Paris, 1948, pp. 810-821.

----- Les trophées romains, contribution à l'histoire de la religion et de l'art triomphal de Rome (BEFAR, 187), Paris, 1957 (= Trophées).

---- -Mosaïques africaines du III' s. ap. J.-G., dans R.A., 2, 1960, pp. 17-49. L'art romain, Paris, 1968.

Observations sur la mosaïque cosmologique de Mérida, dans La Mosaïque gréco-romaine, II, Paris, 1975, pp. 119-124. (2ème Colloque International pour l'étude de la mosaïque antique de 1971) (= Mosaïque Cosmologique).

Conimbriga, 19 (1980), 5-127 
Pleket (H. W.). - An aspect of the Emperor Cult, Imperial Mysteries, dans H.Th.R., 58, 1965, pp. 331-347.

Pohlenz (M.). - Die Stoa, Geschichte einer Geistigen Bewegung, 2 vol., Gottingen 1955-1959, ed. it., Florence, 1967. (= Die Stoa).

Postl (B.). - Die Bedeutung des Nil in der rômischen Literatur, Vienne, 1970 (=Die Bedeutung des Nil).

Preaux (Cl.). - Papyrologie et Philosophie, à propos de Platon, Timée 36b, dans Chronique d'Egypte, 24, 1949, pp. 313-316.

----- La lune dans la pensée grecque, Bruxelles, 1973.

Puech (A.). —Les Apologistes Grecs du Ilème siècle de notre ère, Paris, 1912.

QueT (M.-H.). - Rhétorique, culture et politique: Le fonctionnement du discours idéologique chez Dion de Pruse et dans les Moralia de Plutarque, dans D.H.A., IV, 1978, pp. 51-118.

Ragghianti (C. L.). - Pittori di Pompei, Milan, 1963.

RATTI (E.). - Impero Romano et armonía dell'Universo nella pratica retorica et nella concezione religiosa de Elio Aristide: una ricerca per $\Gamma E I \Sigma$ P $\Omega$ MHN, dans Memorie delVIst. Lomb. Accad. Sc. et Leu., vol. XXXI, fase. 4, Milan, 1971, pp. 282-361 (=Impero).

Rebuffat (R.). - Les divinités du jour naissant sur la cuirasse d'Auguste de Prima Porta; recherches sur l'illustration symbolique de la victoire orientale, dans $M E F B A, 73,1961$, pp. 161-228.

REINHARDT (K.). - Kosmos und Sympathie, Neue $U$ ntersuchungen über Poseidonios, Munich, 1926 ( = Kosmos und Sympathie).

RENARD (M.).- -La mosaïque aux divinités de Boscéaz, près d'Orbe, dans Mélanges J. Carcopino, Paris, 1966, pp. 803-818, et fig. 1-3.

Richard (J. C.). - Pax, Concordia et la religion officielle de Janus, dans M.E.F.B.A., 75, 1963, pp. 303-386.

Richter (G.M A.).-Ancient Furniture, a History of Greek, Etruscan and Boman Furniture, Oxford, 1926.

Rizzo (M.G.E.). — La pittura ellenistica, Milan, 1929.

------Aureae velificantes dans B.G.A.B., LXVII, 1939, pp. 141-168.

Rов в R T (L.).--Recherches épigraphiques, dans BEA, 62, 1960, pp. 276-361.

----- Inscriptions d'Aphrodisias, 1ère partie, dans Antiquité Classique, 35, 1966, pp. 397-432.

—_ Documents d'Asie Mineure, dans BCH, CI, 1977, pp. 113-116.

Rossi (L.). - Il Danubio nella storia, nella numismática e nella scultura romana, dans Num. e Ant. Class., 1, 1972, pp. 111-143. 
Rouge (J.).-Expositio totius mundi et gentium (Coll. Sources Chrétiennes), Paris, 1966 (= Expositio).

----- Recherches sur Vorganisation du commerce maritime en Méditerranée sous VEmpire Romain, Paris, 1966 (= Recherches).

Conceptions antiques sur la mer, dans Mélanges Dion, Paris, 1974, pp. 225-283.

Rougier (L.). - La religion astrale des Pythagoriciens, Paris, 1959.

Sallmann (K. G.). - Die Natur bei Lukrez, Natura und der Naturbegriff, Dissert. Cologne, 1961, publié sous le titre: Studien zum philosophischen Naturbegriff der Romer mit besonderer Berücksichtigung des Lukrez, dans Archio, für Regriffsgeschichte, 7, Bonn, 1962.

Salomonson (J. W.). - La mosaïque aux chevaux de Vantiquarium de Carthage, La Haye, 1965 (= La mosaïque aux chevaux).

SCHONer (E.). - Das Yiererschema in der antiken Humoral pathologie, dans Sudhoffs Archiv, Beiheft 4, Wiesbaden, 1964.

Schwartz (J.). - Le Nil et le ravitaillement de Rome, dans RIFAO, 47, 1948, pp. 179-200.

Settis (S.). - Per Pinterpretazione di Piazza Armerina, dans MEFRA, 87, 1975, pp. 873-994.

SEY RI (H.). - Antiquités Syriennes, dans Syria, 12, 1931, pp. 316-325.

SPEngel (L.). - Rhetores Graeci, 3 vol., Leipzig, 1856, réimp.^ 1966 (= SPENGEL).

Ster (H.). - La mosaïque de Tourmont (Jura), dans Gallia, 19, 1961, pp. 248-254.

------Propositions d'un classement des motifs et des canevas ornementaux des mosaïques, dans La mosaïque gréco-romaine, I (1er Colloque International pour l'étude de la mosaïque antique, Paris, 29/8 - 3/9, 1963), Paris, C.N.R.S., 1965, pp. 353-361.

Steuding (H.). - dans Roscher, II, 2, s.v. Lokal-Personifikationen, col. 2097.

S T RONG (E.).--Terra mater or Italia, dans JRS, 27, 1937, pp. 114-126.

Syme (R.). - Hadrian the Intellectual, dans Les Empereurs romains d'Espagne, pp. 243-249.

TABARRONI (G.). - La rapprezentazione del Faro suile monete di Alessandria, dans Num. e Antich. Class., 5, 1976, pp. 191-203.

Tarradell (M.).-Estudios de Economía antigua de la península ibérica, Barcelone; 1968.

тноuvenot (R.). - Les mosaïques de la Maurétanie Tingitane, dans La mosaïque gréco-romaine, I (1er Colloque Int. pour l'étude de la mosaïque antique, Paris, 29/8 - 3/9, 1963), Paris, C.N.R.S., 1965, pp. 267-274. 
La côte atlantique de la Libye d'après le géographe Ptolémée, dans

Mélanges J. Carcopino, Paris, 1977, pp. 267-275.

Tieche (E.). - Atlas als Personification der Weltachse, dans MH, 1945, 2, pp. 65-86.

Torelli (M.). - I Relievi storici Romani: Problemi de struttura e forme mentali, dans Jerome Lectures, Académie Américaine de Rome, 1978.

Toynbe (J.M.C.). - Roman medallions, American Numismatic Society: Numismatic Studies n 5, New York, 1944.

---- The Hadrianic School. A chapter in the History of Greek Art, Cambridge, 1934 (= Hadrianic School).

—- Art in Roman Rritain, Londres, 1962.

Tranoy (A.) voir etienne (R.), fabre (G.), le roux (P.), tranoy (A.).

Tran Tam Tinh (V.). -Essai sur le culte d'Isis à Pompéi, Paris, 1964.

T U M P L L (K.). — dans R. E., I, 2, 1894, s.y. Anemoi, col. 2176-2180.

T U RCAN (R.). - Dionysos Dimorphos, dans MEFR, 70, 1958, pp. 243-293.

----- Les sarcophages à représentation dionysiaque, essai de chronologie et d'histoire religieuse, Paris, 1966.

---- Les religions de l'Asie dans la vallée du Rhône, Leyde, 1972.

----- Mithras Platonicus. Recherches sur l'hellénisation philosophique de Mithra, Leyde, 1975 (= Mithras Platonicus).

_ Le piédestal de la colonne Antonine, à propos d'un livre récent, dans $R A, 1975$, pp. 305-318.

U SENER (H.). - Gôtternamen, Bonn 1896, 3ème éd., Francfort /Main, 1948.

Vérilhac (A. M.). - La déesse Physis dans une épigramme de Salamine de Chypre, dans RCH, YCYI 1972, pp. 427-433.

Yermaseren (M.J.).—-Mithra, ce dieu mystérieux, Paris, 1960 [-Mithra),

Two Unknown Mithraic Reliefs, dans Hommages à M. Renard, Bruxelles 1969, tome III, pp. 644-645 et pl. CCXXX et CCXXXII (Coll. Latomus, $\left.\mathrm{n}^{\circ} 103\right)$.

----- Mithriaca II, the Mithreum at P onza [Etudes préliminaires aux religions orientales dans l'Empire romain, t. XYI), Leyde, 1974 (= Mithriaca II).

Vernant (J.-P.). - Mythe et pensée chez les Grecs, t. I, Paris, 3ème éd., 1971.

Versnel (H. S.). - Triumphus, an Inquiry into the Origine, Developpment and Meaning of Roman Triumph, Leyde, 1970.

VeYne (P.). - Vénus, l'Univers et les voeux décennaux, dans REL, 38, 1960, pp. 306-323.

Conimhriga, 19 (1980), 5-127 
ViAN (F.). - La guerre des géants devant les penseurs de l'Antiquité, dans $R E G, 65,1952$, pp. 1-39.

VIDAl-NaqueT (P.). - Plato's Myth of Statesman, the ambiguities of the Golden Age and of History, dans JHS, 98, 1978, pp. 131-141.

Vidal-Naquet (P.) voir Lévêque (P.) et Vidal-Naquet (P.).

Vogel (L.). - The column of Antoninus Pius, Cambridge, Mass., 1973 (= The Column).

Vogt (J.)._-Vom Reichsgedanken der Romer, Leipzig, 1942, p. 170-207.

VOÛTE (P.). - Notes sur l'iconographie d'Océan à propos d'une fontaine à mosaïques découverte à Noie, dans MEFRA, 84, 1972, pp. 639-673.

Walters (V. J.). - The Cult of Mithras in the Roman Provinces of Gaul [Etudes préliminaires aux religions orientales dans VEmpire romain), Leyde, 1974.

WASER (O.). - dans Roscher, s.v. Tyché, V, col. 1309-1380.

Weidmann (D.). - L'établissement romain d'Orbe/Boscéaz, dans Archéologie Suisse, 1, 1978, 2, pp. 84-86.

Weizsàcher (P.). — dans Roscher, III, 1, s.v. Okeanos, col. 809-820.

Will (E.). - La date du Mithreum de Sidon, dans Syria, 27,1950, pp. 261-269.

------Une nouvelle mosaïque de Chahba-Philippopolis, dans Ann. Arch, de Syrie, III, 1953, pp. 27-48.

----- Le relief cultuel gréco-romain. Contribution à THistoire de VArt de VEmpire romain (= BEFAR, 183), Paris, 1955 (= Le relief gréco-romain).

Wissowa (G.). — dans Roscher, s.v. Tutela, V, col. 1304-1307.

Zelle r (E.). - Die Philosophie der Griechen, Leipzig, 1881.

Zeller (E.) et Mondolfo (R.). - La filosofia dei Greci nel suo sviluppo storico, 6 vol., Florence, 1951-1974.

Ce travail était sous presse lorsque a paru l'étude d'A. Alfoldi, Aion in Mérida und Aphrodisias (Madrider Beitrage, 6, Mayence, 1979), dont je n'ai pu tenir compte. Voir mon compte rendu à paraître dans R.E.A., 1980. 